\title{
Determinants of cognitive performance and social preferences across age in \\ Barbary macaques (Macaca sylvanus)
}

\author{
Dissertation \\ zur Erlangung des mathematisch-naturwissenschaftlichen Doktorgrades \\ "Doctor rerum naturalium" \\ der Georg-August-Universität Göttingen
}

im Promotionsstudiengang

Behavior and Cognition (BeCog)

der Georg-August University School of Science (GAUSS)

vorgelegt von

Eva-Maria Rathke

aus Siegen

Göttingen, 2020 
Betreuungsausschuss:

Prof. Dr. Julia Fischer,

Kognitive Ethologie, Deutsches Primatenzentrum

Dr. Claudia Fichtel,

Verhaltensökologie \& Soziobiologie, Deutsches Primatenzentrum

Dr. Tanya Behne,

Kognitive Entwicklungspsychologie, Georg-August-Universität Göttingen

Mitglieder der Prüfungskommission:

Prof. Dr. Julia Fischer,

Kognitive Ethologie, Deutsches Primatenzentrum

Dr. Claudia Fichtel,

Verhaltensökologie \& Soziobiologie, Deutsches Primatenzentrum

Dr. Tanya Behne,

Kognitive Entwicklungspsychologie, Georg-August-Universität Göttingen

Weitere Mitglieder der Prüfungskommission:

Prof. Dr. Eckhard W. Heymann,

Verhaltensökologie \& Soziobiologie, Deutsches Primatenzentrum

Prof. Dr. Julia Ostner,

Verhaltensökologie, Georg-August-Universität Göttingen

Prof. Dr. Annekathrin Schacht,

Affektive Neurowissenschaft und Psychophysiologie, Georg-August-Universität Göttingen

Tag der mündlichen Prüfung: 10.11.2020 


\section{Table of contents}

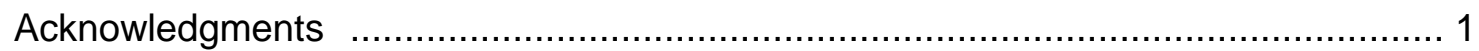

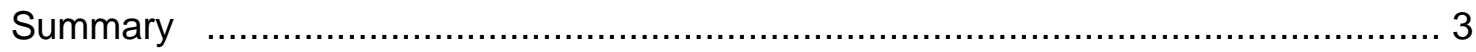

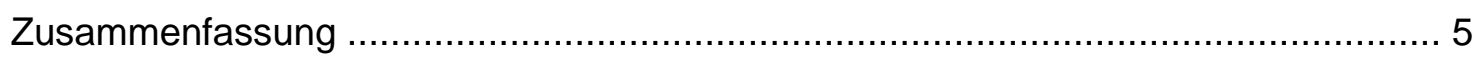

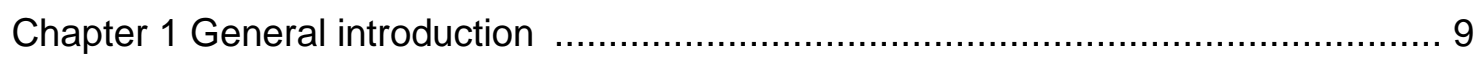

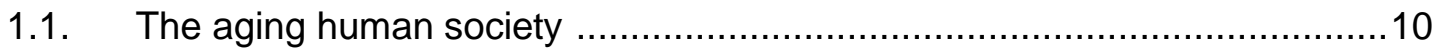

1.2. Why do individuals age and when are they 'old'? .................................12

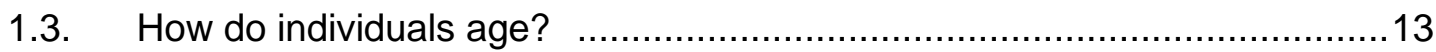

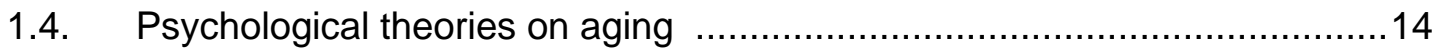

1.5. Applying psychological theories to primates …...................................17

1.6. Age-related cognitive changes ........................................................20

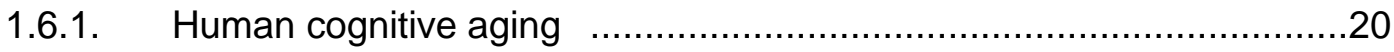

1.6.2. Measuring cognitive performance in animals .................................21

1.6.3. Age-related changes in cognitive capacities in animals ....................21

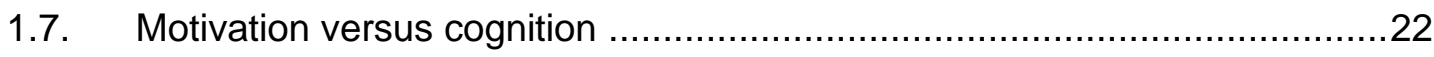

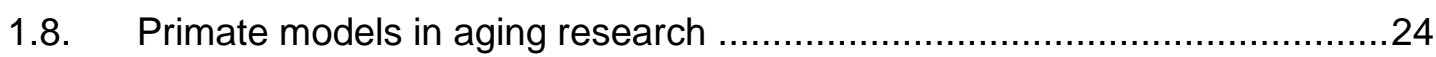

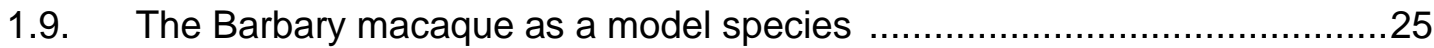

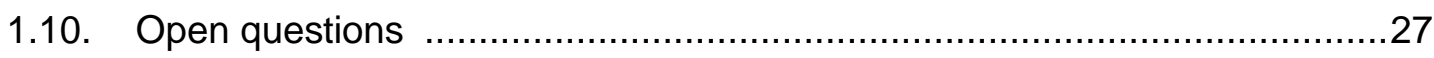

Chapter 2 Social aging in male and female Barbary macaques ...............................31

Chapter 3 Do older Barbary macaques avoid negative social information?

Application of the Strength and Vulnerability Integration model ..............45

Chapter 4 Differential aging trajectories in motivation, inhibitory control and cognitive flexibility in Barbary macaques ......................................61

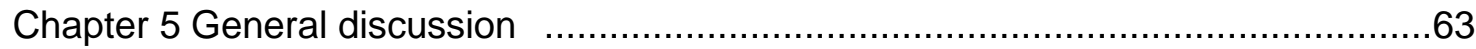

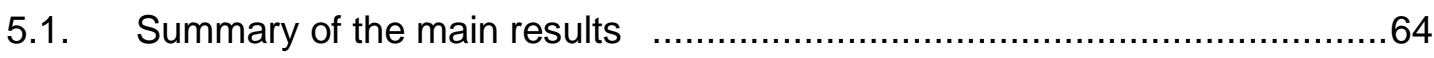

5.2. Social aging across different species .................................................6

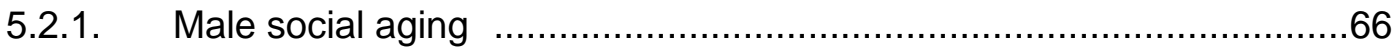

5.2.2. Special roles of aged individuals across the animal kingdom .............68

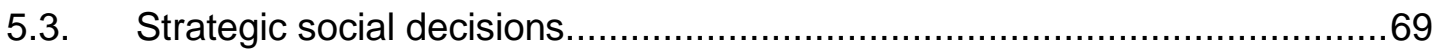


5.4. A question of relevance - application of the positivity effect and the Strength and Vulnerability Integration model to primates .......................... 71

5.5. Motivational changes and problem-solving behaviour ........................... 73

5.6. Cognitive performance across age …................................................ 76

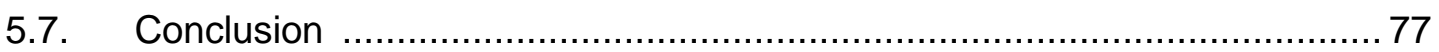

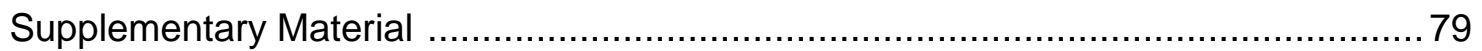

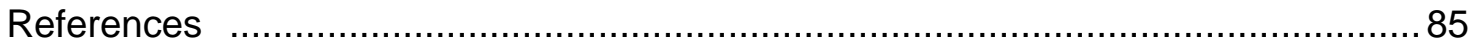




\section{Acknowledgments}

I would like to thank many people who contributed to the success of this project in various ways.

First and foremost, I would like to thank my supervisor Julia Fischer. Thank you for inspiring and guiding my way through the Ph.D. journey and for giving me the opportunity to work on this amazing topic. Thank you for being always available for questions and discussion of research ideas.

I thank my committee members Claudia Fichtel and Tanya Behne for the valuable input during thesis committee meetings, and Claudia Fichtel for agreeing to be my second reviewer. Thank you to the other members of my examination board: Julia Ostner, Eckhard Heymann and Annekathrin Schacht for their time and interest.

Thank you to Ellen Merz, Gilbert de Turckheim and Guillaume de Turckheim for the permission to conduct research at La Forêt des Singes in Rocamadour. Thank you to Davy Ung for the support on site. I am grateful to the staff from La Forêt des Singes for the nice atmosphere, for helping with identifying monkeys and providing WIFI during the winter month.

Special thanks to Magdalena Wimmer, Luisa Beckmann, Kira Breithaupt, Lateefah Roth and Marie Poiret for spending so much time with me in the forest and for helping with the data collection and experiments. Working and living with you made field work such a wonderful experience, especially when sharing the same love to talk about food and the daily monkey soap opera.

I thank Julien Hambuckers, Roger Mundry and Christoph Neumann for the statistical support.

I am grateful to Laura Almeling, who paved the way for this wonderful project and supported me especially in the early stages of this project with ideas and discussion. Thank you to Steffi Keupp for ideas and input whenever needed.

Thank you to all past and present members of the CogEtho Lab for the warm welcome and the productive and supportive atmosphere which made Ph.D. life so much easier. Special thanks to Rebecca Jürgens and Christian Schlögl for being always available for questions and thank you to Mechthild Pohl and Carmen Schlote for navigating through 
bureaucracy. Many thanks to Ludwig Ehrenreich and Marc Strelow for technical support and secured coffee intake.

Especially, I want to thank Fede for the statistical support, guidance and chatting inside and outside of the office. Thank you to Rowan for being such a good office mate, for encouragement and for introducing me to the world of swing dance. I am grateful to Lena for listening, positive thinking and enjoying the same passion for music and sports. Thank you to Filipa for all the emotional support during this journey - who would have thought that after meeting in the Peruvian jungle seven years ago we end up getting a Ph.D. in the same department. I would like to thank Nadine for the constant support since many years, for teaching me how to observe Barbary macaques and revising my manuscript. Daria, thank you for all the wonderful moments of friendship during the last years, for uplifting me and for giving valuable comments on previous versions of the manuscript.

Many thanks to my friends and extended family. Having a strong and supportive community is such a blessing. Thank you for playing music together, for sharing the same enthusiasm about traveling, for all the discussions about life inside and outside of science, and for patiently listening whenever it was needed. Thank you for everything!

Massive thank you to my parents, who constantly supported and encouraged me along the way and were as eagerly interested in old monkeys as I was. This also became clear when we built the food puzzles and picture holder together for the experiments with the monkeys, thank you for the creative support! Finally, I would like to thank my grandmother, who set the path for this a long time ago by giving me a cuddly monkey for my first birthday. The fascination for primates has never stopped. 


\section{Summary}

Aging is a universal process that occurs in almost all organisms and is defined as a progressive decrease in physiological functioning. For centuries, researchers have been interested in aging processes and their consequences. This is partly due to the fact that the proportion of older adults in human societies worldwide has increased in recent decades. In addition to research on the physiological basis of aging, it becomes increasingly important to study social aging. With increasing age, the size of the social network often decreases, which can have an impact on health and mortality risk. Psychological theories have been developed that attempt to disentangle the factors that explain the declining sociality in old age. To better understand age-related changes during lifespan from an evolutionary perspective, comparative studies are essential. Due to a similar physiological and cognitive aging process in the absence of societal norms that shape social aging in human societies, non-human primates can provide valuable insights here.

The aim of this dissertation was to establish a link between the psychology of aging and behavioural biology. For that purpose, I studied Barbary macaques (Macaca sylvanus) as a model species to determine whether comparable patterns also occur in non-human primates. Studying non-human primates allowed to explicitly test hypotheses derived from psychological theories and at the same time provides insights for new theory building. The basis of many psychological theories is the assumption that motivational changes lead to changes in the social environment. With age, the motivation to invest resources in maintaining well-being increases, which can lead to a focus on emotionally important social contacts. It is also assumed that older adults are more adept at applying avoidance strategies to minimize potentially negative situations. At the same time, motivational changes also affect cognitive performance. This is true, for example, when goal-oriented behaviour changes from a gain-oriented to a loss-minimizing strategy.

My study animals were semi-free ranging Barbary macaques living in a forested enclosure in Rocamadour, France. Due to the lack of predation pressure and food provisioning, the animals can grow much older compared to wild populations. Therefore, this population is particularly suitable for the investigation of age-specific research questions. I was especially interested in similarities and differences between the social aging process of male and female Barbary macaques. Since social aging in male nonhuman primates has been little investigated, this work makes a significant contribution to the existing literature. Based on the assumptions of psychological theories, I investigated whether Barbary macaques use avoidance strategies similar to those used by older humans to minimize negative and potentially stressful situations. For this purpose, behavioural 
observations were carried out. To gain a comprehensive insight into social but also cognitive changes with age, I conducted experiments on problem-solving behaviour.

In study 1 (Chapter 2) I demonstrated that males and females show a similar social aging process. For example, the number of partners and the frequency of affiliative interactions decreased with age in both sexes, but this was less pronounced in males as they generally showed less affiliative behaviour. Both sexes had less well-connected partners with increasing age, though males had generally less well-connected partners than females. It also became apparent that older individuals had fewer conspecifics in their proximity and showed less energy demanding behaviours such as climbing or running. The social interest in conspecifics, indicated by commenting on their interactions with others, did not change with age. The results of study 1 suggest that being involved in a smaller social network with increasing age with maintained interest for other conspecifics serves as having a more predictable environment by reducing stress and improving well-being.

Study 2 (Chapter 3) went more into detail on how age influences social behaviour on a communicative level. I show that with increasing age Barbary macaques use less affiliative and aggressive communicative signals such as 'teeth chatter' or 'threat face'. In contrast to the assumptions from psychological theories, I did not find that older individuals apply an avoidance strategy: Older monkeys did not react less to aggressive signals. Furthermore, Barbary macaques were presented with pictures of neutral and aggressive facial expressions. There was no increased attention for neutral facial expressions over aggressive ones. In comparison to younger conspecifics, older Barbary macaques did not react more to affiliative signals. From the sender's perspective, older individuals reacted less to both aggressive and affiliative signals. Potentially, older Barbary macaques become more adept at pursuing indirect strategies to mitigate negative experience, for example reducing the number of interaction partners or spending more time alone.

The results of study 1 and 2 (Chapters 2 and 3 ) indicated age-related motivational changes regarding interactions with social partners. How motivation changes with age in relation to problem-solving behaviour was therefore addressed in study 3 (Chapter 4). Barbary macaques were presented with three different problem-solving tasks (transparent objects with a food reward) to investigate the influence of age on cognitive performance (here: inhibitory control and cognitive flexibility) and motivation (persistence). Inhibitory control and cognitive flexibility belong to the executive functions and are important to control goal-oriented behaviour. The likelihood of approaching and interacting with the experimental apparatus decreased with age. Regarding the individuals that explored the objects, older monkeys were on a par with their younger conspecifics in their inhibitory abilities. The assessment of cognitive flexibility was difficult, since only a minority of the 
monkeys showed flexible behaviour and were successful. Older monkeys were less persistent in exploring the motivation task than younger monkeys. Study $\mathbf{3}$ shows greater age-related variation in motivation than cognitive functioning in Barbary macaques and highlights the importance of age-related motivational changes as a key factor in cognitive performance.

In summary, age is a determining factor for changes in social behaviour and motivation. My results are consistent with previous findings showing a decrease in social activity in various primate species. The exchange of social signals influences the position in the social network in the sense that older subjects not only have a less central position but also receive less attention from their conspecifics. I was able to show that motivation is often an underestimated influencing factor for age-related cognitive performance and problemsolving behaviour. My results lead to further research questions, which will link current findings with other research fields. For example, endocrinology can help to clarify to what extent age-related hormonal changes in stress response or energy balance have an influence on behavioural changes. The findings from studies on nonhuman primates will contribute to a better understanding of human social evolution.

\section{Zusammenfassung}

Altern ist ein universeller Prozess, der bei allen Organismen auftritt und wird als fortschreitende Abnahme der physiologischen Funktionsfähigkeit definiert. Bereits seit Jahrhunderten versuchen Forschende das Rätsel um den Alterungsprozess und dessen Konsequenzen zu lösen. Das liegt unter anderem auch daran, dass in Gesellschaften weltweit der Anteil an älteren Menschen in den letzten Jahrzehnten angestiegen ist. Neben der Erforschung der physiologischen Grundlagen des Alterungsprozesses gewinnen auch immer mehr soziale Aspekte des Alterns an Bedeutung. Mit steigendem Alter nimmt oft die Größe des sozialen Netzwerkes ab, was sich auf die Gesundheit und das Sterblichkeitsrisiko auswirken kann. Es wurden psychologische Theorien entwickelt, die versuchen die entscheidenden Faktoren der abnehmenden Sozialität im Alter zu erklären. Um altersbedingte Veränderungen aus evolutionsbiologischer Sicht besser zu verstehen, sind vergleichende Studien dabei unerlässlich. Aufgrund eines ähnlichen physiologischen und kognitiven Alterungsprozesses bei gleichzeitig fehlenden gesellschaftlichen Normen, die das soziale Altern in menschlichen Gesellschaften prägen, können nichtmenschliche Primaten hier wertvolle Erkenntnisse liefern.

Das Ziel dieser Dissertation war es eine Verbindung zwischen der Alterspsychologie und der Verhaltensbiologie herzustellen. Zu diesem Zweck untersuchte ich Berberaffen 
(Macaca sylvanus) als Modellart, um festzustellen, ob vergleichbare Muster auch bei nichtmenschlichen Primaten vorkommen. Das Studium nichtmenschlicher Primaten erlaubt es, Hypothesen aus psychologischen Theorien explizit zu prüfen und liefert gleichzeitig Erkenntnisse für die Theoriebildung. Die Basis vieler psychologischer Theorien ist die Annahme, dass motivationale Veränderungen zu Änderungen im sozialen Umfeld führen. Mit dem Alter ist die Motivation größer, verfügbare Ressourcen für die Bewahrung des Wohlbefindens zu investieren, was in Folge zur Konzentration auf emotional wichtige Sozialkontakte führen kann. Zudem wird angenommen, dass ältere Menschen versierter in der Anwendung von Vermeidungsstrategien sind, um potentiell negative Situationen zu minimieren. Gleichzeitig wirken sich motivationale Veränderungen auch auf die kognitive Leistungsfähigkeit aus. Dies gilt beispielsweise, wenn sich zielgerichtetes Verhalten von einer gewinnorientierten zu einer verlustminimierenden Strategie ändert.

Bei meinen Versuchstieren handelte es sich um halbwilde Berberaffen, die in einem bewaldeten Gehege in Rocamadour, Frankreich, leben. Durch den fehlenden Prädationsdruck und die gesicherte Nahrungsversorgung werden die Tiere sehr alt im Vergleich mit wildlebenden Populationen. Daher eignet sich diese Population besonders zur Untersuchung von altersspezifischen Fragestellungen. Von besonderem Interesse waren die Ähnlichkeiten und Unterschiede im sozialen Alterungsprozess männlicher und weiblicher Berberaffen. Da das soziale Altern bei männlichen nichtmenschlichen Primaten nur wenig untersucht ist, wird mit dieser Arbeit ein entscheidender Beitrag zur bisher existierenden Literatur geleistet. Basierend auf den Annahmen der Alterspsychologie stellte sich auch die Frage, ob Berberaffen ähnlich wie ältere Menschen Vermeidungsstrategien anwenden, um negative und potentiell Stress auslösende Situationen zu minimieren. Dazu wurden Verhaltensbeobachtungen durchgeführt. Um einen umfassenden Einblick in sowohl soziale als auch kognitive Veränderungen mit dem Alter zu erlangen, habe ich Experimente zum Problemlöseverhalten durchgeführt.

In Studie 1 (Kapitel 2) zeige ich, dass Männchen und Weibchen einen ähnlichen sozialen Alterungsverlauf aufweisen. Die Anzahl der Partner und die Häufigkeit an Interaktionen nahmen mit dem Alter bei beiden Geschlechtern ab, bei Männchen war dies jedoch weniger ausgeprägt, da sie im Allgemeinen weniger affiliatives Verhalten zeigten. Beide Geschlechter hatten weniger gut vernetzte Partner mit zunehmendem Alter, wobei Männchen generell weniger gut vernetzte Partner hatten als Weibchen. Zudem zeigte sich, dass ältere Tiere weniger Artgenossen in ihrem näheren Umfeld hatten und weniger energetisch aufwendige Verhaltensweisen wie Klettern oder Rennen gezeigt haben. Das soziale Interesse an Artgenossen durch Kommentieren ihrer Interaktionen mit anderen hat sich mit dem Alter nicht geändert. Die Ergebnisse von Studie 1 deuten darauf hin, dass die Einbindung in ein kleineres soziales Netzwerk mit zunehmendem Alter bei 
gleichbleibendem Interesse für andere Artgenossen dazu beiträgt, dass die soziale Umwelt berechenbarer wird durch die Verringerung von Stress und die Verbesserung des Wohlbefindens.

Studie 2 (Kapitel 3) geht ausführlicher darauf ein, wie das Alter das Sozialverhalten auf kommunikativer Ebene beeinflusst. In der Studie konnte demonstriert werden, dass Berberaffen mit zunehmendem Alter weniger affiliative und aggressive kommunikative Signale wie ,Schnattern“ oder ,Drohgebärden“ verwenden. Im Gegensatz zu den Annahmen aus psychologischen Theorien fand sich keine Vermeidungsstrategie: Ältere Affen haben nicht weniger auf aggressive Signale reagiert. Außerdem wurden den Berberaffen Bilder von neutralen und aggressiven Gesichtsausdrücken präsentiert. Es zeigte sich keine erhöhte Aufmerksamkeit für neutrale Gesichtsausdrücke im Gegensatz zu aggressiven. Im Vergleich zu jüngeren Artgenossen reagieren ältere Berberaffen nicht verstärkt auf affiliative Signale. Aus der Perspektive des Senders ergab sich, dass auf ältere Individuen sowohl bei aggressiven als auch bei affiliativen Signalen weniger reagiert wird. Möglicherweise werden ältere Berberaffen geschickter darin, indirekte Strategien zur Milderung negativer Erfahrungen zu verfolgen, zum Beispiel durch das Reduzieren der Anzahl an Interaktionspartner oder dadurch mehr Zeit allein zu verbringen.

Die Ergebnisse der Studien 1 und 2 (Kapitel 2 und 3) verdeutlichen, dass eine altersbedingte Änderung der Motivation bezüglich der Beschäftigung mit Sozialpartnern stattfindet. Wie sich die Motivation mit dem Alter in Bezug auf das Problemlöseverhalten ändert wurde daher in Studie 3 (Kapitel 4) behandelt. Um den Einfluss des Alters auf die kognitive Leistungsfähigkeit (hier: Inhibitionskontrolle und kognitive Flexibilität) und die Motivation (Durchhaltevermögen) zu untersuchen, wurden die Affen mit drei verschiedenen Problemlösungsaufgaben (transparente Versuchsobjekte mit einer Futterbelohnung) konfrontiert. Inhibitionskontrolle und kognitive Flexibilität gehören zu den exekutiven Funktionen und sind wichtig, um zielgerichtetes Verhalten zu kontrollieren. In dieser Studie konnte gezeigt werden, dass die Wahrscheinlichkeit sich dem Versuchsapparat zu nähern und mit ihm zu interagieren mit zunehmendem Alter abnimmt. Bei den Individuen, die sich mit dem Apparat beschäftigten, zeigten ältere Affen ähnliche inhibitorische Fähigkeiten wie ihre jüngeren Artgenossen. Da nur eine geringe Anzahl an Affen flexibles Verhalten zeigte und damit erfolgreich war, war eine Beurteilung der kognitiven Flexibilität schwierig. Die Aufgabe, mit der das Durchhaltevermögen der Affen gemessen wurde, zeigte, dass ältere Affen weniger Zeit mit Explorieren verbracht haben als jüngere Affen. Studie 3 zeigt eine größere altersabhängige Variation in der Motivation im Vergleich zu kognitiven Funktionen bei Berberaffen und unterstreicht die Bedeutung von altersbedingten motivationalen Veränderungen als Schlüsselfaktor für die kognitive Leistung. 
Zusammenfassend lässt sich sagen, dass das Alter ein bestimmender Faktor für Veränderungen des Verhaltens und der Motivation ist. Die Resultate dieser Dissertation stimmen mit früheren Ergebnissen zur Abnahme sozialer Aktivität bei verschiedenen Primatenarten überein. Der Austausch sozialer Signale beeinflusst die Position im sozialen Netzwerk dahingehend, dass ältere Tiere nicht nur eine weniger zentrale Position einnehmen, sondern auch von Artgenossen weniger Aufmerksamkeit bekommen. Ich konnte zeigen, dass Motivation ein oft unterschätzter Einflussfaktor für altersbezogene kognitive Leistungen und Problemlösungsverhalten ist. Meine Ergebnisse führen zu weiteren Forschungsfragen, die aktuelle Erkenntnisse mit anderen Forschungsfeldern verknüpfen werden. Beispielsweise könnten endokrinologische Untersuchungen dazu beitragen, inwiefern altersbedingte hormonelle Veränderungen der Stressreaktion oder für den Energiehaushalt einen Einfluss auf verhaltensbiologische Veränderungen haben. Die Erkenntnisse aus Studien an nichtmenschlichen Primaten werden helfen ein besseres Verständnis für die Parallelen aber auch für die Unterschiede im sozialen Alterungsprozess und deren Grundlagen in der sozialen Evolution von Menschen und nichtmenschlichen Primaten zu entwickeln. 


\section{Chapter 1}

General introduction

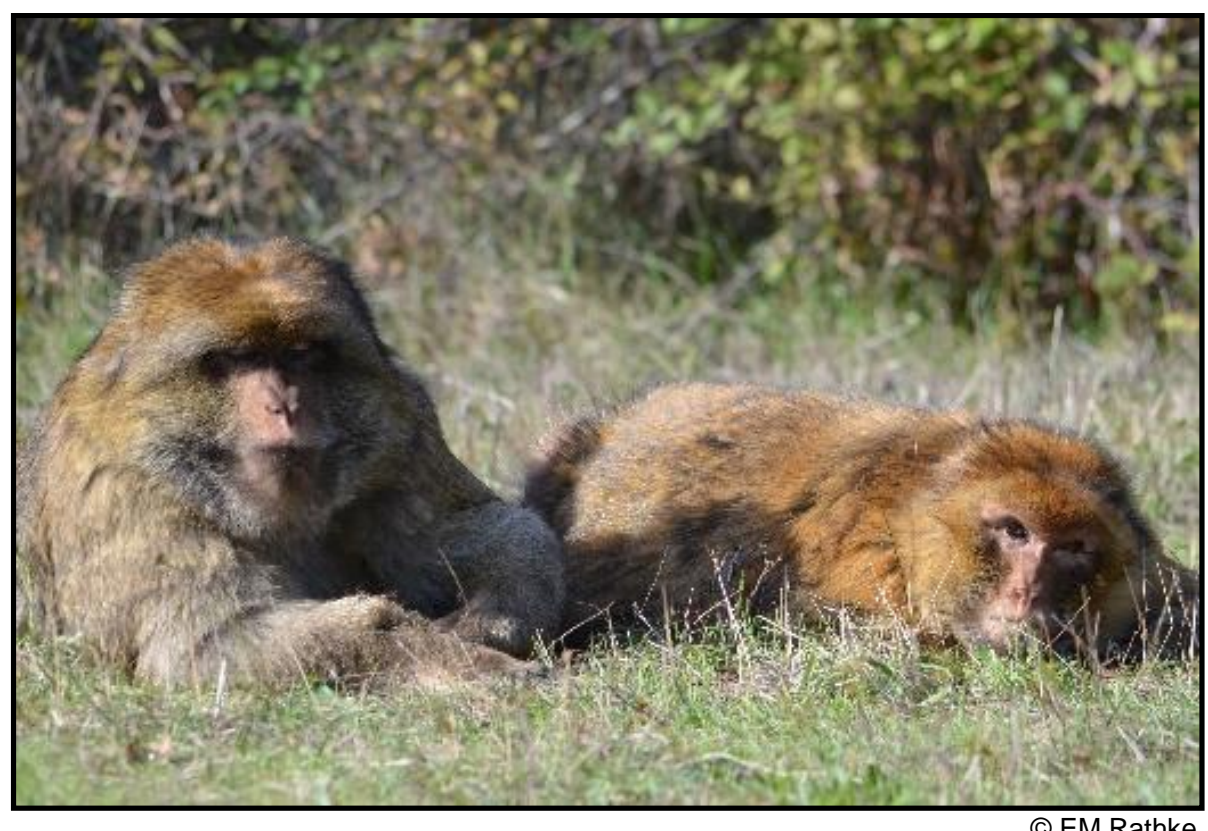




\section{Foreword}

Change is the constant of life. Aging, the process of becoming older, is one of these distinct life changes that concerns almost all living organisms, including humans. Demographic change impacts societies around the world, as more and more countries have a growing proportion of older citizens (Christensen, Doblhammer, Rau, \& Vaupel, 2009). An aging society has consequences for the economy and health care systems, as cost for pensions and medical or nursing care increase with the proportion of elderly in a society. Research on aging in humans is complicated by many confounding variables, such as differences in societal norms, economic status, or living conditions. Since all animals experience aging processes (even though to different extents), and confounding factors are easier to control for, many animal species are used as study organisms in research on aging. Due to a close evolutionary history, and many highly social species, nonhuman primates (hereafter 'primates') gained increasing attention compared to previously used smaller mammals such as rodents in research on understanding aging processes. This is especially true for research on cognitive and social domains. By investigating social and cognitive aging in Barbary macaques (Macaca sylvanus), I aimed to forge ties between human lifespan research and evolutionary biology. By applying psychological theories to Barbary macaques, I aimed to extend the knowledge about similarities and differences in human and primate aging patterns.

In the following introduction, I review the current state of aging research in humans, primates and other animals, which is the foundation of my dissertation. Then, I elaborate on what 'old age' is, whether and how the process of aging can be defined, and what changes occur during the aging process. I further explain the most important theories in the psychology of aging, in particular how the motivation to fulfil social needs, such as being surrounded by a supportive community, changes in the course of life. Moreover, I discuss how cognitive changes occur alongside changes in the social environment. In the concluding part of the introduction, I present the Barbary macaque as my model species. I then introduce the open questions that have arisen from the literature to explain the aims of my work.

\subsection{The aging human society}

In 2020, for the first time in history, the global population consists of more adults above the age of 65 than children below the age of five (United Nations, 2020). This development has dramatic consequences for societies worldwide, challenging health care systems, the economy and social life (Alwin \& Hofer, 2011; Ogura \& Jakovljevic, 2018). For instance, the 
proportion of the working population ( $<65$ years) is not increasing at the same pace as the proportion of older adults (Mason \& Lee, 2011), which challenges the health care systems for elderly in different societies (Bremer, Lüdecke, \& von dem Knesebeck, 2019; Faragher, 2015). It is and will continue to be a matter of political and societal investment in supporting older generations in their well-being and improving their living conditions (Lepore, 2020). Further, changes in cognitive ability in later ages have been linked to the extent of social activity and quality of social relationships. Cognitive diseases like dementia are associated with loneliness in humans, which refers to the perceived extent of social contact with family and friends (Rafnsson, Orrell, D'Orsi, Hogervorst, \& Steptoe, 2020). Often certain norms or social constraints determine living conditions and contentment of older people. In many countries worldwide, aging or 'being old' is associated with negative views on life satisfaction and respect by others (Löckenhoff et al., 2009; North \& Fiske, 2015; Settersten, 2017). Against the long-time anticipated thought that negativity towards older adults is more pronounced in Western (e.g. European) than in Eastern (e.g. Asian) countries, a meta-study found that the aging rate of a population is a more informative proxy for negative perception of older adults (North \& Fiske, 2015). Aging and its consequences are notably not a phenomenon of only industrialized countries. In today's hunter-gatherer societies, adults regularly live to the age 70 and beyond, comparable to people in modern societies (Gurven \& Kaplan, 2007). In some societies, like the Hadza in Tanzania, elderly have a large share in family life, as they care for younger generations (Hawkes, O'Connel, \& Blurton Jones, 1997).

Social interactions are a characteristic that links humans to other societies close to our evolutionary history, such as primates (Amici \& Widdig, 2019). Engaging in social interactions connects us from an early age and all throughout life. Both humans and primates are highly dependent on adult group members in their first years of life (Amici, Kulik, Langos, \& Widdig, 2019) and the importance of social interactions persists beyond reaching adulthood in most primate species (Archie, Tung, Clark, Altmann, \& Alberts, 2014; Silk, 2007). Due to our shared social evolution, it remains essential to study primate societies and how they are coping with increasing age to fully understand the evolutionary origins of human sociality of aging.

In the following sections, I will elaborate why and how organisms, including humans and other animals, age, and how different or similar aging trajectories occur in different species. Then, I will continue by introducing the theoretical background of this thesis derived from human lifespan psychology and connect how those concepts relate to the study of primate social behaviour. 


\subsection{Why do individuals age and when are they 'old'?}

Aging, the process of becoming older, is multidimensional. Whether it is genetics, behavioural biology, or psychology, each discipline describes the aging process from a different angle (Baltes \& Singer, 2001). There is no universal definition of aging (Kirkwood, 2005). From a biological point, aging is mostly described as a progressive decline in physiological functioning (also called senescence) that occurs across most species (Austad, 1997). Natural selection forces are weakened with increasing age as only few individuals in the wild live until old age (Medawar, 1952) and their likelihood to reproduce is lowered (Nussey, Froy, Lemaitre, Gaillard, \& Austad, 2013). This allows the accumulation of mutations that are harmful only at the later stages of life. Accordingly, deleterious mutations have no effect on fitness after the reproductive phase, and aging takes place in the 'selective shadow' (Medawar, 1952; Rose, Rauser, Benford, Matos, \& Mueller, 2007). The human menopause with a post-reproductive phase almost a third of the lifespan in women is an evolutionary paradox in this sense (Shanley \& Kirkwood, 2001). It has been suggested that it evolved as an indirect fitness benefit to support younger related generations and thereby enhance their survival (Hawkes et al., 1997; Shanley \& Kirkwood, 2001). Yet, the evolution of human menopause and potential occurrence in nonhuman animals is still subject to much debate (Brent et al., 2015; Nattrass et al., 2019; Paul, Kuester, \& Podzuweit, 1993; Thompson et al., 2007).

The decline in physiological functioning that is observed among most aging individuals is usually accompanied by a decrease in fertility and an increase in mortality (Kirkwood \& Austad, 2000). The disposable soma theory states that a life history trade-off in energy allocation between reproduction and the maintenance of somatic tissue, i.e. physiological functioning is responsible for the rate of aging. If survival is at high risk in early age due to harsh environmental conditions such as predation risk, then energy is rather invested into reproduction than somatic maintenance (Kirkwood \& Austad, 2000; Nussey et al., 2013). Recent studies challenged that the allocation of energy is the sole determinant of aging and put forward explanations based on functional deterioration on the cellular level (Cohen, Coste, Li, Bourg, \& Pavard, 2020; Maklakov \& Chapman, 2019).

One biological marker for aging on the cellular level is telomere length. Telomeres, which mark the end of the chromosomes and protect them from degradation, get shorter with age. Thereby, telomere length functions as an indicator for higher risk of suffering from cancer (Kim, Kaminker, \& Campisi, 2002; Kirkwood, 2005). Another biological marker which received much attention in recent years is the 'epigenetic clock'. This method is based on 
a mathematical algorithm that estimates biological age based on the pattern of methyl groups attached to the DNA, which are known to change with age (Horvath \& Raj, 2018).

It has long been assumed that only humans and animals living in captive conditions regularly reach older ages (Nussey et al., 2013). Yet, there are also wild populations of several species that show signs of senescence, such as worn fur, loss of teeth or changes in posture (Nussey et al., 2013). For instance, killer whales (Orchinus orca) (Brent et al., 2015; Foster et al., 2012), painted turtles (Chrysemys picta) (Warner, Miller, Bronikowski, \& Janzen, 2016), giraffes (Giraffa camelopardalis) (Carter, Brand, Carter, Shorrocks, \& Goldizen, 2013), African elephants (Loxodonta africana) (McComb et al., 2011), or chimpanzees (Pan troglodytes) (Thompson et al., 2007) live up to the maximum of their species-specific age range in the wild. For animals, the threshold of 'being old' is impossible to define on a general level. The term 'old' might apply to individuals of a different age in the wild compared to captive populations. This is due to many factors, such as the mortality rate depending on ecological stressor such as harsh climate conditions, fluctuating food availability and predation pressure. Individuals in the wild might show declining physiological functioning earlier than in captivity (Carey \& Gruenfelder, 1997; Gaillard \& Lemaître, 2020).

Regarding humans, the age of retiring at 65 is often taken as a threshold to consider a person as 'old' (United Nations, 2020). Yet, this threshold has been considered arbitrary (Libertini, 2013). With a population that is increasingly reaching older ages, the term 'old' has to be redefined depending on the demographic situation. This is reflected in better health conditions of adults around 65 years and has led to the discussion about setting a new - older - retirement age (Sanderson \& Scherbov, 2013).

Regarding the study species' age range, Barbary macaques can live up to 30 years in captivity. Generally, macaques in captivity are considered as 'old' between the ages 15 to 20 years (Berghänel, Schülke, \& Ostner, 2010; Brent, Ruiz-Lambides, \& Platt, 2017; Corr, 2003). Even with a shorter lifespan than humans, macaques show similarities in how they age (Colman, 2018; Colman \& Anderson, 2011), which I will address in more detail in section 1.8. Primate models in aging research.

\subsection{How do individuals age?}

Besides physiological changes with age, social changes are also major determinants in life. In humans, often the transition to retirement relates to a change or reduction of the social network. For example, the decrease in network size is estimated as one person less 
per decade, considering ages from 10 to 85 years (Wrzus, Hänel, Wagner, \& Neyer, 2013). Here, the social environment is seen as an important key to physical and mental health. Being engaged in close positive social relationships is related to how much adults take care of themselves and is therefore an important part of healthy aging (Bremer et al., 2019; Carstensen, Fung, \& Charles, 2003; Charles \& Carstensen, 2010; McLaughlin, Vagenas, Pachana, Begum, \& Dobson, 2010). A small social network, for example, combined with a lack of social support, increases the risk of physical or mental illness (Cacioppo \& Cacioppo, 2012; Cornwell \& Waite, 2009; Steptoe, Shankar, Demakakos, \& Wardle, 2013). Loneliness, i.e. a mismatch between desired and realized social contact, is a growing problem in many societies, particularly affecting people with low income (Kemperman, van den Berg, Weijs-Perrée, \& Uijtdewillegen, 2019; Smith, Jackson, Kobayashi, \& Steptoe, 2018). Only in recent years, an increasing number of programmes to counteract loneliness in old age have been initiated (Bremer et al., 2019; Cordier \& Wilson, 2014). For instance, England has named the first so-called Minister of Loneliness to deal with increasing risk of becoming socially isolated along with the consequences of diminished health (Walker, 2018).

But why do people seem to have a smaller social environment with increasing age? Is it only due to social upheavals such as retirement or illness, or do the social needs and motivation for social interactions also change? The psychology of aging has been trying to answer these questions for decades and developed theories that describe the relationship between social activity and well-being with age (Baltes \& Singer, 2001). Motivational changes are one of the foundations of these theories. Changes in behaviour are modulated by the motivation to either maintain the current state or minimize the decline (Heckhausen, Wrosch, \& Schulz, 2019). In the following sections, I will introduce some of the most prominent theories and follow up discussing their application to primates.

\subsection{Psychological theories on aging}

The disengagement theory (Cumming \& Henry, 1961) and the activity theory (Havighurst, 1961) are two of pioneering theories to describe age-related changes in human sociality. The core idea of the disengagement theory is the assumption that older adults decrease their social contacts and withdraw from society in order to prepare for death (Cumming \& Henry, 1961). In contrast, the activity theory considers a decline in social activity by the lacking physical ability and diminishing of the social environment that is equally old. Activities are shifted towards more feasible occupations (Havighurst, 1961). Both theories have been challenged in the past and have been superseded by a framework of theories that set socially motivated decisions into more focus. 
One of the most important theories in psychology of aging is the socioemotional selectivity theory (Carstensen, 1993). A fundamental assumption of this theory is that the awareness of the remaining limited lifetime is driving motivational shifts regarding social activities. If the remaining lifetime is perceived as limited, which is often but not necessarily the case with increasing age, emotionally driven goals are prioritized. It is expected that people selectively invest more into close social relationships while abandoning the weaker ones. Thereby, they reduce their social network towards social partners of high emotional quality, with whom a positive and familiar relationship is shared (Charles \& Carstensen, 2010). Smaller social networks are perceived as more satisfying among elderly than among younger adults (Luong, Charles, \& Fingerman, 2011). The scope of the socioemotional selectivity theory has been steadily expanded by different models and further theories on which I will elaborate in the following sections.

Similar to the socioemotional selectivity theory, the selection, optimization and compensation model focuses on motivational priorities and goal setting with increasing age (Nikitin, Burgermeister, \& Freund, 2012; Nikitin, Schoch, \& Freund, 2014; Riediger \& Freund, 2006). Besides the awareness about a limited remaining time, this model rather describes goal setting under consideration of age-associated adversities. The key assumptions are that older adults become more selective in their goals, and preferably turn to more achievable goals in terms of physical or cognitive effort. For example, studies revealed that older adults withdraw from participating in cognitive tests more often if they perceive the tests as cognitively exhausting or associate them with great effort (Ennis, Hess, \& Smith, 2013). In addition, remaining skills are optimized, which then compensate the overall deficits that arise with age (Charles \& Carstensen, 2010; Heckhausen, Wrosch, \& Schulz, 2010; Hess, 2014). Some work indicated that younger adults rather focus on maximizing their goals, are more willing to take greater risks and show more persistence in reaching them. In contrast, older adults have been found to be more motivated to maintain current levels and their decisions are driven by minimizing losses (Freund, 2006; Hess, 2014).

The socioemotional selectivity theory states that older adults tend to proactively focus on positive, familiar encounters, thereby maintaining a high level of emotional wellbeing. Yet, stressful and negative experiences cannot always be avoided. How older adults cope with those situations, and what their mechanisms are to avoid them is taken up by the Strength and Vulnerability Integration model (Charles, 2010; Charles \& Hong, 2015). Strength refers to the life experience that older adults can use to better regulate their emotions and navigate within their social environment. Vulnerability refers to the physical deterioration related to aging that makes it more difficult to deal with stressors. Such stressors are, for instance, the higher likelihood of suffering from chronic illness with 
increasing age (Christensen et al., 2009), but also interpersonal conflicts that demand emotional coping mechanisms (Moos, Brennan, Schutte, \& Moos, 2006). Older adults possess fewer physical resources that make them less resistant to stressors like interpersonal confrontations. Some work indicated that elderly are less likely to recover from stressful emotional situations such as interpersonal conflicts (Charles, 2010). It appears that older people rather engage in avoidance strategies when dealing with negative situations as their physical and mental resources provide less capabilities to cope with unpleasant experiences (vulnerability). The improved emotion regulation in older adults which makes them leave a conflict or wait whether the situation resolves itself is seen as a strength to ensure their emotional well-being (Birditt \& Fingerman, 2005; Charles \& Hong, 2015; Luong et al., 2011).

The motivational shift with increasing age that has been proposed by the previous models is also recognized in attentional changes. The positivity effect describes the tendency of elderly to remember but also attend more to positive than to negative information. Older adults rather remember images with positive (happy) context than neutral ones (Mather \& Carstensen, 2005). Further, older adults show an attentional bias towards happy faces, and away from angry faces, each presented with a neutral counterpart (Lindstrom et al., 2009; Mather \& Carstensen, 2003). To illustrate, younger and older adults were shown two pictures of faces on a screen for one second. Afterwards, a dot appeared at the position of the previously seen neutral or emotional (positive/negative) picture. Reaction time towards the dot was measured. If a participant already focused on a particular picture the reaction time to look towards the dot would be shorter compared to relocating attention. The results revealed that older adults had faster reaction times towards a positive picture when shown together with a negative, and similarly faster reaction times towards a neutral picture when shown together with a negative one (Mather \& Carstensen, 2003).

The attentional bias towards positivity has been linked to pursuing higher emotional wellbeing with increasing age. In contrast, children or younger adults have been found to attend more to negative information, i.e. look longer towards negative images or recall negative information better. Potentially, they experience unpredictable circumstances more often which makes them more attentive to a variety of situations, which include possibly negative encounters (Carstensen \& Mikels, 2005; Charles, Mather, \& Carstensen, 2003; Isaacowitz, Wadlinger, Goren, \& Wilson, 2006; Mather \& Carstensen, 2005).

Yet, the positivity effect has also been subject of debate as there have been inconsistent results. A meta-study showed, however, that differences in studies can be attributed to different methodological paradigms (Carstensen \& DeLiema, 2018; Reed \& Carstensen, 2012). For example, the extent of the effect appears to be context-dependent and people 
feel differently motivated depending on whether the goal they have been asked to reach is relevant to them or not (Löckenhoff \& Carstensen, 2007). Motivational changes based on personal relevance therefore play a significant role in social attention across age.

\subsection{Applying psychological theories to primates}

Comparative studies are becoming increasingly important in aging research connecting psychology and behavioural biology as they allow examining psychological theories of agerelated changes in terms of their evolutionary roots. The essential aspect here is that investigating primates means investigating patterns in human behaviour without the social norms or conventions of the human society that shape behaviour and choices people make. In addition, the assumption that motivational changes occur because older adults reflect on their life and the time remaining and make decisions based on this does not hold for primates as they are presumably not aware of their limited lifespan. If motivational changes with increasing age are also found in primates, then the assumption that these changes in humans are exclusively based on cognitive justifications - the explanation humans give oneself for the changes experienced - would be only partially correct. Studying primates allows to test the application of psychological hypotheses in a broader species spectrum and can also help to identify new theories on the development of age-related changes in human sociality. Therefore, one of the goals of this thesis aimed at investigating age-related motivational changes in physical (problem-solving tasks) and social environment (interaction with conspecifics) in accordance with theoretical frameworks in human psychology.

In fact, many primates show similar social network changes to patterns observed in humans with increasing age. In accordance with the socioemotional selectivity theory, older primates also show a reduction in their social network, which is accompanied by more time spent alone or with sleeping and resting. For instance, aged chimpanzees engaged in less affiliative social behaviours compared to younger individuals (Webb, Hau, Lambeth, \& Schapiro, 2018). Older rhesus macaques (Macaca mulatta) spend less time with affiliative behaviour, both given to and received from conspecifics (Brent et al., 2017; Corr, 2003). Similar results were found for female Barbary macaques, Japanese macaques (Macaca fuscata) and long-tailed macaques (Macaca fasciularis) (Almeling, Hammerschmidt, Sennhenn-Reulen, Freund, \& Fischer, 2016; Nakamichi, 2003; Veenema, Spruijt, Gispen, \& van Hooff, 1997). Furthermore, older females in Japanese and long-tailed macaques shifted their social activity towards related females, indicated by no age-related decline when considering only related females (Nakamichi, 2003; Veenema et al., 1997). Other studies show how time distribution is shifted towards fewer individuals. Tufted capuchin 
monkeys (Sapajus sp.), for instance, restrict their attention to fewer individuals but spent more time with them when they get older (Schino \& Pinzaglia, 2018). Similar results have been revealed in female Barbary macaques, that groom fewer conspecifics for longer periods when they get older (Almeling, Sennhenn-Reulen, Hammerschmidt, Freund, \& Fischer, 2017). Older Barbary macaques and long-tailed macaques spent more time with other older females, possibly because they are more familiar to them (Sosa, 2016; Veenema et al., 1997). However, there are also studies that have found no decrease in social interactions in Japanese macaques (Baker, 2000; McDonald Pavelka, 1991). The directionality of the interactions might explain inconsistent results in social aging. Studies on rhesus macaques, Japanese macaques and Barbary macaques have shown that older females were less socially active and approached others less to initiate social interactions. In contrast, younger group members approached older monkeys for affiliative interactions, irrespective of the imbalance of giving and receiving affiliation (Almeling et al., 2016; Corr, 2003; Nakamichi, 1984).

In addition, the majority of studies on social aging in primates focuses on females and lacks information about males. In many primate species the social environment and pressure differ for males and females as they age. Due to a hierarchy based on physical dominance, males often drop in rank when they grow older. As in females, social relationships are equally important in males. Therefore, maintaining social relationships with other males can provide supportive coalitions to defeating younger males (Bissonnette, Bischofberger, \& van Schaik, 2011; Bissonnette, de Vries, \& van Schaik, 2009). Yet, data on social aging in males is scarce and results are mixed (Corr, 2003; Sosa, 2016). Therefore, one of the goals of this project was to investigate whether male primates show changes in their social behaviour with increasing age, and whether there exist differences to female aging patterns. This topic will be further addressed in section 1.10. Open questions and in study 1 (Chapter 2) of this thesis.

Further, what remains unclear is which underlying factors influence such an age-related decrease in social interactions? While the quantitative number of partners or the frequency of both positive and negative interactions has been examined, literature on other social factors contributing to the social network structure, such as signals (facial expressions) and social attention, is scarce. Just as humans, primates might show a positivity effect and shift their attention towards positive, affiliative signals. Studies already reported that Barbary macaques show interest in social stimuli until old age and follow human's gazes, or maintain interest in pictures or playbacks of conspecifics (Almeling et al., 2016; Rosati \& Santos, 2017). Surprisingly, older rhesus macaques that have been tested in a looking time task rather focused on negative pictures (showing aggressive facial expressions) than on neutral ones and did not express a positivity effect (Rosati, Arre, Platt, \& Santos, 2018). This finding 
might underlie the highly despotic social system of rhesus macaques, with a strict dominance hierarchy and escalating conflicts. Barbary macaques, on the contrary, live in a rather egalitarian system with more relaxed social relationships and a hierarchy less skewed towards few dominant individuals (Thierry, 2007). Whether an age-related positivity effect exists in this species is currently unknown and will be addressed in study 2 (Chapter $\mathbf{3}$ ).

In accordance with the Strength and Vulnerability Integration model, older female macaques show less intense aggressive behaviour, and are less targeted by other individuals (Brent et al., 2017; Sosa, 2016; Veenema et al., 1997). Potentially, this indicates older females' ability to navigate in their group in a way to avoid confrontations (Almeling et al., 2017; Brent et al., 2017). In old age, the physical resources to recover from stressors are potentially lower, which lead to avoidance strategies. Some studies revealed changes in the immune system of aged primates, which make them more susceptible to diseases or other stressors (Meyer, Kerns, Haberthur, \& Messaoudi, 2012; Rivera et al., 2018). In Barbary macaques, the proportion of using facial displays over high intensity aggression is higher in aged females than younger females. This finding suggests a reduction of physical effort as aggressive movements such as chasing are highly energy demanding. Further, using low-level aggression might function as a protection mechanism to prevent others from approaching and thereby avoid being involved in a costly fight, including potential injuries (Almeling et al., 2017). Whether older Barbary macaques differ in their signal use and response, i.e. whether they use less communicative signals and, in accordance with the Strength and Vulnerability Integration model, avoid the signals of others more, will be addressed in Chapter 3.

In order to gain a comprehensive understanding of how increasing age shapes different aspects of life, it remains important to investigate how cognitive performance, i.e. problemsolving behaviour but also how the motivation and persistence to explore the physical environment changes with age. I will first review age-related cognitive changes in humans before I will turn to cognitive performance in primates and, for comparison, in other animal species (section 1.6.). Problem-solving abilities have been attributed not only to cognitive abilities but also non-cognitive traits (van Horik \& Madden, 2016), for instance how persistent an individual explores a task. Similar to motivational changes in social behaviour, the changes in explorative behaviour and persistence towards a goal (in humans) or a reward (in animals) changes with age (section 1.7.). How motivation changes with age was one of the main goals of this thesis and forges the connecting tie between behavioural changes in the social and physical environment. 


\subsection{Age-related cognitive changes}

\subsubsection{Human cognitive aging}

Age-related changes in the brain often relate to atrophy of the prefrontal cortex (Solbakk et al., 2008). This brain region is related to top-down regulatory processes, for instance executive functions. These are cognitive functions that enable an individual to adapt its behaviour and thoughts to the environment (Miyake et al., 2000; Miyake \& Friedman, 2012). Executive functions comprise for instance working memory, inhibitory control and cognitive flexibility (Diamond, 2013). They come into play when automated action is no longer effective and must be prevented, for example when well-learned behaviours have to be inhibited such as driving a car on the right side of the road in different countries (Bedard et al., 2002; Rey-Mermet \& Gade, 2018). Thus, they contribute significantly to the functioning of everyday life.

There is great variability between age-related trajectories of cognitive functions. While general knowledge and verbal skills (crystalized intelligence) are less affected by age and even improve during the sixties, executive functions like inhibitory control or cognitive flexibility (fluid intelligence) appear to more affected by age (Harada, Natelson Love, \& Triebel, 2013; Hedden \& Gabrieli, 2004; Lindenberger, 2014). Since many executive functions need time to develop in the first years of life, the extent of these abilities are highly age-dependent and should therefore be considered holistically over the entire life span (Diamond, 2013; Gratton, Cooper, Fabiani, Carter, \& Karayanidis, 2018).

Inhibitory control, for example, requires specific brain structures, especially the prefrontal cortex, to mature, which takes until early adulthood (Solbakk et al., 2008). Children up to the age of three years, for example, are more likely to have problems inhibiting an automatic, prepotent movement than older children (Vlamings, Hare, \& Call, 2010). With age, the ability to inhibit automated movement or decisions decreases again. Older adults take more time to react than middle-aged adults in tests that require to stop an ongoing action when asked to (Hasher, Zacks, \& May, 1999; Williams, Ponesse, Schachar, Logan, \& Tannock, 1999). Additionally, irrelevant information are more distracting and harder to ignore for older compared to younger adults (Darowski, Helder, Zacks, Hasher, \& Hambrick, 2008; Zanto, Hennigan, Östberg, Clapp, \& Gazzaley, 2010). Further, cognitive flexibility is characterized by the ability to respond to changing conditions. It requires to assess the current situation and change to a more appropriate strategy (also called set shifting) in order to succeed in a task (Ridderinkhof, Ullsperger, Crone, \& Nieuwenhuis, 2004; Taconnat et al., 2009). The prerequisite for this is also related to inhibitory control 
since flexible adaptation to new circumstances depends on stopping previous strategies or actions. Often, the number of perseverative errors, i.e. repeating a non-successful thought or strategy, is used as a proxy of cognitive flexibility. To illustrate, older adults produced more errors than younger adults when reacting to changing categories i.e. sorting cards first by colour and then by shape (Rhodes, 2004; Taconnat et al., 2009). Comparative science has the potential to contribute to a better understanding of our evolutionary history and how living under different ecological and social conditions can lead to the development of different cognitive abilities changing throughout an individual's lifespan.

\subsubsection{Measuring cognitive performance in animals}

Cognitive performance is measured on a behavioural basis in animals (Völter, Tinklenberg, Call, \& Seed, 2018). This applies, for example, to how well or poorly they perform in a problem-solving task (Joly et al., 2017; Völter et al., 2018). Whether a cognitive ability is well-expressed in a species depends on the ecological and social challenges individuals must face. For instance, high memory capabilities are found in certain rodent or bird species, which hide their food for several months (Emery \& Clayton, 2001). Squirrels (Sciurus carolinensis) perform well in problem-solving tasks that involve adapting their behaviour to changing modalities (Chow, Lea, \& Leaver, 2016). Like in humans, executive functions such as inhibitory control or cognitive flexibility constitute an important aspect in problem-solving behaviour in animals. A classical task to measure inhibitory control is presenting an individual with a transparent barrier that requires walking or reaching around to obtain a food reward, also called the detour task. Several bird species including New Caledonian crows (Corvus moneduloides), ravens (Corvus corax) and jackdaws (Corvus monedula) are able to retrieve the reward and show abilities on par with primates (Kabadayi, Taylor, Bayern, \& Osvath, 2016). Likewise, primates possess a high level of cognitive skills including the use of tools, innovation and novel problem solving, future planning and flexible adaptation to changing environmental conditions (Amici, Aureli, \& Call, 2008; Joly et al., 2017; Visalberghi et al., 2009), which are (at least in part) owing to the need to manage their complex social lives (Byrne, 1996; Silk, 2007).

\subsubsection{Age-related changes in cognitive capacities in animals}

Within the order of rodents, several species have been used as animal models in cognitive aging studies, revealing that executive functions, such as memory and cognitive flexibility, decline with age (Barense, Fox, \& Baxter, 2002; Bizon, Foster, Alexander, \& Glisky, 2012). Since rodents and humans differ greatly in their lifespan and cognitive capacities, primates have the potential to serve as far better model species for testing agerelated changes in cognitive functioning (Verdier et al., 2015). Older chimpanzees (Pan 
troglodytes), bonobos (Pan paniscus), orang-utans (Pongo abelii) and gorillas (Gorilla gorilla) and common marmosets (Callithrix jacchus) exhibit more problems than juvenile or younger adult conspecifics in a detour task, in which they had to reach around a transparent barrier to obtain a food reward (Manrique \& Call, 2015). Aged common marmosets showed more difficulty in inhibiting movement, whereas all younger monkeys were successful in a detour task including a transparent barrier (Ross et al., 2019). Concerning flexible behaviour in problem-solving, older apes had more difficulties applying new strategies to solve problems (Manrique \& Call, 2015; Massen, Antonides, Arnold, Bionda, \& Koski, 2013). Older marmosets were often not able to adapt their behaviour to changing situations (either left, right or front side open of a transparent cube with a food reward), but continued with the strategy they first had been successful with (Ross et al., 2019).

The question whether the success rate or the time an individual spends with a problemsolving task is a marker for its cognitive abilities, has been recently addressed in comparative research. There is a growing debate about including non-cognitive skills such as motivation as contributing factors in the study of problem-solving behaviour (Griffin \& Guez, 2014; van Horik \& Madden, 2016). Such motivational factors have long been neglected in the study of problem-solving skills in animals (van Horik \& Madden, 2016). Therefore, this thesis aimed at incorporating the influence of motivation into studying cognitive performance in a primate model species. In particular, I aimed to set the focus on age-related changes in cognitive abilities (inhibitory control and cognitive flexibility), the motivation to explore, and the persistence to continue exploring a food puzzle (study 3 Chapter 4).

\subsection{Motivation versus cognition}

Motivation is a multifaceted term and broadly refers to the interplay between intrinsically driven behaviour by needs, interests or goals and factors that extrinsically influence behaviour such as incentives or the opportunity to achieve a goal (Botvinick \& Braver, 2015; Hess, 2014). Further, intrinsic goals can be characterized by physiological measures such as hunger or thirst, but also refer to the need for social contact. Extrinsic goals in humans refer to money or other achievements, whereas in nonhuman animals extrinsically motivated behaviour can be elicited by a food incentive (Ebel \& Call, 2018). The willingness or intensity with which an individual strives to achieve a goal is often called persistence which is also a form of motivation. In animals this is often measured as the time an individual spends with a food puzzle for instance (Chow et al., 2016; Griffin \& Guez, 2014; Huebner \& Fichtel, 2015; Thornton \& Samson, 2012). 
Regarding extrinsic motivation, it has been shown that a reward in both humans as well as primates influences their performance (Braver et al., 2014; Heckhausen et al., 2019). In humans, a reward (money) leads to higher attention, and fewer mistakes in tasks which required to choose from several options, recall memories or inhibit a movement (Botvinick \& Braver, 2015). The prospect of a reward and the motivation to receive it therefore has a positive effect on the cognitive performance (Chiew \& Braver, 2011; Padmala \& Pessoa, 2011). In chimpanzees, the presence of a reward affects exploration efficiency. For example, in problem-solving tasks involving a food reward, performance was lower and chimpanzees appeared to be distracted by the incentive compared to tasks without a food reward (Ebel \& Call, 2018). Besides difference in motivation based on the availability of a food reward in animals or a monetary incentive in humans, age has also been increasingly investigated as a determinant of motivation.

The selection, optimization and compensation model suggests that older adults are more motivated to minimize losses than to maximize gains, and to preserve the current state, while younger adults rather focus on maximizing gains (Freund, 2006). This is associated with the fact that older adults become more selective in their goal setting, regarding both social interaction and cognitively demanding tasks. The invested effort to achieve a certain goal differs depending on the relevance or value the goal has for a certain individual. Higher relevance increases the persistence to reach a goal (Jimura, Locke, \& Braver, 2010). In line with this, the positive relationship between one's perception of effort and the probability of giving up in a memory card game was stronger in older than younger adults (Ennis et al., 2013). Further, children have a higher motivation to explore the environment compared to adults. For example, when children were presented with different options to win stickers, they were more interested in exploring the given options than maximising their pay-out. Adults in a comparable test were more exploitative than children. The exploration tendencies instead of exploitative behaviour in children might represent a strategy to train senses, which subsequently helps to adjust to changing environment that will later in life become helpful (Sumner, Steyvers, \& Sarnecka, 2019).

Studies in primates and other animals corroborate these findings. Juveniles or subadults show higher motivation to explore novel objects (with and without a food incentive) than adults (e.g. callitrichid monkeys: Kendal, Coe, \& Laland, 2005, spotted hyenas (Crocuta crocuta): Benson-Amram \& Holekamp, 2012, several bird species: Franks \& Thorogood, 2018. How the motivation to explore the physical environment changes beyond reaching adulthood has rarely been investigated. Older capuchin monkeys seem less interested in exploring objects (Schino \& Pinzaglia, 2018). A decrease in interest in new objects was also observed in Barbary macaques already in early adulthood (Almeling et al., 2016). Likewise, Barbary macaques show motivational differences with age. Only when novel objects were 
equipped with a food incentive, older macaques were interested and manipulated the device, except for the oldest individuals in the group (>19 years old), which did not approach (Almeling et al., 2016). In general, motivational factors, such as persistence or the tendency to participate in a task, are still little studied in relation to aging in primates and will more comprehensively addressed in Chapter 4.

\subsection{Primate models in aging research}

Considering the short generation time and easy housing conditions, rodents are among the most commonly used animal models in aging research (Mitchell, Scheibye-Knudsen, Longo, \& de Cabo, 2015; Verdier et al., 2015). This is particularly true for research related to genetic or physiological underpinnings of aging (Mitchell et al., 2015). Studying aging in primates, however, requires long-lasting social groups with individuals of different ages. As our closest relatives, primates hold the potential to help us gain insights in human social evolution. Humans and most primate species live in social groups and maintain differentiated social relationships (Shultz \& Dunbar, 2007; Silk, 2007). Compared to other mammals, primates have a longer infancy period and a long lifespan (Leigh, 2001; Mumby \& Vinicius, 2008). Captive and semi-free ranging primate groups offer the possibility to investigate changes in behaviour in an age-heterogeneous population with a higher number of older individuals compared to the wild. Great apes can live in captivity for around 50 years, with some exceptions even until their seventies (Lacreuse, Parr, Chennareddi, \& Herndon, 2018; Segal, 2012). Macaques live up to around 30 years (in rare instances up to 40 years) in captivity (Colman, 2018). Several publications on macaques consider them as 'old' starting at an age of 15 to 20 years (Berghänel et al., 2010; Brent et al., 2017; Corr, 2003). Therefore, macaques constitute a good model species for aging research in comparison to chimpanzees or other apes as they show similar physiological aging as humans but at the same time only live half as long as chimpanzees do, allowing the collection of data about age-related changes much faster.

Moreover, primates show similar physiological aging processes as humans do. With increasing age, the visual and hearing abilities deteriorate (Spear, 2004; Torre \& Fowler, 2000). The age-related changes in brain structures also resemble those in humans (Chen et al., 2013; Cramer et al., 2018; Verdier et al., 2015). The primate brain weight decreases in a similar way to that of humans (Fraser, Khaitovich, Plotkin, Pääbo, \& Eisen, 2005; P. R. Hof et al., 2002). Moreover, age-related bone diseases such as osteoporosis and arthritis, occur in chimpanzees as well as rhesus macaques (Colman \& Binkley, 2002; Morbeck, Galloway, \& Sumner, 2002; Roth et al., 2004). Due to the physiological similarities and common ancestral origins, primates constitute excellent model species to investigate the 
determinants of cognitive and social aging. Especially, the growing scientific interest in comparative studies on the consequences of aging and underlying determinants in health and sociality urges for more studies connecting different disciplines from medicine, biology and psychology (Snyder-Mackler et al., 2020).

Compared to humans, primates also provide a variety of benefits when studying agerelated topics. Human behaviour is affected by many confounding factors which are nearly impossible to separate or to control for (Snyder-Mackler et al., 2020). With regard to the aging process, social and cultural environment are likely to influence older generations by norms and constraints. Further, social integration is often measured by the extent or quality of social contact based on questionnaires and thereby exposed to subjective perception (Amici \& Widdig, 2019; Rafnsson et al., 2020). In primates, however, factors that define an individual's life such as age, sex, dominance rank but also ecological conditions such as food availability, predation risk or impact of weather (dry/rainy season) are easier to control for. In captive or semi-free ranging conditions, factors like predation risk or food availability are even absent. Therefore, comparative studies in behavioural biology and cognitive research are of great importance, to improve our knowledge on the evolutionary roots of human social behaviour.

\subsection{The Barbary macaque as a model species}

Barbary macaques are native to Algeria and Morocco, which makes them the only macaque species native to Africa (Fooden, 2007). They live in multi-male-multi-female groups (Aureli, Das, \& Veenema, 1997; Mehlman, 1986; Thierry, 2007). Females are philopatric and remain in the natal group throughout their lives. Males often migrate to other groups after sexual maturity (Aureli et al., 1997; Mehlman, 1986). The hierarchy differs between the sexes. Males increase in rank by networking and by competing with other males in aggressive conflicts. The female hierarchy is based on matrilineal lines that depend on the mother's dominance rank, where daughters inherit the rank of their mother (Preuschoft, Paul, \& Kuester, 1998; Timme, 1995). Barbary macaques have a mating season that begins in late autumn and continues into winter. The offspring is born after a gestation period of around 5.5 months, with a birth season that can extend into early summer (Kuester \& Paul, 1984, 1992; Ménard \& Vallet, 1997). Compared to other macaques species, Barbary macaques are characterized as rather egalitarian, i.e. they have less escalating conflicts, and aggressive disputes are not always decided in favour of the more dominant individual (Preuschoft et al., 1998; Thierry, 2007). Barbary macaques have differentiated social relationships (Berghänel, Ostner, Schröder, \& Schülke, 2011; Young, Majolo, Schülke, \& Ostner, 2014), which they keep into old age (Almeling et al., 
2016). For these reasons, they are a highly suitable species to study age-related changes in social behaviour, cognitive abilities and motivation.

\section{Barbary macaques at La Forêt des Singes in Rocamadour}

Due to veterinary care, provision of food and lack of predation, the Barbary macaques at La Forêt des Singes in Rocamadour in southern France represent an excellent study population of an aging society. Three social groups live in a 20 -hectare area. The park is open to tourists from April to November, who can walk through the area on designated paths to observe the monkeys. The population in the study year 2017 consisted of 170 animals and in 2018 of 180 animals between the three groups (for history of the park and more details see de Turckheim \& Merz, 1984). Several times a day the animals are fed with fresh fruits, vegetables and cereals. They also feed on the natural vegetation like leaves, roots and insects. Water is available ad libitum. Due to numerous research projects, the Barbary macaques are well habituated to being observed. All individuals can be clearly identified by their identification number tattooed on their inner thigh. In addition, the monkey's physical appearance, for example differences in facial pigmentation, or genital swelling in females enable distinguishing between individuals. The large age-heterogeneous population at $\mathrm{La}$ Forêt des Singes makes it possible to use age as a continuous variable, in contrast to various other studies that were only able to differentiate between certain age groups, i.e. young and old (Joly, Ammersdörfer, Schmidtke, \& Zimmermann, 2014; Ross et al., 2019). Further, the semi-free ranging conditions allow investigating social activity in a population with stable social groups, including low fluctuation of available focal observation animals and their social partners. 


\subsection{Open questions}

In the previous sections, I have shown the similarities and differences in human and primate aging and elaborated on why it is important to consider primates as a model organism in aging research. To comprehensively study age-related changes in social behaviour and cognitive abilities in Barbary macaques, I conducted observational studies as well as experimental approaches. Therefore, I spent a total of 13 months in the park La Forêt des Singes in Rocamadour in the South of France to investigate the following three topics.

\section{Social aging in male and female Barbary macaques - closing the gap (Chapter 2)}

Most studies on social aging in primates are limited to females. In many primate species males and females have different life histories (Silk, 2002). In female philopatric species, such as baboons and macaques, females stay in their natal group all life, while males leave the group around the age of maturity (Paul \& Kuester, 1985). Therefore, their position in the social network is not determined by a kin-based hierarchy as it is in females, but rather depends on their own motivation to build a supportive social network (Ostner \& Schülke, 2014). Likewise, this pattern has also been observed in semi-free ranging populations where males often do not change their natal group. Still, young adolescent males spend more time in the periphery and are often targeted by other males' coalitions (Berghänel et al., 2010; Rathke, Berghänel, Bissonnette, Ostner, \& Schülke, 2017). Whether male and female social networks differ beyond reaching adulthood and up into old age is little researched (Corr, 2003; Schino \& Pinzaglia, 2018). In the present study, I used different measures from social network analysis (degree, strength, clustering coefficient and eigenvector centrality) as well as classical behavioural parameters to obtain a more comprehensive insight in both female and male social environment. Social network analysis has become a helpful tool to study both direct and indirect patterns in social groups of animals (Brent, 2015; Sueur, Jacobs, Amblard, Petit, \& King, 2011). Proximity, physical activity (running, jumping, climbing), as well as commenting behaviour complemented the social network analysis and gave insights into the monkey's social integration and activity patterns. I expected to find age-related as well as sex-specific differences in the social network positions. For males, I considered two possible outcomes. Due to the high number of ambivalent social relationships in Barbary macaques (Fischer, Farnworth, SennhennReulen, \& Hammerschmidt, 2017), the risk of an unpredictable and potentially stressful social encounter is similar for males and females. Therefore, if males become more selective in their social partners, I expected to find a similar decline in social activity as in females. This would be reflected in lower values in the social network metrics. Yet, some 
work reported that older Barbary macaques can also maintain high-ranking positions when they invest in their social relationships (Bissonnette et al., 2011; Henkel, Heistermann, \& Fischer, 2010; Ostner \& Schülke, 2014; Rathke et al., 2017). In this case, I would expect varying male social activity with age and a different pattern than in females. In terms of the social integration, previous studies reported a decrease in individuals in close proximity for female Barbary macaques (Almeling et al., 2017), and for both sexes in capuchin monkeys (Schino \& Pinzaglia, 2018). I expected to find a similar decline in the number of spatially proximate monkeys for both sexes. Concerning the physical activity, previous literature showed that female macaques engage less in running or climbing than younger individuals do. As male and female physiology appears to decline similarly (Hamada \& Yamamoto, 2010), I expected to find a similar decline in physical activity in males. Social interest in group members has been reported to maintain at a similar level across age in females (Almeling et al., 2016, 2017). Therefore, I analysed commenting behaviour to third party interactions. Since this behaviour does not include any active participation and energetic demands, I expected to find a maintained social interest for both males and females across age.

\section{Testing the Strength and Vulnerability Integration model in Barbary macaques} (Chapter 3)

A decrease in social interactions when getting older has been observed in many primate populations (Almeling et al., 2016; Corr, 2003; Veenema et al., 1997). The decrease seems to be partly driven by the older monkeys themselves, which engage less proactively in affiliative interactions (Almeling et al., 2016; Brent et al., 2017). A possible explanation for the decline in social interactions could be that older animals are less able to cope with stressful situations. Every interaction also carries the risk of an aggressive confrontation. Based on the assumptions of the positivity effect and the Strength and Vulnerability Integration model from humans, I investigated whether Barbary macaques engage in avoidance strategies to cope with stressful interactions. I analysed whether older Barbary macaques respond less to other group member's aggressive signals (facial expressions and non-tactile body movements such as ground slap). To further investigate whether older Barbary macaques show a positivity effect, I analysed whether with increasing age, monkeys respond more to affiliative signals, i.e. facial expressions such as teeth chattering or lip-smacking. Most studies on communicational changes investigated differences between juveniles and adults (Fröhlich \& Hobaiter, 2018; Hesler \& Fischer, 2007; Liebal, Pika, \& Tomasello, 2004; Pika, Liebal, \& Tomasello, 2003). Studies that cover the age range beyond adulthood are rare. Further, I analysed if the previously reported decline in social activity, i.e. grooming, but also aggressive behaviours, is reflected in communicative 
signals. I expected to find a similar decline in affiliative and aggressive signals. Additionally, I conducted a looking time task to test whether older monkeys tend to look less towards negative and aggressive pictures compared to neutral facial expressions. By using these two approaches - observational data on signal and response behaviour and looking time task - I aimed to get a comprehensive insight into changes in Barbary macaques' communicative behaviour with age.

\section{$\underline{\text { Cognitive and motivational changes with age in Barbary macaques (Chapter 4) }}$}

Among the several studies on cognitive performance in old age (Bliss-Moreau \& Baxter, 2019; Herndon, Moss, Rosene, \& Killiany, 1997; Lacreuse et al., 2018; Manrique \& Call, 2015), only a few have targeted cognitive performance after reaching adulthood in wild primates or under semi-free housing conditions (Almeling et al., 2016). An important difference is that animals in captivity often undergo long training periods to reach the threshold at which they can participate in cognitive tests. By this, other cognitive functions, such as advanced memory abilities, are potentially selected for as only individuals with these abilities pass a pre-determined threshold. In addition, motivation is often neglected as an influencing factor. Studies conducted under semi-free ranging conditions do not have these limitations. There was no threshold to pass which allowed to further test motivation to participate at all. In addition, under such settings, the monkeys cannot be separated for testing alone, which better reflects natural conditions in which, for example, an opponent might approach to compete for a food reward. This study thus stands out from others by assessing cognitive abilities under the consideration of motivational factors. Barbary macaques participated voluntarily in three different cognitive tests to assess inhibitory control, cognitive flexibility and persistence.

The results of experiments and analyses will be presented in the next three chapters and then comprehensively discussed in Chapter 5. 


\title{
Chapter 2
}

\section{Social aging in male and female Barbary macaques}

\author{
Eva-Maria Rathke $e^{1,2,3}$ \& Julia Fischer ${ }^{1,2,3}$ \\ ${ }^{1}$ Cognitive Ethology Laboratory, German Primate Center, Leibniz Institute for \\ Primate Research, Kellnerweg 4, 37077 Göttingen, Germany \\ 2Department for Primate Cognition, Georg-August-University Göttingen \\ ${ }^{3}$ Leibniz ScienceCampus Primate Cognition, Göttingen
}

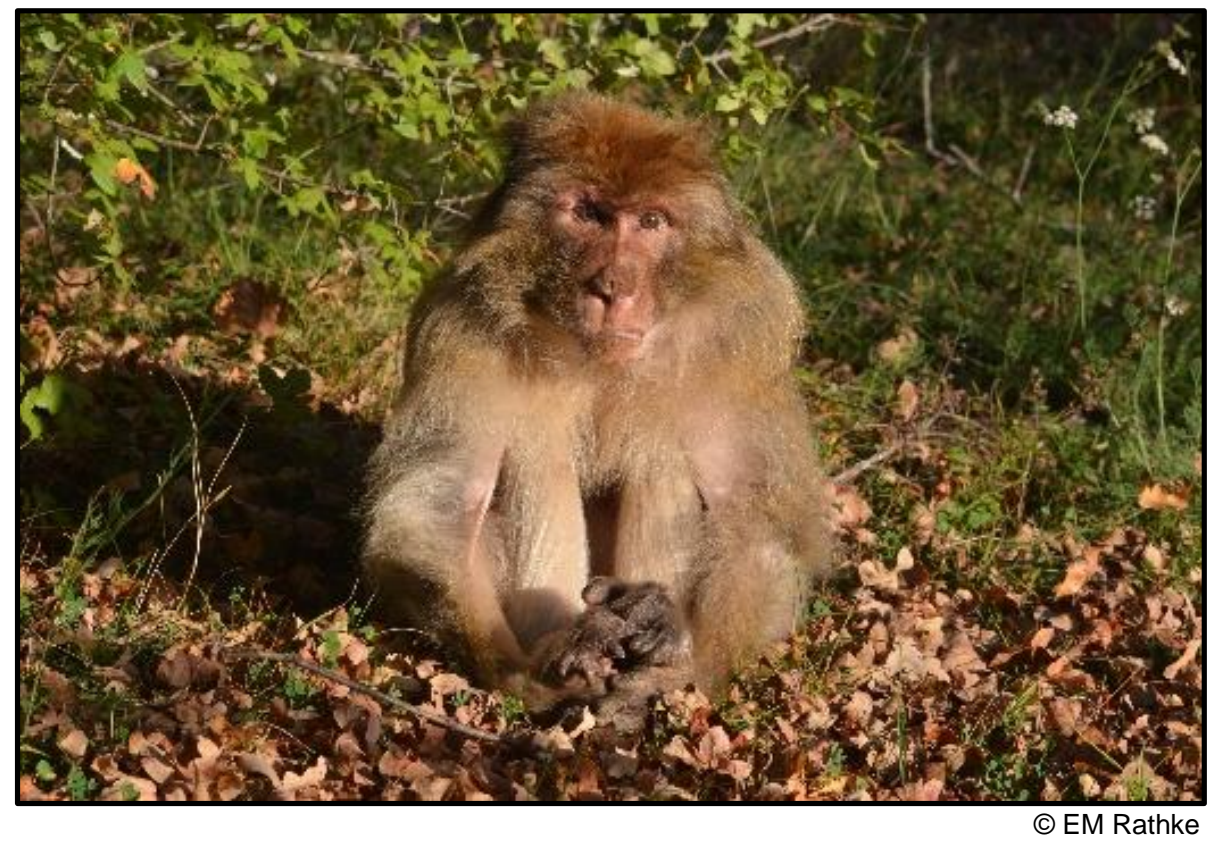

Manuscript in preparation 


\section{Abstract}

Aging brings about notable changes in sociality, with an increasing focus on important partners in both humans and nonhuman primates. Several studies have shown that older nonhuman primates have fewer social partners and shift their types of interactions. The majority of these studies, however, involved only female individuals. Much less is known about the trajectory of social aging in males. We collected 2180 hours of focal observation data in a large age-heterogeneous sample of 34 male and 50 female Barbary macaques (Macaca sylvanus; age range 1-30 years) living in two social groups at the outdoor enclosure at La Forêt des Singes in Rocamadour (France). To track age-related changes in social engagement of both sexes, we used classical behavioural as well as social network analysis, to measure age-related variation in the number of partners, the frequency of affiliative interactions, and the position in the social network (eigenvector centrality and clustering coefficient). We found that females were more central in most social network metrics than males, i.e. had more social partners and were more engaged in affiliative interactions than males. We did not find notable sex differences in relation to age: both sexes showed a similar decline in social activity as well as energy demanding activities like jumping or running. Our results thereby extend our knowledge on the social life of older nonhuman primates and emphasize that age has distinct impact on social behaviour in males and females.

Keywords: aging, social network analysis, social behaviour, Barbary macaques

\section{Introduction}

The growing proportion of older people in societies around the world strongly impact health systems and economic growth in the coming decades. With increasing life-span, a larger share of the population is afflicted by chronic ailments such as diabetes or cardiovascular diseases (Christensen et al., 2009). In affluent societies, the proportion of people that are no longer working is also growing. Changes in health and economic situation are often accompanied by changes in social life. Aging people often experience a decline in social network size, which may sometimes result in complete social isolation. Loneliness is perceived as a growing societal problem in older generations (Carstensen, 1993; Smith et al., 2018). A decline in social activity and social network size can be attributed to a number of factors, including the shift from work life to retirement, the loss of social partners due to mortality, i.e., changes in opportunity, on the one hand, as well as shifts in the motivation to engage in social interactions on the other hand. 
A number of psychological theories have been put forward to account for age-related changes in motivation and sociality in humans (reviewed in Charles \& Carstensen, 2010). The socioemotional selectivity theory (Carstensen 1993) proposes that the awareness of a limited lifetime leads to an increased focus on fewer but more meaningful social partners. Recent studies on nonhuman primates have put this conjecture to a test (Almeling et al. 2016; Rosati et al. 2020). Nonhuman primates are an interesting model, as they share several physiological features with humans, but are assumed to lack an awareness of their own limited lifetime. If they would also experience a shrinking social network with age, this may indicate that motivational changes with age are not simply a result of one's insight into a limited future time but may also be driven by more deeply rooted biological processes. There is ample evidence that older subjects tend to rest more, spend more time on their own and have fewer social partners (Almeling et al., 2016; Corr, 2003; Veenema et al., 1997).

What is less well understood to date is to which degree sociality changes with age in relation to sex. Women continue to have larger social networks than men into old age, and being alone tends to have greater impact on older men than on women (McLaughlin et al., 2010). Further, older women tend to have more widespread social networks than older men, including unrelated social interaction partners (Cornwell, 2011). To better understand how age affects the social network structure from an evolutionary perspective, comparable data for males and females for different nonhuman primate species are needed.

One important factor in this context is the identity of the dispersing sex. To date, most studies have focused on the philopatric sex. In female-philopatric species such as the members of the genus Macaca, females typically prefer to interact with the members of their own matriline throughout their life (Roubová, Konečná, Šmilauer, \& Wallner, 2015; Silk, Seyfarth, \& Cheney, 1999). Male macaques as the dispersing sex, in contrast, are prone to experience a variable network throughout life as they leave their natal group after reaching sexual maturity (Paul \& Kuester, 1985). Note however that even in captive conditions with several social groups, males may be less likely (or unable) to leave and instead may be forced to stay in their natal group. Irrespective, male social life changes during early age and adolescence: young adolescent males spend more time in the periphery and are often the target of aggression by older conspecific males (Berghänel et al., 2010; Rathke et al., 2017). Their position in the group is not determined by a kin-biased hierarchy but rather by their own ability to build up a network of supportive social relationships (Ostner \& Schülke, 2014). In chimpanzees, in contrast, males are the philopatric sex and share stronger social relationships than female chimpanzees. Aged males also have more mutual partners they spend time with compared with younger males who have more one-sided relationships 
(Rosati et al., 2020). These differences in life-history between males and females suggest that both sexes may experience substantial differences in sociality in old age.

To fill this gap in knowledge, we used a social network approach and focused on four social network metrics, namely degree, strength, eigenvector centrality, and clustering coefficient in an affiliative social network. The degree represents the number of connections (edges) an individual (node) has to other individuals, in this study, the number of social partners. The strength of sociality is described by the frequency of interactions exchanged between two individuals (Lehmann \& Ross, 2011; Newman, 2003). Considering indirect relationships, the eigenvector centrality measures how well-connected an individual's partners are. High eigenvector centrality values indicate that the subject has many partners who themselves are connected to many partners. The clustering coefficient describes subgrouping structures resulting from connectedness of an individual's partners. A high clustering coefficient reveals highly inter-connected partners, i.e. all partners of an individual are also connected to each other (Brent, 2015; Newman, 2003; Sueur et al., 2011).

For females, in accordance with previous findings, we expected a decrease in social activity with age. This should be reflected in fewer partners and less time spent in affiliative interactions (lower degree, lower strength). With regard to the indirect connections, we expected that older females would exhibit lower values in eigenvector centrality and clustering coefficient compared to younger females.

For males we considered two possibilities. If males become more selective in their social partners with age, potentially due to the unpredictability and potentially stressful social encounters, we expected to find a similar trajectory as in females. This would be reflected in lower degree and strength values and occupying more peripheral positions regarding the indirect metrics. Yet, previous studies showed that older Barbary macaque males may maintain a high-ranking position when they invest in their social relationships (Henkel et al., 2010; Ostner \& Schülke, 2014; Rathke et al., 2017). Older males may therefore invest more in affiliative interactions with potential male coalition partners, but also with females to increase mating opportunities (Bissonnette et al., 2011). In this case, we would expect greater variation in male social activity with age, with some males continuing to hold central positions, and others being more reclusive.

We complemented the social network analysis by investigating the gregariousness of the subjects (number of individuals in $2 \mathrm{~m}$ proximity) as well as their social interest. To assess the latter, we recorded how frequently subjects would utter vocalizations in response to ongoing social interactions in the environment ('commenting behaviour', Brumm, Kipper, Riechelmann, \& Todt, 2005). We analysed the commenting behaviour in both aggressive 
and affiliative events. A previous study on females of the same population had not reported changes in commenting behaviour with age. We therefore expected no such changes for females (Almeling et al., 2016, 2017), but potentially greater variation for males. Additionally, we investigated if age impacts physical activity in terms of energy demanding behaviours such as running, climbing, or jumping. In line with the idea that age-related physiological decline appears to affect both sexes equally (Hamada \& Yamamoto, 2010), we expected to find similar results for females and males.

\section{Methods}

Subjects and study site

We conducted behavioural observations during two consecutive field seasons from April to June and September to November in 2017 and 2018 at "La Forêt des Singes" in Rocamadour, France (for the history of the population and more detailed information de Turckheim \& Merz, 1984). The population consisted of three social groups and consisted of 170 individuals in 2017 and 180 individuals in 2018. The monkeys are provisioned with cereal, fruits, and vegetables several times during the day. Natural food sources like leaves, grains, roots, and insects are eaten by the monkeys as well. Water is provided ad libitum. Tourists can observe and feed the monkeys from designated routes. The monkeys are wellhabituated to behavioural observations. All individuals are identifiable by their inner-leg tattoo and by distinctive physical characteristics such as scars or facial pigmentation. The population is age-heterogeneous, with some monkeys reaching up to 30 years. We categorized individuals as 'old' when they were 20 years or older, following previous studies on macaques (Berghänel et al., 2010; Corr, 2003; Paul et al., 1993).

We collected data in two groups: 'Petit Bassin (PB)' (2017) and 'Grand Bassin (GB)' (2018), consisting of 50 females and 34 males in total. We collected all affiliative behaviour, including grooming, contact sit, hugging, and sex-specific affiliative behaviours like 'triadic interactions' (Taub, 1980) in males and 'anti-parallel' greeting in females, a behaviour where females stand next to each other, grab or hug each other and teeth chatter at each other's hind-quarters. In total, we collected 2180 hours (25.95 \pm 1.5 hours/individual) of focal observations using a 30 min continuous data sampling protocol (Altmann, 1974; Martin \& Bateson, 1986). Data collection took place 5 to 6 days a week, from 9 am to $8 \mathrm{pm}$. Focal observations were balanced across daytime and observer. We collected data using handheld computers (Samsung Galaxy Note 2), equipped with Pendragon Forms (Pendragon Software Cooperation, Libertyville, IL, USA). Aggressive interactions were collected during continuous focal observations and ad libitum sampling to establish the 
dominance hierarchy. To calculate the dominance hierarchy, we used all dyadic and decided interactions, i.e., clear submission and no counter-aggression. We calculated the dominance rank based on the normalized David's score, using the package EloRating in $\mathrm{R}$ (Neumann \& Kulik, 2014).

\section{Data analysis}

For the social network analysis, we used a weighted matrix including all affiliative behaviours. Network visualisations were generated using the Fruchterman Reingold layout (Fruchterman \& Reingold, 1991). To calculate the degree, strength, eigenvector centrality and clustering coefficient, we used the R package igraph 1.2.4.1 (Csárdi \& Nepusz, 2006). For both degree and strength, the direction of an interaction can be described. In this study, we noted how many partners engaged in affiliative interactions with an individual (indegree) and how many partners an individual affiliated with (outdegree). The same applies to the frequency of received (instrength) or given (outstrength) affiliative interactions. For proximity, we used the mean number of partners (number of individuals divided by number of focal observations) that were in a $2 \mathrm{~m}$ radius (which does not include individuals that are closer than 1 meter and interacting with the focal individual). For energy-intensive activities, we added up frequencies of climbing, running, jumping, and 'tree shaking'. All occurrences of 'commenting behaviour' were used for the analysis of social interest. We compiled different data sets for each social network measure as well as the classical behavioural measurements (proximity, activity, commenting) and added information about sex, age, and dominance rank of each individual.

\section{Statistical analysis}

Statistical analyses were carried out using R 3.4.3 (R Core Team, 2019). To analyse the impact of age and sex on degree, strength, proximity, activity, and commenting, we fitted Generalized Linear Models (GLM) with negative binomial error distribution. For eigenvector centrality and clustering coefficient, we ran Linear Models (LM). Age, sex, and rank were included as fixed effects. We included interactions with rank to control for possible effects with age and sex, as rank is known to decrease with age, and males often hold higher positions than females (Bissonnette, Lange, \& Van Schaik, 2009). If the interactions were not found to have a statistically significant effect $(P<0.05)$, we excluded them and continued the analysis with the main effects. For both GLMs and LMs, we used the package Ime4 (Bates, Mächler, Bolker, \& Walker, 2015). The analysis of degree revealed that a quadratic relationship produced a much better fit than the linear relationship. Prior to fitting the models, we z-transformed age and rank to achieve more interpretable estimates 
(Schielzeth, 2010). To rule out collinearity, we determined the Variance Inflation Factors (VIF), using the package car and the function vif (Fox \& Weisberg, 2011). Stability was determined in terms of the model estimates using the function dfbeta. In the GLMs, we included the dyadic focal observation hours (log-transformed) as an offset term to control for observation effort (McCullagh \& Nelder, 1989). Similarly, in the linear models we included dyadic focal observation hours as weights term. With regard to the model assumptions, we checked the linear models for normal distribution and homogenous residuals by visually inspecting a qq-plot and a scatter plot of the residuals plotted against the fitted values (Zuur, leno, \& Elphick, 2010). We checked the GLMs for overdispersion. We conducted full-null model comparison for each model, to investigate whether the full model was significantly better at explaining the observed variation compared to the null model (lacking age and sex) (Dobson, 2002). P-values were obtained from the likelihood ratio test performed with drop1 function (Barr, Levy, Scheepers, \& Tily, 2013).

\section{Results}

\section{Social network metrics}

Both age and sex influenced an individual's position in the group. Figure 1 depicts social networks based on the instrength (Figure 1a) and outstrength (Figure 1b) of study group PB. The interaction pattern illustrates that the highest frequencies of interactions occurred between young females (white circles, figure 1).

(a)

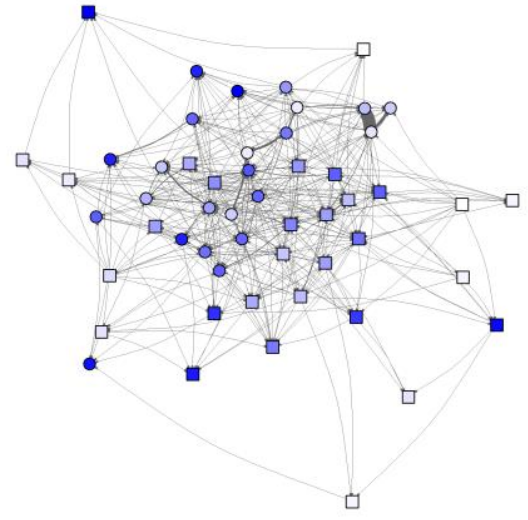

(b)

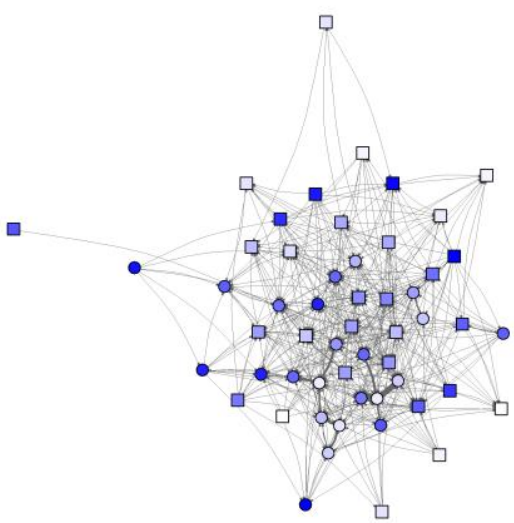

Figure 1. Social network based affiliative interactions (a: instrength, b: outstrength). Nodes represent individuals with circles showing females and squares showing males. Individuals under the age of 2 are excluded here owing to better visualisation. In figure 1 a) we removed one individual that did not interact with any other individual. The colour of the nodes indicates an individual's age (colour intensity increases with age). Lines between nodes depict an affiliative interaction between them, and the thickness of the line demonstrates the frequency of interactions.

The number of partners that initiated affiliation with a given subject decreased with subject age after a peak at the age of 15 years (indegree, GLM: $N=84, z=-3.37, P<0.001$, figure 2a). Instrength, the weighted measurement of indegree, was also lower for older monkeys (GLM: $N=84, z=-6.79, P<0.001$, figure $2 b$ ). In other words, older monkeys were 
less frequently the target of affiliative interactions. Younger monkeys ( $\leq 10$ years) received affiliation from on average 21 individuals ( $\varnothing 132$ interactions), whereas older monkeys ( $\geq$ 25 years) had on average 13 partners and only a third of affiliative interactions (38) compared to younger monkeys. They were also less active in initiating such affiliative interactions themselves: Both outdegree and outstrength were lower in older compared to younger monkeys (GLM: N=84, $z=-2.40, P=0.02$, figure $3 a$ ). For instance, older monkeys ( $\geq 25$ years) affiliated with 13 partners and were actively involved in 30 affiliative interactions on average, whereas younger monkeys ( $\leq 10$ years) had 21 partners and affiliated more than four times as much as older monkeys ( $\varnothing 133$ interactions). Further, the frequency of affiliative interactions given (outstrength) decreased with age (GLM: N=84, $z=-8.35$, $\mathrm{P}<0.001$, figure $3 \mathrm{~b}$ ). With regard to the indirect measurements, eigenvector centrality values were lower for older monkeys (GLM: 84, $t=-4.74, P<0.001$, figure $4 a$ ), indicating that older individuals had fewer well-connected partners. A six-year-old female had the highest eigenvector values (1) and 41 affiliation partners (indegree+outdegree) that themselves had many partners. In contrast to that, one of the oldest females (28 years) had one of the lowest values (0.0009) and only 12 partners that were similarly poorly connected to others. The clustering coefficient, in contrast, was not affected by age (GLM: $N=84, t=0.80, P=0.43$, figure $4 \mathrm{~b}$ ). The values varied from 0.33 to 0.76 . The highest value of 1 would indicate that all partners of an individual would be also interconnected with each other. For more details see Supplementary Material of Chapter 2, tables 1-6.

We found that indegree followed a similar trajectory in males and females. Generally, males were less frequently approached by other individuals compared to females. The predicted value for indegree was on average 4.18, meaning that males had around 4 partners less than females. Older individuals of both sexes experienced fewer approaches by conspecifics than younger individuals ( $G L M: N=84, z=-2.64, P=0.01$, figure $2 a$ ). The number of affiliations received (instrength) was higher for females than for males (GLM: $\mathrm{N}=84, \mathrm{z}=-5.28, \mathrm{P}<0.001$, figure $2 \mathrm{~b}$ ). The predicted value of receiving affiliation was on average 53.7 interactions lower in males compared with females. Males and females did not differ in the number of partners they affiliated with (outdegree) (GLM: $N=84, z=-0.24$, $P=0.81$ ). The number of affiliations (outstrength) given was lower for males than for females (GLM: $N=84, Z=-6.40, P<0.001$, figure $3 b$ ), i.e. the predicted values for males were on average 54.41 interactions lower compared with females. Males had lower eigenvector centrality values than females (GLM: $N=84, t=-3.66, P<0.001$, figure $4 a$ ). Sex did not influence the clustering coefficient ( $G L M: N=84, t=-0.04, P=0.97$ ). For more details see Supplementary Material of Chapter 2, tables 1-6. 
(a)

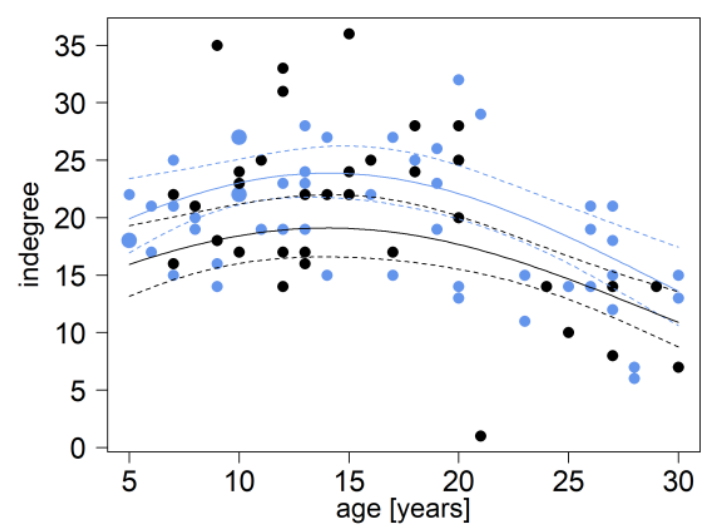

(b)

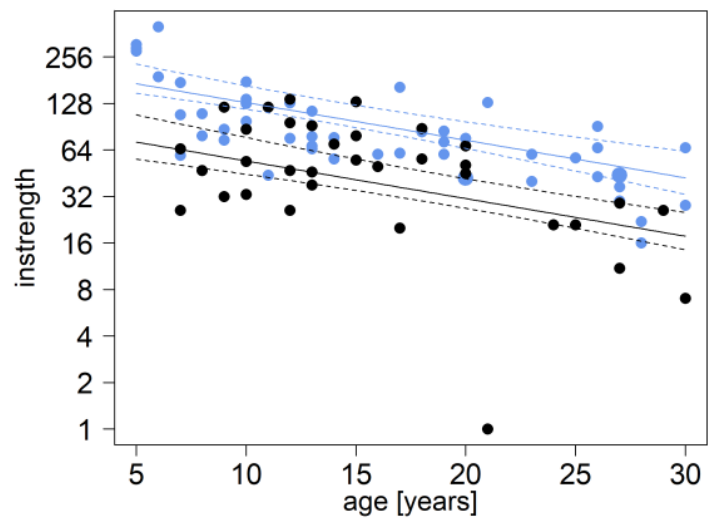

Figure 2. Number of partners and frequency of affiliation received in relation to age. (a) number of partners an individual received affiliation from (indegree). (b) frequency of interactions received from another individual in relation to age (instrength). The instrength is shown on a log-scale, due to four monkey's large number of interactions. Solid lines in both plots depict the fitted model (corrected for observation hours), and dotted lines show the $95 \%$ confidence intervals. Females are depicted in blue, males in black. The volume of the points corresponds to the number of individuals with the respective age.

(a)

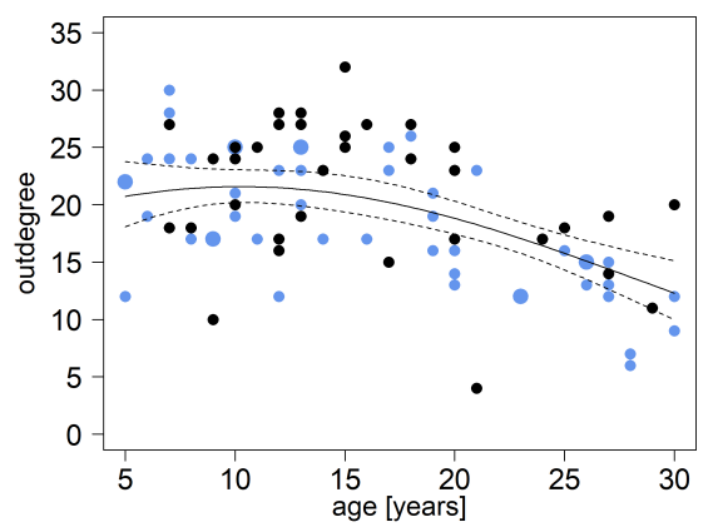

(b)

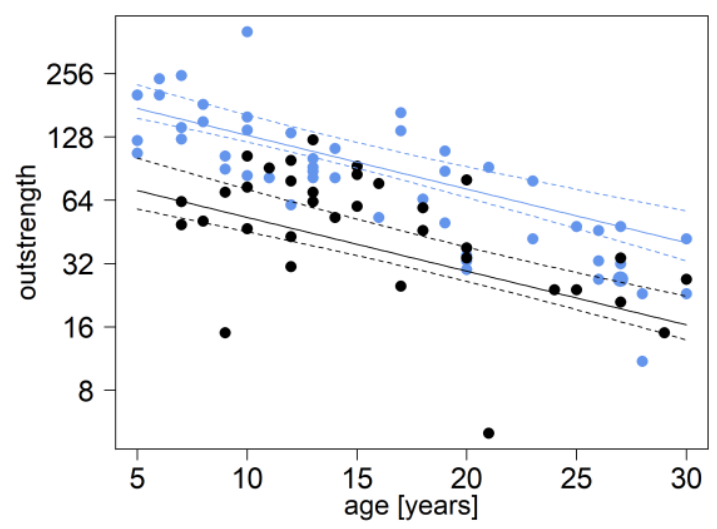

Figure 3. Affiliation given in terms of number of partners and frequency of affiliation in relation to age. (a) depicts the number of partners an individual actively affiliated with (outdegree). (b) depicts the frequency of interactions an individual gave in relation to age (outstrength). Females are depicted in blue, males in black. The outstrength is shown on a log-scale, due to one monkey's large number of interactions. Solid lines in both plots depict the fitted model (corrected for observation hours), and dotted lines show the $95 \%$ confidence intervals. The volume of the points corresponds to the number of individuals with the respective age. 
(a)

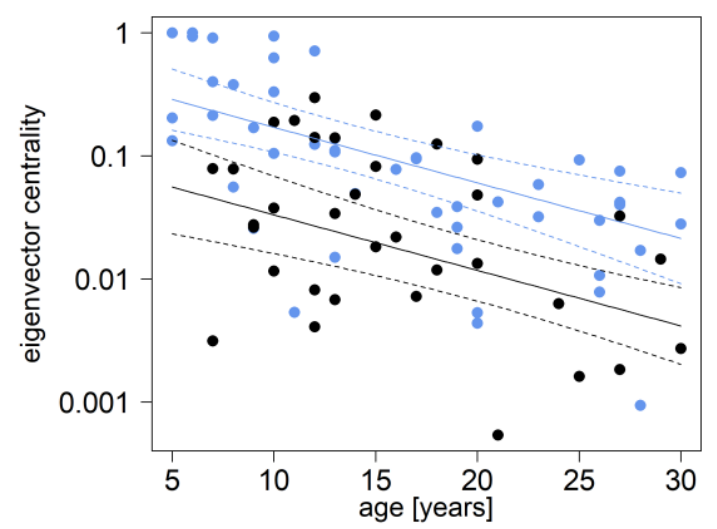

(b)

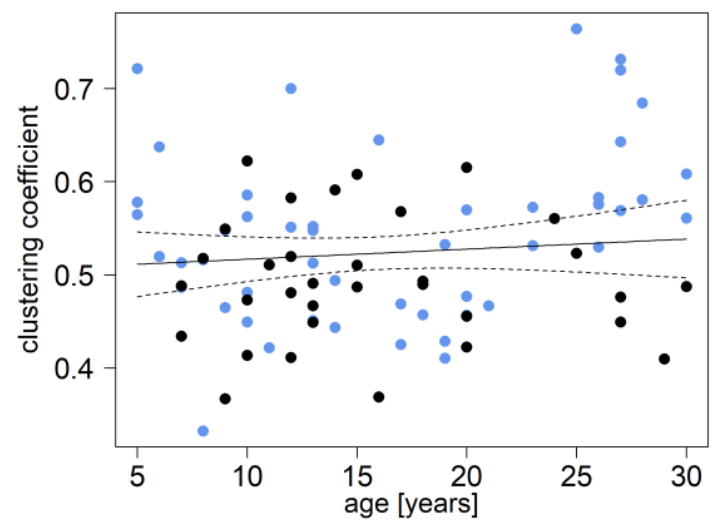

Figure 4. Two indirect social network metrics with regard to age. (a) eigenvector centrality (logscaled) in relation to age. Females are depicted in blue, males in black. (b) clustering coefficient in relation to age. Solid lines depict the fitted model (corrected for observation hours), and dotted lines show the $95 \%$ confidence intervals.

Activity and social integration

With increasing age, individuals had fewer individuals in close proximity (GLM: $N=84$, $\mathrm{Z}=-3.96, \mathrm{P}<0.001$, figure $5 \mathrm{a}$ ). To illustrate these results, individuals at the age of 10 years had on average 0.58 partners, i.e. 30 individuals in their close proximity during on average 53 observations. Aged individuals (27 years old) had on average 0.22 individuals in proximity (11 individuals/53 observations). Sex did not influence number of individuals in proximity (GLM: $N=84, z=1.08, P=0.27$ ). Older monkeys were less active regarding energy demanding behaviours like running, jumping, or climbing (GLM: $N=84, z=-10.03, P<0.001$, figure $5 b$ ). Again, males and females did not differ in their activity patterns (GLM: $N=84$, $\mathrm{Z}=1.75, \mathrm{P}=0.09$ ). Age did not influence commenting behaviour ( $\mathrm{GLM}: \mathrm{N}=84, \mathrm{z}=-0.96$, $P=0.32$, figure $5 c$ ). Overall, males commented less than females (GLM: $N=84, z=-3.91$, $\mathrm{P}<0.001)$. For more details, see Supplementary Material of Chapter 2, tables 7-9. 
(a)

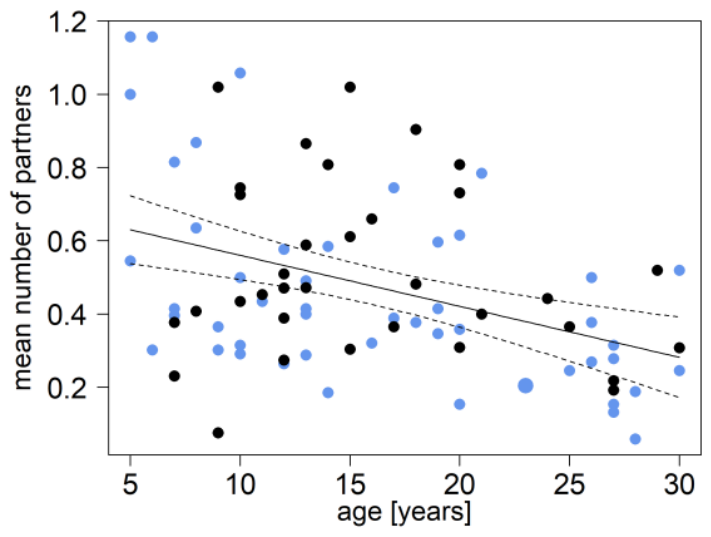

(c)

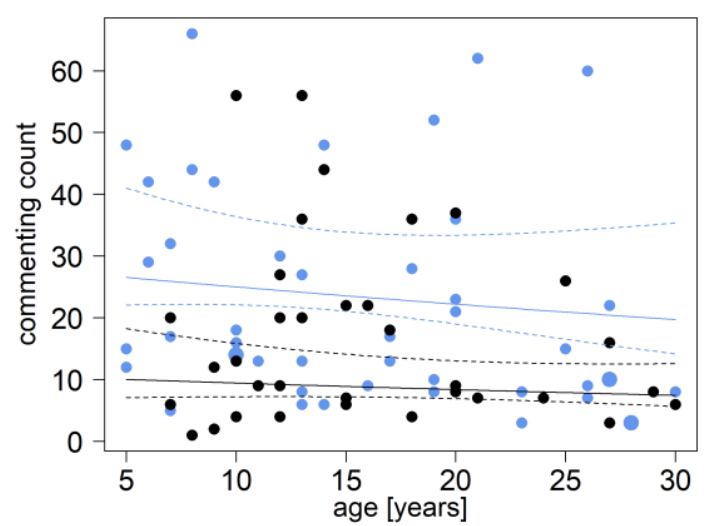

(b)

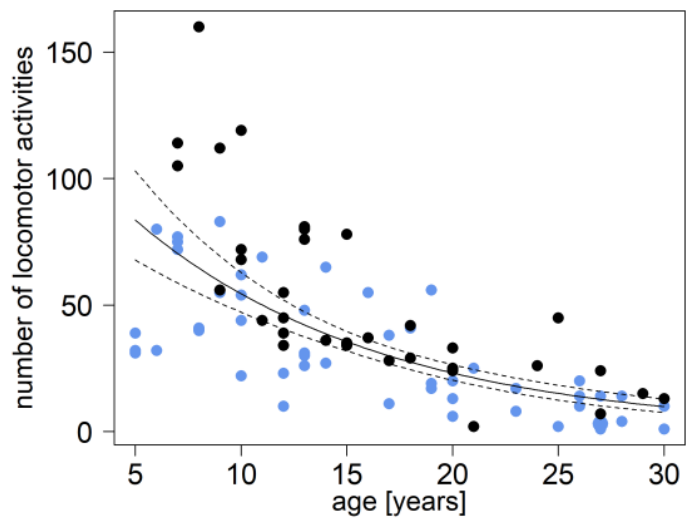

Figure 5. Activity patterns and social interest in relation to age. (a) mean number of partners in proximity (number of partners divided by number of focal observations) in relation to age. (b) frequency of energy demanding behaviours with age. (c) frequency of commenting behaviour with age. The volume of the points in all plots correspond to the number of individuals with the respective age. The solid line depicts the fitted model (corrected for observation hours), and the dashed lines represent the $95 \%$ confidence intervals.

\section{Discussion}

Males experienced a similar age-related social decline than females: they approached fewer partners for affiliation (outdegree) and initiated fewer affiliative interactions (outstrength). After a peak around the age of 15 years, the number of social partners that initiated affiliation with the subject (indegree) decreased and the amount of affiliation that an individual received (instrength) also declined with age. While males showed similar agerelated variation in terms of their sociality as females, they were on average less sociable. Note however that a small number of young adult males had a high number of social partners, but they did not necessarily spend more time socializing. This could be related to female preference for younger males. A previous study indicated that female Barbary macaques initiated consortship more often with younger compared with older males (Bissonnette et al., 2011). Animals of both sexes were also spatially more reclusive when they were older. Yet, social interest remained high regardless of age. In summary, the 
pattern we observed for males does not differ substantially from that we had previously reported (Almeling et al. 2016) and here replicated for females.

These findings refute our initial working hypothesis that some males at least continue to be important "players" in the social network. Previous studies in this population reported that males differ in their infant carrying activities which impacts their position in the social network, i.e. higher number of male social partners (Henkel et al., 2010). Older Barbary macaque males in another population change their competitive strategy from solitary aggression to coalitionary activity with other aged males (Rathke et al., 2017). Further, males invest in social relationships as they are more likely to partner up with a male they prior affiliated with (Berghänel et al., 2011). These findings indicate that there may be variation in male sociality with regard to the composition of the group. Future studies are needed to investigate whether aged males focus their social activity more on partners they support, or those by whom they are supported by.

Another study in the same population corroborated our findings that males are less active in the affiliative network than females. Yet, males in that study did not experience a similar decline in social activity with age as females did (Sosa, 2016). The affiliative network in Sosa (2016) was based on grooming interactions, which are rare between males (Paul, Kuester, \& Arnemann, 1996). Potentially, including other affiliative behaviours in our study design like contact sitting or specific behaviours like triadic interactions, a behaviour common among male Barbary macaques (Henkel et al., 2010; Paul et al., 1996), would have added more details on changes in social behavior with age in both sexes. In contrast to a previous study on the same population (Almeling et al., 2016) females in our study experienced a slight decline in partners affiliating with them, which had not been observed before. In the previous study, for female Barbary macaques older than 25 years of age, the number of partners that approached them for affiliation dropped (Almeling et al., 2016).

Only few studies had investigated sex differences in social aging. In grey mouse lemurs (Microcebus murinus), older individuals from both sexes engaged less in affiliative interactions compared to younger individuals (Picq, 1992). In tufted capuchins (Sapajus $s p$.), affiliation decreased for females but not for males. Yet, male affiliation was generally low and thus the result may reflect a floor effect (Schino \& Pinzaglia, 2018). In rhesus macaques (Macaca mulatta), older males received more affiliative behaviour than younger males and had more individuals in proximity (Corr, 2003), a finding opposite from our results. A closer inspection of the results, however, showed that the majority of social partners were juveniles. Shifting towards interactions with infants might be a strategy to avoid costly interactions with adult individuals that could end in a physical confrontation. Thus, the decline of affiliative interactions in our study and the different composition of social 
partners in rhesus macaques may be the result of different strategies to reduce stressful social interactions. Overall, it emphasizes that more comparable data is needed on male social aging in different nonhuman primate species.

We expected that when males are able to build a supportive network, they maintain central positions throughout adulthood and thereby show a different social aging pattern than females. Yet, males had lower eigenvector centrality values than females. For both sexes the eigenvector centrality value decreased with age. This finding indicates that older monkeys in this study appeared to play a less central role in the network and males are less central than females irrespective of age. Other studies investigating eigenvector centrality with regard to age did not find this effect in rhesus macaques (Liao, Sosa, Wu, \& Zhang, 2017). Yet, the study was based on age classes (juveniles, sub-adults, adults) instead of individual ages and therefore could not evaluate a potential age effect within the adult class. We found that younger females exhibited the highest eigenvector centrality values, which indicates having many partners that are well-connected themselves. The matrilineal social structure in many primate societies is likely linked to those higher eigenvector centrality values in females compared to males. In vervet monkeys (Chlorocebus pygerythrus), females had higher eigenvector centrality values than males (Blaszczyk, 2018). In female baboons, a higher eigenvector centrality was linked to higher infant survival potentially owing to maintaining a central position in the group and by this reducing risk of predation (Cheney, Silk, \& Seyfarth, 2016). Contrary to our predictions, the clustering coefficient was not affected by age nor sex. Apparently, older Barbary macaques did not cluster or affiliate in sub-groups more than younger conspecifics. Another study on Barbary macaques reported the same (Sosa, 2016). This does not generally contradict our finding that age is associated with a smaller social network but rather suggests that the affiliative network is cohesive across ages, with younger individuals exhibiting more central positions.

The decrease in energy demanding activities mirrors findings on the decline of physiological function in primates (Roth et al., 2004). Our results are further in line with numerous studies that reported a decrease in activity (less running and climbing) in females (Almeling et al., 2017) and increase in resting behaviour in both sexes (Baker, 2000; Corr, 2003). Commenting behaviour, the uttering of vocalisations towards conspecifics' interactions was not affected by age and remained high throughout adulthood. This is in accordance with previous studies on female Barbary macaques (Almeling et al., 2017). While commenting does not include energy demanding actions, it supports the assumption that older monkey's withdrawal rather concerns active participation but not a general decrease in social interest. 
Our findings corroborate the idea that an awareness of one's own limited future time perspective is not the only factor driving changes in social behaviour (Almeling et al., 2016; Schino \& Pinzaglia, 2018). This study adds to the existing literature by investigating physiological and social age-related changes in both sexes across adulthood. In old age, both male and female Barbary macaques were less sociable. Partly, this low social activity may be attributed to the waning of energy, as reflected in the lower amount of energy demanding activities. Yet, when old females engaged in grooming interactions, these were longer than those of young females (Almeling et al. 2016), suggesting that the overall decrease of affiliative interaction is not just a result of physical weakness, but also a change in motivation. Finally, this study underscores the importance of including a large number of individuals from different ages and both sexes to fully understand social aging patterns.

\section{Acknowledgements}

We would like to thank Ellen Merz, Gilbert de Turckheim and Guillaume de Turckheim for the permission to conduct this study at La Forêt des Singes in Rocamadour. We further thank the staff at the park for support. We are particularly grateful to Magdalena Wimmer, Luisa Beckmann, Lateefah Roth and Marie-Laure Poiret for their help in collecting the data. We thank Roger Mundry and Christoph Neumann for valuable statistical support. The study was funded by the Deutsche Forschungsgemeinschaft [DFG, German Research Foundation, project number 360742713 (Fi707/22-1) and 254142454/GRK 2070]. We further acknowledge support through a Seed fund by the Leibniz ScienceCampus Primate Cognition, funded by the Leibniz Association. 


\title{
Chapter 3
}

\section{Do older Barbary macaques avoid negative social information? Application of the Strength and Vulnerability Integration model}

\author{
Eva-Maria Rathke $e^{1,2,3}$ \& Julia Fischer ${ }^{1,2,3}$ \\ ${ }^{1}$ Cognitive Ethology Laboratory, German Primate Center, Leibniz Institute for \\ Primate Research, Kellnerweg 4, 37077 Göttingen, Germany \\ ${ }^{2}$ Department for Primate Cognition, Georg-August-University Göttingen \\ ${ }^{3}$ Leibniz ScienceCampus Primate Cognition, Göttingen
}

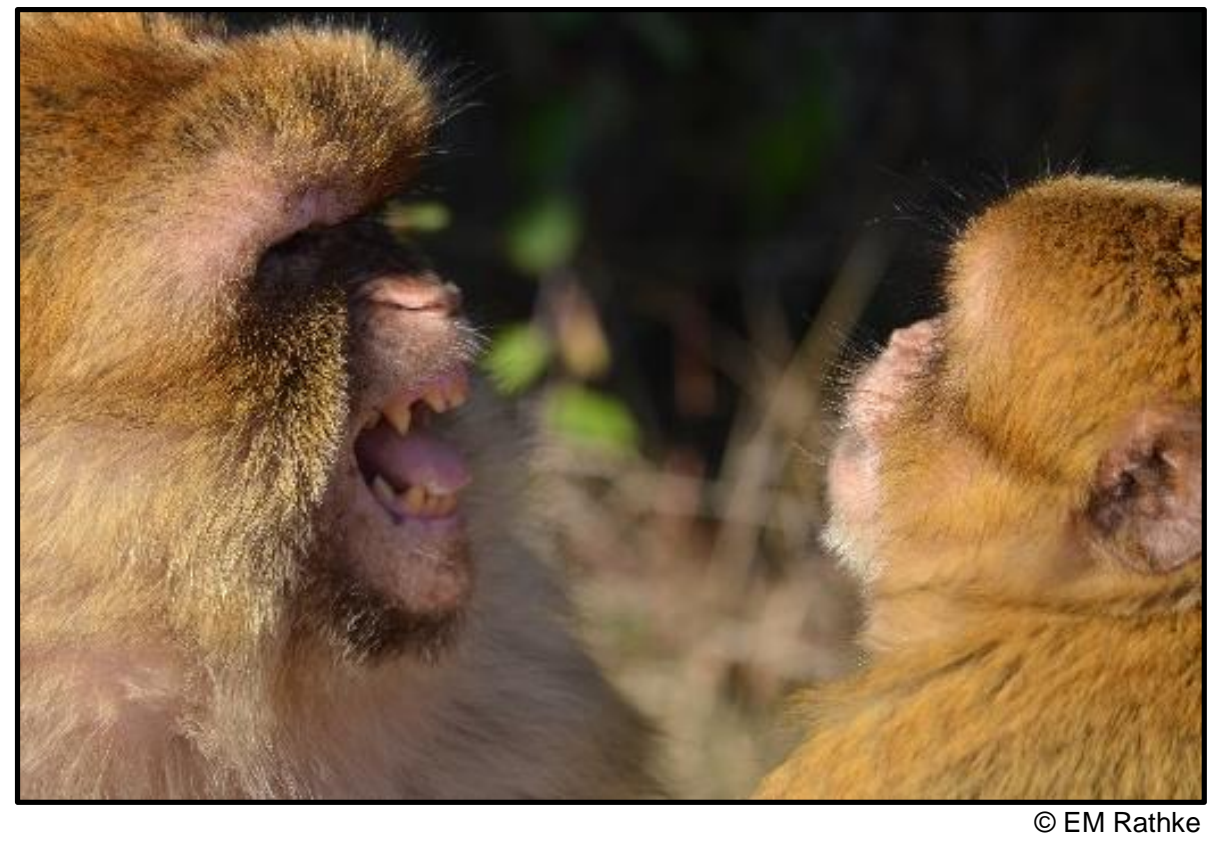

Manuscript in preparation 


\section{Abstract}

Humans report a higher life-satisfaction with increasing age. This "paradox of wellbeing" has been attributed to the human ability to regulate the exposure to negative experiences. The Strength and Vulnerability Integration (SAVI) model predicts that older adults develop strategies to mitigate exposure to negative situations. We tested assumptions from the SAVI model in Barbary macaques (Macaca sylvanus) and combined analyses of the use of and responses to natural communicative signals ( $\mathrm{N}=111$ subjects) with an experimental test. We presented monkeys $(\mathrm{N}=47)$ with pictures of aggressive and neutral facial expressions of unknown conspecifics. The study took place in a large ageheterogeneous population (age range 1 to 30 years) at 'La Forêt des Singes' in Rocamadour, France. We found that older Barbary macaques used less aggressive and affiliative signals than younger conspecifics. The monkey's response pattern did not conform to the predictions of the SAVI model. In fact, not the recipient's age but instead the signaller's age played a decisive role in response behaviour. Barbary macaques reacted less towards older conspecific's signals. Further, older subjects were not looking less to aggressive facial expressions compared to neutral ones in the field experiment. There was also no overall effect of age on looking time. Our results suggest that the SAVI model is either less applicable to nonhuman primates or functions on a different social level. Potentially, older individuals become more adept at pursuing other, more indirect strategies to mitigate negative experience such as reducing the number of interaction partners or spending more time alone.

Keywords: aging, motivation, positivity effect, SAVI model, Barbary macaques

\section{Introduction}

Initially, lifespan developmental theories posited that human life satisfaction would peak in the early 20s and slowly decline thereafter (Charles, 2010; Charles \& Carstensen, 2004). Contrary to these early assumptions, it is now widely accepted that older persons are generally more satisfied with their lives than persons in mid adulthood (e.g. Gana et al. 2013; Carstensen and Löckenhoff 2003), despite decreased social activity and increasing number of ailments in older age. This "paradox of well-being" has been attributed to the fact that older adults are better able to regulate their emotions than younger adults (Carstensen \& Löckenhoff, 2003).

The Strength and Vulnerability Integration (SAVI) model is a theoretical framework that describes how older adults regulate their emotions under the assumption that their goal is 
to avoid situations that could potentially lead to negative outcomes (Charles, 2010). Strength refers to better emotion regulation due to life experience and the motivation to invest in activities and behaviours that serve well-being, whereas vulnerability refers to the increasing physical impairment that makes it less possible to defend oneself against stressors such as negative interactions (Charles \& Hong, 2015; Luong et al., 2011). The SAVI model suggests that older people try to avoid interpersonal conflicts and potentially stressful situations (Birditt \& Fingerman, 2005) by engaging in more passive coping strategies such as shifting attention away from the stressor, or waiting if the situation resolves itself (Birditt, 2014; Birditt \& Fingerman, 2005; Blanchard-Fields, 2007).

A related mechanism is to shift attention towards positive, and away from negative information, the so-called positivity effect (Mather \& Carstensen, 2005). Older adults remember positive pictures of facial expressions or situations, better than negative or neutral ones (Carstensen \& DeLiema, 2018; Mather \& Carstensen, 2005). Furthermore, when older adults look at emotional facial expressions (positive or negative) compared to neutral facial expressions, they show selective attention towards positive (happy) faces (Mather \& Carstensen, 2003). These effects correspond to differential brain activation in response to positive vs. negative social information. The Late Positive Potential (LPP) describes neuronal activity after observing an emotional stimulus (Schupp et al., 2000). Older adults showed higher LPP waves while looking at positive pictures compared to younger adults (Rehmert \& Kisley, 2013).

Both the avoidance of negative experience and the positivity effect are considered as results of self-regulation processes, partly affected by the insight into one's limited lifespan (Reed \& Carstensen, 2012). Yet, these effects may also be driven by more basic motivational changes across age that are shared with other species, primarily nonhuman primates (hereafter 'primates').

Primates are increasingly appreciated as a valuable model in aging research, as they undergo similar physiological changes as humans (Roth et al., 2004; Verdier et al., 2015). As in humans, primates can reach advanced age and experience physical deterioration including age-related bone diseases such as osteoporosis and arthritis (Roth et al., 2004; Spear, Moore, Kim, Xue, \& Tumosa, 1994; Torre \& Fowler, 2000). Great apes, for instance, can live into their fifties in captivity (with some exceptions until 70 years), while macaques reach up to 30 years (Corr, 2003; Lacreuse et al., 2018; Zeamer, Decamp, Clark, \& Schneider, 2011). With increasing age, primates have fewer social partners and engage in fewer social interactions (Nakamichi, 1984; Tarou, Bloomsmith, Hoff, Erwin, \& Maple, 2002; Veenema et al., 1997). This provides the opportunity to put some of the assumptions of 
psychological theories developed for humans to a test in organisms whose aging behaviour is not affected by societal norms and age-related prejudices (McDonald Pavelka, 1990).

Recent comparative approaches provided further insights into motivational and social aging in monkeys (Almeling et al., 2016; Fischer, 2017; Rosati et al., 2018; Schino \& Pinzaglia, 2018). In Barbary macaques (Macaca sy/vanus), older females shift their social preferences to fewer partners, while maintaining longer affiliative interactions with them; this finding has been taken as evidence for increased social selectivity with age (Almeling et al. 2016 ; 2017). Although they were as likely to show aggressive behaviours as younger females, they mostly used low-level threat expressions and appeared to avoid potentially costly interactions with other group members (Almeling et al., 2017). Building on these previous findings, we set out to study how the use and the responses to communicative signals varies with age. The exchange of such signals is at the heart of social interactions. Extending previous analyses focusing on females (Almeling et al., 2017), we here considered males and females.

There are two ways in which communicative behaviour may contribute to altered social behaviour: signallers may change the propensity with which they use specific signals, and recipients may change the propensity with which they respond to specific signals. In accordance with the SAVI model, we expected that older Barbary macaques adopt avoidance strategies such as walking away or ignoring other group members' signals. If primates show a positivity effect, as humans do, they should show stronger responses to positive signals than negative ones. To test these predictions, we combined analyses of the natural signalling behaviour with an experimental test of the allocation of social attention in a large age-heterogeneous population of Barbary macaques.

We first analysed changes in usage of aggressive and affiliative signals (Liebal \& Call, 2012; Slocombe, Waller, \& Liebal, 2011), including facial expressions and non-tactile behaviours as a function of age. The development and usage of signals from adolescence to young adulthood has been extensively studied in some primate species (Fröhlich \& Hobaiter, 2018; Hesler \& Fischer, 2007; Liebal et al., 2004; Pika et al., 2003). The signal repertoire increases during the juvenile phase and decreases into adulthood again, based on a shift from play behaviour to more agonistic signals (Hesler \& Fischer, 2007; Pika et al., 2003). Studies on communicative signals in advanced age, however, are rare. Secondly, and more important for testing the predictions from the SAVI model, we analysed the responses to both aggressive and affiliative signals. We predicted that older recipients were more likely to react to affiliative signals while they would be more likely to avoid or ignore aggressive signals compared to younger macaques. In addition, we tested whether the signaller's age influenced the recipient's response (ignore or reciprocate/react 
submissively) to an affiliative or aggressive signal, to develop a comprehensive understanding how age affects the monkeys' regulation of interactions.

We conducted a field experiment that focused on the response to pictures of unknown conspecifics displaying different facial expressions to investigate the avoidance of negativity. Looking time tasks are a classical paradigm for assessing cognitive and perceptual abilities in both humans and nonhuman animals. Originally developed to study the cognitive abilities of human infants (Fantz, 1964), this paradigm gained further scientific interest in adult psychology in studies on emotional processing (Fox et al. 2000). From a comparative perspective, it has been shown that humans and primates perceive faces in a similar way, i.e. scan a face holistically (Dahl, Wallraven, Bülthoff, \& Logothetis, 2009) and share similar attention mechanisms (Lacreuse, Schatz, Strazzullo, King, \& Ready, 2013). A variety of primate species can distinguish between pictures of different species (Rakotonirina, Kappeler, \& Fichtel, 2018), known and unknown individuals (Parr, Winslow, Hopkins, \& de Waal, 2000; Schell, Rieck, Schell, Hammerschmidt, \& Fischer, 2011) or different facial expressions (Micheletta, Whitehouse, Parr, \& Waller, 2015; Parr \& Heintz, 2009).

Recently, a looking time task in rhesus macaques (Macaca mulatta) suggested selective attention in older adulthood. Pictures of neutral and aggressive facial expressions were shown to rhesus macaques and looking time was measured. Older rhesus macaques directed their attention towards negative rather than neutral pictures (Rosati et al., 2018). Paralleling that study design, we also used pictures depicting unfamiliar conspecifics displaying aggressive facial expressions ('open mouth threat face') or neutral facial expressions. Following the SAVI model, older monkeys should spend less time looking at images depicting aggressive facial expressions.

\section{Methods}

\section{Subjects}

Data collection was carried out in the enclosure 'La Forêt des Singes' in Rocamadour, France (for history of the population and more detailed information see de Turckheim \& Merz, 1984). In 2017, a total of 170 Barbary macaques lived in the park, split into 3 social groups (in 2018, $\mathrm{N}=180$ ). The monkeys are provisioned with cereal, fruits, and vegetables several times during the day. Naturally occurring food source such as leaves, grains, roots or insects are eaten by the monkeys as well. Water is provided ad libitum. Tourists can observe and feed the monkeys from designated routes and feeding spots. The monkeys 
are habituated to behavioural observations. All monkeys are identifiable by their inner-leg tattoo or by distinctive physical characteristics like scars or facial skin pigmentation. The population is age-heterogeneous, with monkeys up to 30 years. We considered monkeys as being 'old' when they reached 20 years (Berghänel et al., 2010; Corr, 2003; Paul et al., 1993).

\section{Communicative signal analysis}

\section{Data collection}

We collected behavioural data from April to June and from September to November 2017 (group: 'Petit Bassin', N=60), and during the same months in 2018 in a second group ('Grand Bassin', N=51, further details about group composition see Supplementary Material of Chapter 3, table 1). Handheld computers furnished with Pendragon Forms were used to collect behavioural data (Pendragon Software Cooperation, Libertyville, IL, USA). We used a 30 min continuous sampling protocol (Martin \& Bateson, 1986) balanced across the day from 9 am to $8 \mathrm{pm}$. In total, we collected 2180 hours $(25.95 \pm 1.5$ hours/individual of continuous focal observations). We recorded all affiliative, aggressive, submissive, sexual, and solitary behaviours. Aggressive interactions were collected ad libitum to facilitate constructing a dominance hierarchy. We used all dyadic and decided interactions (clear submissive reaction and no counter-aggression) to establish a dominance hierarchy. We calculated the dominance rank based on the normalized David's score, which is part of the EloRating package in R (Neumann \& Kulik, 2014).

\section{Analyses}

To investigate the effect of age on communicative signal usage (number of signals), we extracted all aggressive facial expressions (including 'ground slap' as a non-tactile behaviour) and all affiliative facial expressions. We added information about age, sex and dominance rank. Further, we were particularly interested in whether both the age of the signaller and the recipient determined the response to an aggressive or affiliative signal. We scored whether the recipient responded: "no response" was scored as "ignore", but only when we, to the best of our abilities, assumed that the recipient had seen the signaller's behaviour. If we deemed that the recipient had not been able to see a signal, e.g. when facing in another direction, we excluded the incident from the analysis. 
Statistical analysis was conducted using R 3.4.3 (R Core Team, 2019). We ran Generalized Linear Models (GLM) with negative binomial error distribution to analyse the influence of age on the number of aggressive and affiliative signals. We used a Generalized Linear Mixed Model (GLMM) with binomial error structure and logit link function to investigate the impact of age on the likelihood of a response ( $1=$ response; $0=$ ignore/reject) towards affiliative, and aggressive signals. We fitted the GLM (function $g / m$ ) and GLMM (function glmer) using the R package Ime4 (Bates et al., 2015). Age and rank were ztransformed for better interpretation of the estimates and the intercept and for better chance of model convergence. Rank was only included in the analysis of affiliative signals and not in the analysis of the aggressive signals due to the circularity of using aggressive signals to calculate the dominance rank. We included age as an interaction with sex due to a potential relationship. We removed interactions from the models when they were not significant, in order to interpret the main effects. The analysis of the aggressive signals revealed that the number of signals in relation to age was better predicted by a quadratic relationship. In the GLM, we included the dyadic focal hour (log transformed) as an offset. We checked model stability using the function dfbeta and potential collinearity by determining the Variance Inflation factors (Fox \& Weisberg, 2011). In the GLMM, we included age, sex for the signaller and age for recipient as fixed effects. We did not use recipient sex because males were less often targets of aggression and less often recipients of affiliation than females were. The signal category (affiliative/aggressive) was included as a fixed effect. Signaller identity, recipient identity and dyad were included as random intercepts. We included dyad as a random intercept due to the possibility that some dyads interacted more with each other than others. Receiver age, signaller age, signaller sex and signal category were included as a random slope. We manually dummy coded and centred sex and signal category before including it in the random slope. In some models we excluded parts of the random slopes again due to being unidentifiable (Matuschek, Kliegl, Vasishth, Baayen, \& Bates, 2017). We checked model stability by comparing the estimates obtained from the model which was based on the data with estimates from models with the levels of the random effects excluded one at a time. The function we used to assess stability was provided by Roger Mundry (University of Vienna). To rule out collinearity, we determined Variance Inflation Factors (Fox \& Weisberg, 2011).

For both GLM and GLMM, we used a likelihood ratio test and compared the full model with the null model lacking the predictor of interest 'age' but comprising the same random effects structure as the full model (Forstmeier \& Schielzeth, 2011). The p-values for each model were obtained by using the function drop 1 (Barr et al., 2013). 


\section{Results}

\section{Signal usage}

In total, monkeys used $2.56 \pm 1.58$ aggressive signals/hour. The frequency of aggressive signals per hour was $2.95 \pm 1.30$ for monkeys younger than 15 years, dropped to $2.85 \pm 1.79$ for 15 to 25-year-olds and was lowest for monkeys older than 25 years $(0.97 \pm 0.88)$. Regarding affiliation, monkeys used 1.24 \pm 1.01 signals/hour. The fewest affiliative signals were used by a 19-year-old female ( 0.11 signals/hour), and the highest by a 10-year-old female (3.91 signals/hour). These findings mirror the statistical result. Usage of aggressive signals decreased after a peak in mid adulthood (GLM: $N=84, \mathrm{Z}=-4.38, \mathrm{P}<0.001$, figure 1a). Likewise, the number of affiliative signals decreased with increasing age (GLM: $N=83, \mathrm{z}=-$ $4.19, \mathrm{P}<0.001$, figure $1 \mathrm{~b})$. For more details see Supplementary Material of Chapter 3 , tables 2 and 3.

(a)

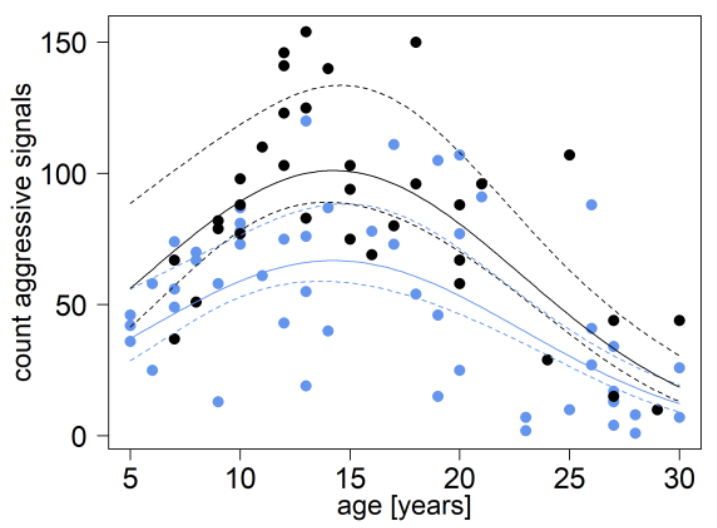

(b)

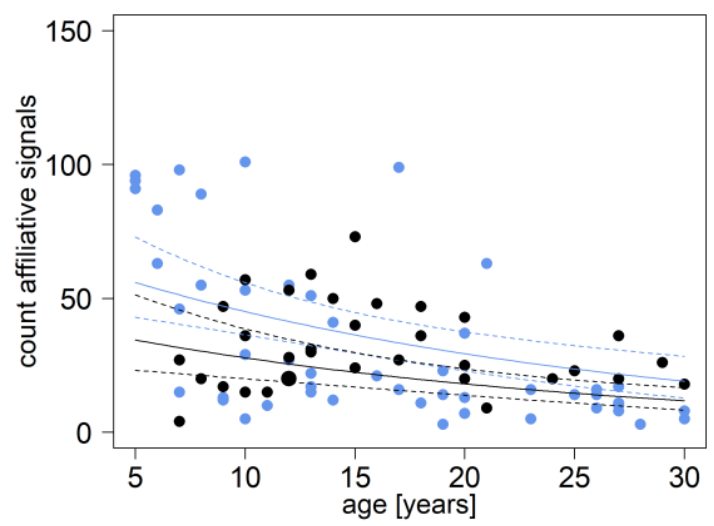

Figure 1. Total number of aggressive (a) and affiliative (b) signals with regard to age. The area of the points depicts the frequency of a signal at a given age (in years). The solid line depicts the fitted model and the dashed lines indicate the lower (2.5\%) and higher (97.5\%) confidence intervals.

\section{Signal and response behaviour}

The response towards affiliative or aggressive signals differed in relation to both signaller and recipient age and sex. We found a lower likelihood of responding to older signallers regarding aggressive and affiliative signals (GLMM: $N=3126, z=-3.85, P<0.01$, figure 2). There was no difference in reacting towards aggressive or affiliative signals (GLMM: $N=3126, z=0.24, P=0.82$ ). Considering signalers under the age of 15 years, $77.07 \%$ of the subjects provoked a response after an aggressive signal. For monkeys between 15 and 25 years the likelihood of a response (submission) dropped to $68.35 \%$ and decreased to $56.67 \%$ in monkeys older than 25 years. A similar decline has been observed 
with regard to the response to affiliative signals. For more details see Supplementary Material of Chapter 3, table 4.

(a)

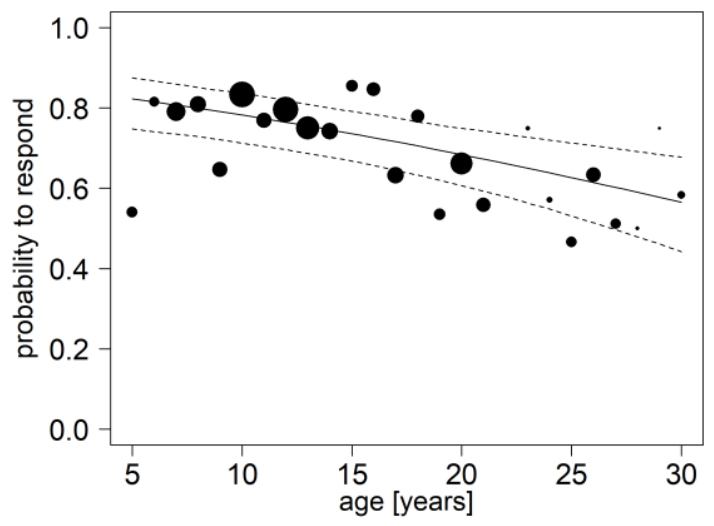

(b)

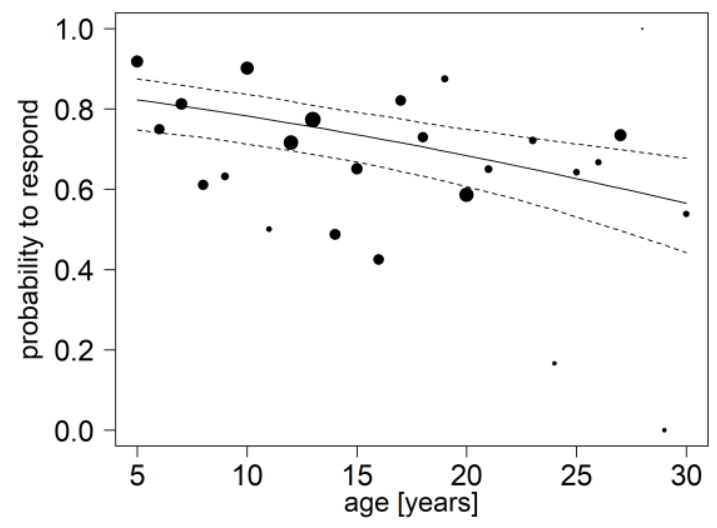

Figure 2. Probability to respond to either an aggressive signal (a) or an affiliative signal (b) in relation to the signaller's age. Values closer to 1 indicate higher probability of a response: either submission, counter-aggression for aggressive signals or reciprocation, staying for affiliative behaviour. The area of the points indicates number of signals per age (in years). The dashed lines indicate the lower $(2.5 \%)$ and higher $(97.5 \%)$ confidence intervals.

\section{Looking time task}

\section{Data collection}

We conducted a looking time task in the 'Grand Bassin' group from April to June 2018. We tested 47 monkeys: 25 adult females ( 5 to 30 years old), and 13 adult males (7-27 years old), 6 sub-adult males (3-6 years old) and 3 juvenile males.

\section{Picture stimuli}

We used a similar approach following Schell and colleagues (2011). We took 26 pairs of pictures (11 females, 15 males) of a neutral and a mildly aggressive facial expression ('open mouth threat face') of females and males with a Nikon E-300. We took pictures of individuals from a neighbouring group ('Petit Bassin') the subjects rarely interact with, to reduce biased response due to a potential relationship. Pictures were printed on matte DINA4 paper in $17 \mathrm{~cm}$ diameter. In total, every individual could be presented with four different pictures, a male pair and a female pair (Figure 3). Individuals are kept constant in a pair. 
(a)

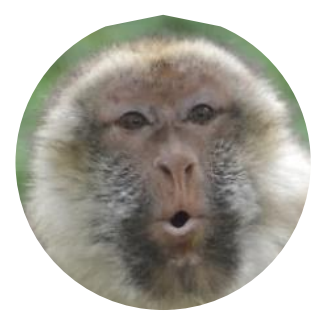

Female aggressive

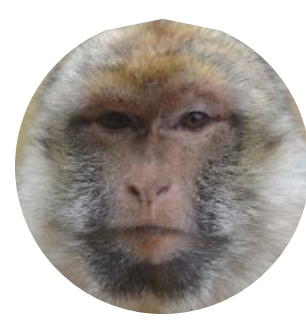

Female neutral

(b)

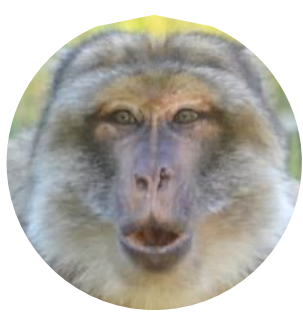

Male aggressive

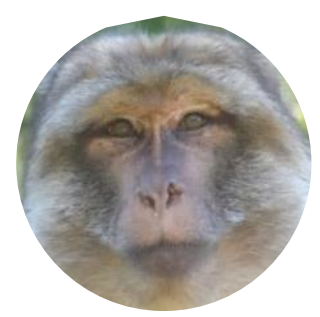

Male neutral

Figure 3. Picture stimuli. Female aggressive and neutral facial expression (a). Male aggressive and neutral facial expression (b).

\section{Setup and procedure}

The picture was placed in the wooden frame with two plastic rails to keep it in place. The experiment was run by two experimenters. The first experimenter sat down approximately three meters away from the test subject with the wooden frame and a picture inside. White cardboard covered the picture before the test started. We balanced the order in which the pictures were shown (e.g. first: female aggressive, second: female neutral). The process of assigning a picture pair to a monkey was randomized. The second experimenter handed the picture over to the first experimenter who was blind to the type of picture. During the testing procedure, the first experimenter wore a baseball cap and sunglasses to avoid any visual contact. The first experimenter attracted the subject's attention by tapping against the wooden frame. Once the subject looked up or in the direction of the picture the first experimenter pulled the white board away. The monkey's reaction to the picture was recorded using a Panasonic HC-X929 video camera. The session started once the presenter sat down with the picture. We started recording, then removed the white cardboard. We then filmed for one minute. When the monkey left the test area (one-meter radius around the test setting) during the recording, we terminated the trial. After each trial, there had to be at least a break of four days before testing again to avoid habituation to the testing paradigm. Subjects could complete up to four trials (female aggressive/neutral; male aggressive/neutral).

\section{Data analysis}

We assessed looking time by examining the videos frame-by-frame with 25 frames per second with the program Mangold Interact (Version 17). Looking time was analysed in two ways. We scored the total looking time within the given minute, as well as the 'disengagement time', which we defined as the latency from looking at the picture until looking away for the first time. We also documented the occurrence of certain behaviours 
(yes/no) the subjects showed during testing such as self-directed behaviours (yawn, scratch or self-grooming), approach or depart the test setting, communicative signals (lifting eyebrows, head bob, lip-smack) and picture manipulation (touch).

We conducted a total of 177 trials. Six subjects participated in only three out of four possible sessions. Thus, we only used two of these three sessions (the picture pair, either female aggressive/neutral or male aggressive/neutral) for the comparison of looking times. One subject only participated in one presentation. Therefore, we could not use this session for any comparative analysis. One subject received a picture of a male and a female facial expression but not two pictures of a pair and was therefore excluded from the analysis. Since one subject was disturbed by another monkey, we could only use one set of pictures, resulting in 166 trials. Inter-observer reliability was assessed from $\mathrm{N}=56$ of the videos using the intra-class reliability correlation coefficient $\operatorname{ICC}(1, k)$ from the R package irr, revealing excellent agreement for looking time (0.98) and behaviour towards the pictures (1) (Hallgren, 2012).

\section{Statistical analysis}

To estimate the effects of age on the looking time we ran Linear Mixed Models (LMM), using the function Imer from the package Ime4 (Bates et al., 2015). We included subject age, subject sex, picture type (aggressive/neutral), and the interaction of subject age and picture type as fixed effects. Subject identity and picture identity were included as random effects. The reason for including picture identity as a random effect was the potential influence of the picture on the looking time. We used the picture stimuli several times (two to five times). We checked whether the assumptions of normally distributed and homogeneous residuals were fulfilled by visual inspection of a qq-plot of the residuals and residuals plotted against fitted values. These indicated no deviation from the assumptions. We calculated the Variance Inflation Factor using the package car (Fox \& Weisberg, 2011). The model stability was assessed on the level of the estimated coefficients and standard deviation by excluding the levels of the random effects one at a time. We used a likelihood ration test to compare the full model including all predictors with the null model lacking the predictor of interest (subject age).

\section{Results}

The full-null model comparison to investigate the total looking time did not show a significant difference between the full model and the null model $\left(x^{2}=0.88, \mathrm{df}=2, \mathrm{P}=0.64\right.$, figure 4 ) indicating that age did not have an effect in the interaction or as a main effect. $A$ 
similar result was obtained for the full-null model comparison of the disengagement time $\left(x^{2}=1.78, \mathrm{df}=1, \mathrm{P}=0.18\right.$, Supplementary Material of Chapter 3 , figure 1$)$. For more details see Supplementary Material, Table 5 and 6.

(a)

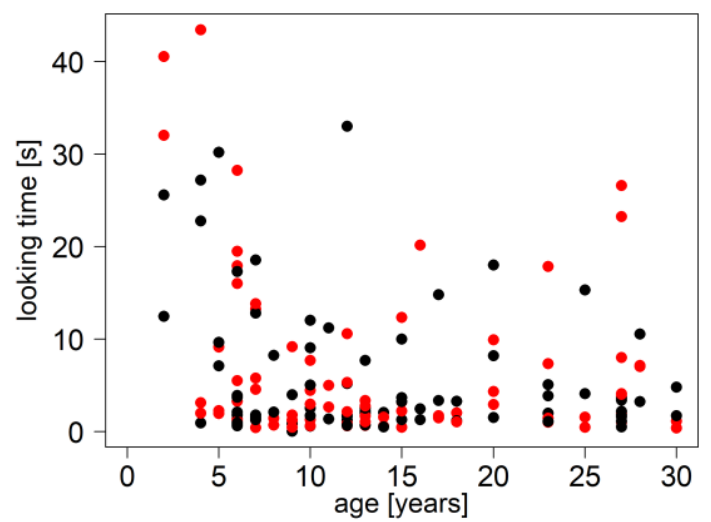

(b)

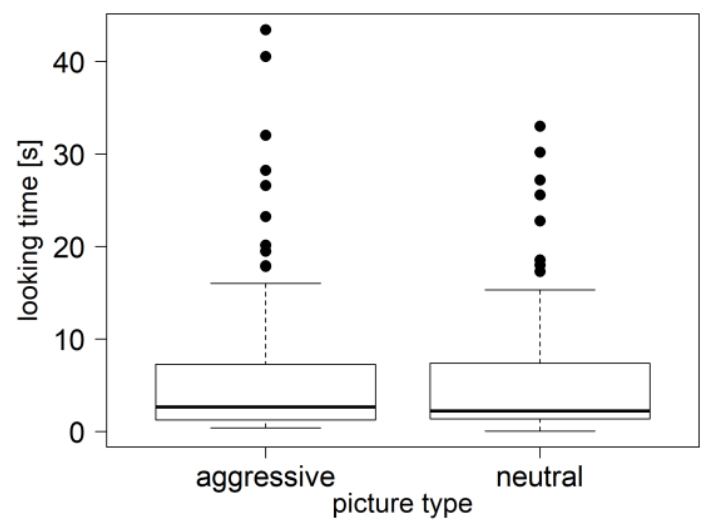

Figure 4. Total looking time towards the aggressive and neural pictures during one-minute exposure. (a) depicts looking time in relation to age. (b) depicts looking time by picture type (aggressive, neutral). Every point represents one data point. Colours in (a) indicate picture type (red=aggressive; black=neutral).

In total, 15 subjects reacted behaviourally when confronted with the picture by either reacting aggressively, submissively, or touching it in $57 \%$ of trials. This pattern was highly skewed towards juvenile and diminished in early adulthood (Supplementary Material of Chapter 3 , table 7 , figure 2). In comparison, the remaining 32 adult individuals did not react with any kind of behaviour during all their trials.

\section{Discussion}

By using two different approaches, we investigated whether communicative signals and social attention changes with increasing age in Barbary macaques. We found that older Barbary macaques used fewer aggressive and affiliative signals than younger ones. With regard to the response behaviour, we showed that, contrary to our expectations, it is not the age of the recipient but instead the age of the signaller that seemed to play a decisive role in both affiliative and aggressive signals. Older monkeys' signals were more likely to be ignored than signals of younger monkeys. Further, in the field experiment, we did not find evidence for an age effect in the looking time to aggressive compared to neutral facial expressions. Older monkeys did not look less towards the negative picture than younger monkeys. This result mirrors our findings in the response analysis where the receiver's age was not predictive of the likelihood to respond to an aggressive signal. 
Our results extend those from previous studies on age-related decline in social activity (Almeling et al., 2016; Brent et al., 2017; Corr, 2003; Schino \& Pinzaglia, 2018). With increasing age, many primate species become less social and show a decline in physical activity (Almeling et al., 2017; Corr, 2003). Older female Barbary macaques groom less frequently, but grooming bouts were longer (Almeling et al., 2017). This decline is also reflected in our results, as older monkeys used less affiliative signals like teeth chattering and lip smacking. Age affected both sexes similarly, yet males were less affiliative than females across adulthood. This is in line with the literature, as in philopatric species such as macaques and baboons, females have strong affiliative relationships (Silk, Altmann, \& Alberts, 2006) and interact more with their social partners than males (Cooper \& Bernstein, 2008; Henkel et al., 2010; Lehmann \& Ross, 2011; Sosa, 2016).

The use of aggressive signals increased with age and then, similar to the pattern of affiliative signals, decreased again after a peak at the age of about 15 years. In line with previous studies (Eaton, Modahl, \& Johnson, 1981; Lehmann \& Ross, 2011), males showed more aggressive signals than females independent of age. Some work already revealed that males reach their highest-ranking positions around the age of 15 and decline in rank afterwards, which supports our findings (Bissonnette, Lange, et al., 2009; Rathke et al., 2017). Further, older males after the age of 15 years, increase their coalitionary activity, potentially to counterbalance lower physical competitive abilities (Rathke et al., 2017).

Concerning the response behaviour, we did not find any confirmation for the SAVI model or the positivity effect. The likelihood to respond to affiliative or aggressive signals did not change with increasing age. The response to affiliative signals was equally high in older monkeys compared to younger ones. According to the positivity effect, we would have expected to find an increase in response to positive signals. Yet, our result supports previous studies and indicates that older monkeys are similarly interested in exchanging affiliative signals than younger monkeys, even though they themselves signal less (Almeling et al., 2016). What remains unclear and requires further investigation is whether the motivation to respond to certain partner's affiliation more than to others, and by this show a selective preference for fewer partners with which a close social bond is shared for instance. Older capuchin monkeys (Sapajus $s p$.), for instance, shift their focus to preferred partners with whom they spend most of their affiliative interactions (Schino \& Pinzaglia, 2018).

Further, the receiver's age did not influence the likelihood of responding to aggressive signals and therefore does not confirm the SAVI model. Potentially, assumptions of the $S A V I$ model are met via different pathways, i.e. avoidance strategies may rather include creating spatial distance and spend more time alone. For example, older female Barbary macaques tended to be spatially more reclusive (Almeling et al., 2017). The signaller's age, 
however, appeared to be more predictive of the response (react or not react) than the recipient's age. Regarding the support in aggressive interactions, aged macaques are potentially not preferred allies for younger adults. Some work on coalitionary activity in Barbary macaques reported that aged macaques were more likely to support each other while younger adults not necessarily depended on the help of others due to their stronger physicality (Berghänel et al., 2010; Noë \& Sluijter, 1995; Rathke et al., 2017). These findings suggest that besides being more socially selective with age, also younger group members shape the social environment for older individuals. For instance, older female macaques were still integrated into the social group and received grooming even without reciprocating it to the same extent (Almeling et al., 2016; Brent et al., 2017). This might be related to the positive effect grooming does not only have for the recipient but also for the grooming individual. By grooming others, the level of the stress hormone cortisol is reduced in macaques (Gust, Gordon, Hambright, \& Wilson, 1993; Shutt, MacLarnon, Heistermann, \& Semple, 2007). Similar stress relieving effects have been found in crested black macaques (Macaca nigra), indicated by fewer aggression and less scratching after grooming another individual (Aureli \& Yates, 2010). Grooming older group members may thus be a by-product of a stress reliving strategy since the risk of receiving aggression from older individuals is supposedly lower (Sosa, 2016). However, results about age-related changes in directing aggression are mixed and potentially species-specific (Brent et al., 2017; Corr, 2003).

That the relevance of a signal plays a decisive role could also explain the result of our field experiment. Contrary to our assumption that older monkeys would rather avoid looking at the aggressive picture and that the looking time would therefore be shorter compared to the looking time towards the neutral facial expression, we found that there is no age difference in this respect. Since it was a picture and not a video, or a real monkey, this may have influenced the looking time. It is possible that showing a picture was less relevant to the monkeys. There are studies, however, that show that monkeys can combine a facial expression from a picture with the same expression in a video (Micheletta et al., 2015). Some studies have further shown that monkeys react to pictures, process the content of the picture, and draw conclusions from it. For example, they can distinguish between different facial expressions, but also between conspecifics from their own group and from another group (Henkel et al., 2010; Pokorny \& de Waal, 2009). Nevertheless, our study found indications of an effect of young age. Until early adulthood individuals reacted to the picture with different behaviours, for example threatening or trying to take the picture away, regardless of whether it was the aggressive or neutral facial expression. Possibly, juvenile and sub-adult Barbary macaques' pronounced play behaviour was responsible for the reaction. Aggressive behaviour has been reported in the context of play behaviour and is considered to contribute to group integration and the development of motor and social skills (Mayhew, Funkhouser, \& Wright, 2020). 
Regarding the relevance of signals and the consequences they have in primates, the social system appears to be influential. A comparable looking time task in rhesus macaques found an age-related negativity effect i.e. older individuals shifted their attention towards aggressive facial expressions. Rhesus macaques differ from Barbary macaques in terms of their social tolerance and are classified as a rather despotic species. Aggressive confrontations are decided to the advantage of the more dominant individual and counteraggressions rarely occur (Thierry, 1985, 2007). Accordingly, it might be more important for older rhesus macaques to focus on aggressive signals. Recently, this pattern has been found in female rhesus macaques that showed an attentive bias towards aggressive situations (of third parties) compared to affiliative or solitary ones (Schülke, Dumdey, \& Ostner, 2020). This effect seems to persist into old age, as older female rhesus macaques showed more vigilance behaviour, potentially as a strategy to reduce stressful aggressive interactions (Brent et al., 2017).

In contrast, Barbary macaques, live in a relatively egalitarian system (Preuschoft et al., 1998; Thierry, 2007) with a significant number of ambivalent relationships (Fischer et al., 2017) and ambiguous social signals (Hesler \& Fischer, 2007). Due to the flat dominance hierarchy, the higher-ranking individual does not always prevail in conflicts and the outcome of an aggressive interaction is more asymmetric compared to rhesus macaques (Preuschoft et al., 1998; Thierry, 1985). In Barbary macaques, it further depends on the motivation or support of others how likely it is to win in a conflict (Preuschoft et al., 1998). Escalating fights after an 'open mouth threat face' are rare (Kuester \& Paul, 1992), suggesting that this signal rather opts to discourage others to approach and thereby avoid a costly fight (Almeling et al., 2017). Therefore, this signal may elicit less attention in Barbary macaques than it does in rhesus macaques. Consequently, the social system plays a major role in the expression of social attention throughout life. More studies in different social systems would provide further information on how the social attention of affiliative and aggressive signals changes with age.

In conclusion, we did not find the patterns we would expect according to the positivity effect and the SAVI model. This indicates that while there are changes in the social environment similar to those in humans such as a decrease in social relationships, other areas of social life develop differently with age. Concerning communicative signals, age appears to play a more distinctive role for the signaller compared to the recipient than previously anticipated. Our results highlight the importance of considering various social aspects beyond the number of partners, such as communicative signals, when studying social aging in primates. This study further urges the need for comparative studies that deal 
with the complexity of different social systems in primates to gain further knowledge into trajectories of social aging.

\section{Acknowledgements}

We would like to thank Ellen Merz, Gilbert de Turckheim and Guillaume de Turckheim for the permission to conduct this study at La Forêt des Singes in Rocamadour. We further thank the staff at the park for support. We are particularly grateful to Magdalena Wimmer, Luisa Beckmann, Lateefah Roth and Marie-Laure Poiret for their help in collecting the data. We thank Roger Mundry for valuable statistical support. The study was funded by the Deutsche Forschungsgemeinschaft [DFG, German Research Foundation, project number 360742713 (Fi707/22-1) and 254142454/GRK 2070]. We further acknowledge support through a Seed fund by the Leibniz ScienceCampus Primate Cognition, funded by the Leibniz Association. 


\title{
Chapter 4
}

\section{Differential ageing trajectories in motivation, inhibitory control and cognitive flexibility in Barbary macaques (Macaca sylvanus)}

\author{
Eva-Maria Rathke $e^{1,2,3}$ \& Julia Fischer ${ }^{1,2,3}$ \\ ${ }^{1}$ Cognitive Ethology Laboratory, German Primate Center, Leibniz Institute for \\ Primate Research, Kellnerweg 4, 37077 Göttingen, Germany \\ ${ }^{2}$ Department for Primate Cognition, Georg-August-University Göttingen \\ ${ }^{3}$ Leibniz ScienceCampus Primate Cognition, Göttingen
}

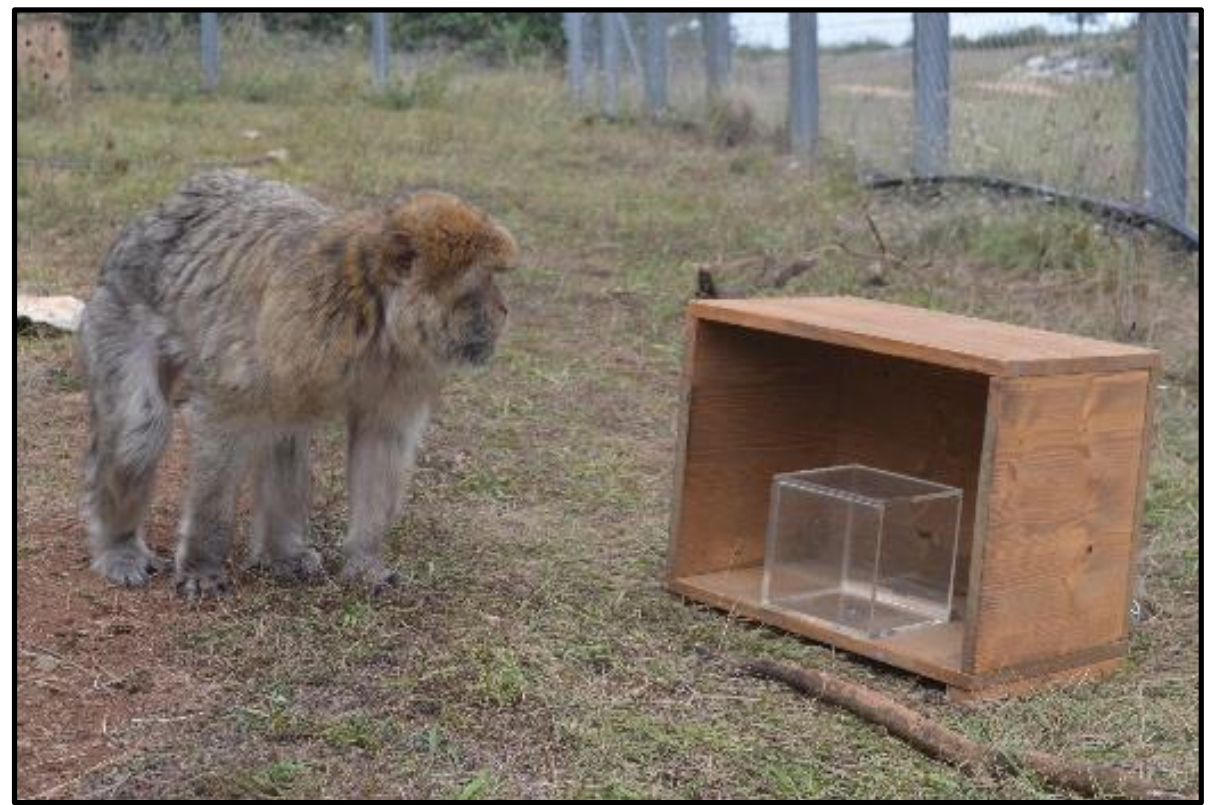

(c) EM Rathke

Published in Philosophical Transactions of the Royal Society B 375, 20190617 (2020) http://dx.doi.org/10.1098/rstb.2019.0617

Author contributions: E.M.R. and J.F. designed the study; E.M.R. conducted the experiments and analysis; E.M.R. and J.F. wrote the manuscript. 


\section{Chapter 5}

General discussion

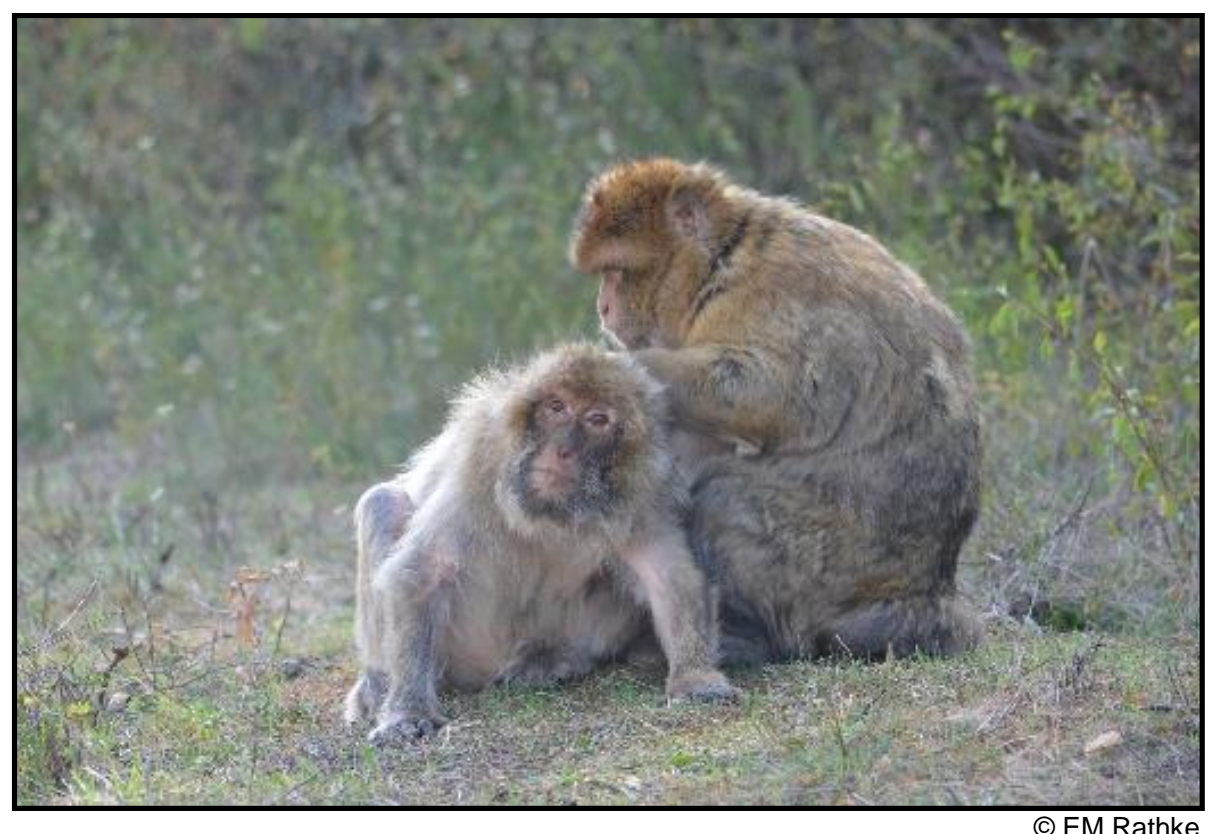


In the following Chapter, I will first summarize the results of the previous Chapters 2, 3, and 4. Based on these findings, I will discuss how aging affects social behaviour across the animal kingdom and whether older individuals occupy a special role in their society. Further, I will set age-related changes in social behaviour in an evolutionary context and scrutinize the mechanisms behind these apparent shifts. Drawing on the relationship between motivation and behavioural or attentional shifts, I will discuss the behavioural strategies that older individuals may engage in to avoid stressful encounters and provide ideas for future research. In the last sections of the discussion, I will draw attention to the motivational changes that occur in problem-solving behaviour and discuss how risk-taking in the context of cognitive tests changes with age. In the concluding part of this thesis, I will emphasize the importance of interdisciplinary study designs for a comprehensive understanding on the effects of age on social life.

\subsection{Summary of the main results}

Fewer affiliative partners and less social activity in male and female Barbary $\underline{\text { macaques }}$

In Chapter 2, I reported that age has a distinct influence on different social network metrics. Older monkeys had both fewer partners (indegree and outdegree) and less frequent interactions (instrength and outstrength). Age affected both sexes in a similar way, but males were generally less affiliative than females and their social engagement declined less strong than in females. Age and sex had different impacts on the indirect social network measures. Eigenvector centrality decreased in males and females, with males showing generally lower values. With regard to age-related differences, older monkeys had less wellconnected partners than younger ones. The clustering coefficient was not affected by age nor sex. Regarding their social integration, both sexes had fewer conspecifics in their close vicinity with age. In line with previous studies, older monkeys still seemed to be interested in their group members' interactions as commenting on aggressive conflicts and affiliative interactions (often involving an infant) did not vary with age. In addition, older animals showed less physical activity, i.e. less climbing or running.

\section{Age-related changes in communication}

By demonstrating an age-related change in communication, the results of Chapter 3 expand those from previous studies on an age-related decline in affiliative or aggressive behaviours. With increasing age, Barbary macaques used less affiliative signals like teeth chattering or lip smacking. Further, aggressive signals (e.g. open mouth threat, head bob 
or stare) first increased with age and then, similar to the affiliative signal pattern, again declined around the age of 15 years. I did not find an indication for the positivity effect or the Strength and Vulnerability Integration model, as the response behaviour of older monkeys did not differ from that of younger ones. There was no increased response towards positive signals nor a decrease in response towards negative signals. Yet, the sender's age appears to play a more decisive role both in affiliative and aggressive signals, compared to the recipient's age. There were less responses towards older monkeys' signals compared to younger ones.

\section{$\underline{\text { No indication for an age-related negativity avoidance }}$}

The looking time task presented in Chapter $\mathbf{3}$ did not indicate any age difference in the avoidance of negative (aggressive) signals. Older monkeys did not look less towards the negative picture than younger monkeys. This reflects the observational results from Chapter 3, where I showed that the receiver's age was not predictive of the likelihood to respond to an aggressive signal. These results do not support the assumptions of the Strength and Vulnerability Integration model from humans which assumes that increasing age leads to a change in behaviour to avoid potentially unpleasant experiences (Charles, 2010). Apparently, the avoidance of negative signals is less clearly pronounced in primates.

\section{Less motivation to explore new objects}

In Chapter 4, I demonstrated that the motivation to explore the physical environment decreases with age. Barbary macaques exhibited clear age-related variation in motivation to engage with all three tasks (inhibitory control, cognitive flexibility, persistence). With increasing age, monkeys were less likely to approach and explore a baited object. In the unsolvable task, specifically targeting persistence, older monkeys spend less time exploring.

\section{Different trajectories of cognition and motivation}

In Chapter 4 I further demonstrated, that while the motivation to approach and explore the problem-solving objects decreased with age, the cognitive performance was less clearly related to age. The ability to inhibit a prepotent movement such as reaching forward when presented with a transparent barrier did not appear to affect monkeys' performance with regard to their age. Further, the time they needed to succeed varied, but not in relation to age. Cognitive flexibility - the ability to switch to an alternative strategy - was rather difficult to interpret as only 21 out of 99 monkeys explored the object's side which was openable 
while the majority of monkeys stayed at the blocked side behind which the reward laid. They were apparently not able to take other opening possibilities into account. Further, only nine monkeys were able to succeed and obtained the reward. This task seemed to be beyond the cognitive capacity of most monkeys independent of their age.

The results of Chapters 2, $\mathbf{3}$ and $\mathbf{4}$ have shown that the aging process impacts different aspects of life. Drawing on these results, I will compare these results with other primate species - including humans - and non-primate species, and set them into a broader context.

\subsection{Social aging across different species}

The results of Chapter 2 are in line with the previous literature. Various studies in different primate species showed that age affects the social behaviour. In particular female primates have less partners with increasing age, spend less time affiliating with others and more time on their own (Almeling et al., 2016; Corr, 2003; Nakamichi, 2003; Veenema et al., 1997; Veenema, van Hooff, Gispen, \& Spruijt, 2001). The social decline is found across different social systems with varying dominance hierarchies, from despotic rhesus macaques and Japanese macaques (Aureli et al., 1997; Brent et al., 2017; Corr, 2003) to egalitarian Barbary macaques (Almeling et al., 2016; Sosa, 2016, this study). Additionally, studies on other species outside the macaque genus reported this pattern, i.e. tufted capuchin monkeys (Schino \& Pinzaglia, 2018) and chimpanzees (Webb et al., 2018).

These findings support the assumptions from the socioemotional selectivity theory in humans that suggest a social bias towards people with whom a familiar and positive relationship is shared (Carstensen, 1993). Smaller network sizes, i.e. fewer social partners, with increasing age are therefore not a sign of losing interest in social activities but rather changes in motivation and a refocusing on personal emotional values. Further, interest in seeking new social contacts has been reported to decrease in older adults (Lang \& Carstensen, 2002). Building up on the framework of the socioemotional selectivity theory and the question why older adults become more selective and which strategies they apply to maintain emotional well-being, section 5.4. and 5.5. will address the positivity effect and the Strength and Vulnerability Integration model.

\subsubsection{Male social aging}

Another aim of this thesis was to contribute to the scarce data on male social aging. Males in many primate species show generally less affiliative behaviour than females (Cooper \& Bernstein, 2008; Henkel et al., 2010; Lehmann \& Ross, 2011; Sosa, 2016). Yet, 
whether there is a similar age effect as in females is less clear in the literature. The results in Chapter 2 demonstrate that males and females experience a similar decline in affiliative behaviour, whereas females had a less pronounced decline regarding the interaction strength (frequency of interactions). However, the females did not differ from males regarding the age-related decline in the number of partners. Only a few studies so far have analysed data from both males and females. A study on male and female chimpanzees revealed a decrease with age in affiliative behaviour, but did not test for sex differences (Webb et al., 2018). In mouse lemurs, both sexes showed a decline of social behaviour (Picq, 1992). Yet, mouse lemurs are a solitary species and behavioural tests, not observational data, was used to assess changes in their social behaviour (seeking contact or staying in distance). This depicts that results must be interpreted with regard to speciesspecific characteristics.

Other studies did not find a less pronounced or absent age effect in males. In tufted capuchins, affiliative behaviour is generally low and a decrease might thus not be of high biological significance (Schino \& Pinzaglia, 2018). A study in Barbary macaques, did not find a similar age effect for males and females (Sosa, 2016): females showed a decline in social activity, males did not. Yet, the study included only grooming interactions. Grooming in males is quite rare and is mainly directed towards females or infants (Paul et al., 1996). Males themselves show male-specific behaviour such as triadic interactions in which two males interact affiliatively with an infant (Henkel et al., 2010; Paul et al., 1996). Including further affiliative behaviours such as triadic interactions or contact sitting (with both females and males) may have added more information on social aging patterns and potentially explains differences between studies.

A study on rhesus macaques found that older males received more affiliative behaviour than younger ones (Corr, 2003) - a reverse picture to the results from Chapter 2. This pattern could be explained by a rank-acquiring strategy of grooming a higher-ranking individual in order to get coalitionary support at later stages (Schino, 2007). The majority of male social partners, however, were juvenile individuals suggesting that this pattern is related to age instead of rank. Potentially, older males spend more time with juvenile individuals as a strategy to avoid costly interactions with adult individuals that could end in a physical confrontation. Thereby, the decline of affiliative interactions in Chapter 2 and the different composition of social partners in rhesus macaques do not contradict but complement each other by a potential underlying strategy to reduce stressful social interactions. The overall lacking and mixed results in males urge for further studies on how males' social behaviour changes in different primate species. That would help to gain a more comprehensive understanding of social aging trajectories in primates. 


\section{Methodological differences}

Some studies did find neither a decline nor age-related changes in affiliative behaviour in females (McDonald Pavelka, 1990) or both sexes (Baker, 2000). This may well be due to the fact that different methods were applied. For instance, differing housing conditions (e.g. paired, trios, groups) might trigger different social needs and cause a reduced comparability of several studies (Baker, 2000).

Additionally, age can be incorporated as a continuous or a categorical variable, resulting in different results in the same study (Brent et al., 2017). While age as a continuous variable revealed that with increasing age female rhesus macaques groom less, the categorical analysis with young ( $<17$ years) versus old ( $\geq 18$ years) did not find an age effect (Brent et al., 2017). Further, the chosen age categories also vary across studies. A study on rhesus macaques defined monkeys older than 20 years as 'old' (Corr, 2003), whereas the previous study set (Brent et al., 2017) the threshold two years earlies. Therefore, results might differ and within- and between-species collaborations are needed to bring methodological differences aside for a comparable insight on social aging in both sexes.

\subsubsection{Special roles of aged individuals across the animal kingdom}

In animal groups in which older individuals benefit from ecological knowledge, older group members can play a specific role in this regard. In the case of killer whales (Orcinus orca), for instance, older females frequently hold a leading position. This has been explained by the possibility that older individuals are more likely to find productive fishing grounds based on their experience or memory in times of food scarcity (Brent et al., 2015). Similar patterns were found in elephants where the matriarch plays an important role in group cohesion. Further, reproductive success was higher in groups of older matriarchs (McComb, Moss, Durant, Baker, \& Sayialel, 2001). In addition, the matriarch's age determined the group's response to hazards such as the sounds of lions (McComb et al., 2011). Recently, a study showed that older male elephants also play a leading role in allmale groups. Younger males may profit from traveling with older bulls by their greater knowledge about the environment (Allen, Brent, Motsentwa, Weiss, \& Croft, 2020). Among primates, there are a few studies that report a special role of older individuals. There are anecdotes about an older baboon leading the group to water and food sources during times of food shortage (Kummer, 1995). A more recent study on bonobos revealed that older females can act as key individuals in the group. They take leading role in group movements more often than younger females (Tokuyama \& Furuichi, 2017). The same pattern is seen 
in vervet monkeys, where older females lead the group to feeding sites $(\mathrm{H}$. C. Lee \& Teichroeb, 2016).

The studies discussed in section 5.2. (Social aging across different species) differ from those mentioned above by the fact that they were conducted in captivity or in semifree conditions. Thus, no ecological experience of older animals in times of food shortage is benefited from. Comparable conditions in which ecological knowledge is useful and serves survival are therefore not applicable here. The next section will address how older individuals navigate in their social environment but also how conspecifics behave towards older individuals. I will set the focus in particular on how different behavioural strategies could be related to an age-related avoidance of risky interactions.

\subsection{Strategic social decisions}

Female Barbary macaques have been shown to change their aggressive behaviour with age more towards aggressive signals such as the open mouth threat face (Almeling et al., 2017). Potentially, this shift towards a lower aggressive signal opts as a strategy to avoid stressful encounters by ensuring distance to conspecifics, but at the same time does not involve a physical confrontation. This assumption is based on the Strength and Vulnerability Integration model in human psychology. According to this model, older adults engage in strategies to avoid negative situations due to their reduced ability to cope with stressors both mentally and physically (Charles, 2010). Additionally, the positivity effect demonstrates the shift in attention and memory towards positive information over negative and neutral ones that is more pronounced in older than younger adults. Based on this theoretical framework and the previous findings in Barbary macaques, the goal of Chapter $\mathbf{3}$ was to investigate whether Barbary macaques engage in strategic choices to either avoid or achieve social contact with age. Further, to gain a more complete insight into changes in social behaviour, I was interested in not only how individuals change their behaviour with age but also how others respond to them. Thereby, the results will help to further understand whether older Barbary macaques actively withdraw from their social group or whether group members also contribute to this withdrawal and may isolate older group members.

The results of Chapter $\mathbf{3}$ did not indicate an age-related positivity effect. Older monkeys did not show an increased response to affiliative signals. They reacted to their conspecifics' signals to a similar degree than younger monkeys did. Contrary to the Strength and Vulnerability Integration model, older monkeys did not respond less to negative signals. The looking time task corroborated that finding, as there was no age effect for the looking time towards the negative or the neutral picture. Irrespective of age, monkeys responded less to 
older monkeys' affiliative and aggressive signals than to those of younger ones. These results reinforce the assumption that not only older individuals withdraw from society but to some degree also receive less attention.

The conclusion from Chapter $\mathbf{3}$ is that the avoidance strategies older individuals pursue function on a different level than during direct interaction with conspecifics. For instance, older primates are found to be more peripheral. With increasing age, Barbary macaques had fewer partners in their close proximity. This finding is in line with previous work on several primate species (Toque macaque (Macaca sinica): Ratnayeke, 1994; rhesus macaque: Brent et al., 2017; tufted capuchin monkeys: Schino \& Pinzaglia, 2018). Other studies report that older individuals not only had fewer partners, but also spend more time on their own (Nakamichi, 1984; Veenema et al., 1997).

Besides being more peripheral and having fewer partners, avoidance of potentially negative situations and reinforcing positive ones is achieved by selecting individuals to spend time with. There are indications that similar to older human's social selectivity also occurs in aged primates. Older Barbary macaques, Toque macaques and tufted capuchin monkeys show signs of being socially selective (Ratnayeke, 1994; Schino \& Pinzaglia, 2018). Selectivity has been defined as spending more time with some group members than with others (Schino \& Pinzaglia, 2018) or grooming less individuals but for a longer duration (Almeling et al., 2017; Ratnayeke, 1994). The latter could also function as an energy saving strategy, as switching to another partner would be more costly and increases unpredictability of a new contact attempt. By being selective in the partner choice, unpredictable social partners are avoided and the risk of a fight that can lead to an injury could be reduced. Future studies should further investigate social selectivity in primates. This especially applies to the question whether older primates' interaction patterns are shifted towards positive interactions on the dyadic level. For example, studies regarding this topic to date are cross-sectional and only provide a snapshot of the current situation. Whether selectivity becomes apparent over years, as it has been observed in humans (Charles \& Carstensen, 2010; van Tilburg, 1998), needs to be addressed in primates as well. This could be achieved by longitudinal studies that investigate whether the number of social partners decreases with age and - as proposed in the socioemotional selectivity theory - shifts to individuals with whom a predominantly positive relationship was maintained at the beginning of the study.

Social withdrawal and increased social selectivity are not contradictive with a remaining social interest in old age. In Chapter 2, I showed that commenting behaviour is not affected by age for both males and females indicating that there is no decrease in social attention that is given to both aggressive but also affiliative third-party interactions. As this behaviour 
does not include energy demanding actions, it emphasizes the assumption that active participation but not social interest in general changes with age. A previous study on female Barbary macaques found similar results (Almeling et al., 2016). Further, a study in Japanese macaques reported that social interest via contact calls even increased with age (McDonald Pavelka, 1990). Similar, the attention towards close social partners does not change with age as a looking time task in Barbary macaques found that both sexes had similar interest in images of preferred conspecifics (Almeling et al., 2016). The results of Chapter 3 demonstrate that older and younger Barbary macaques respond to affiliative signals to a similar degree. Generally, these findings show that while social interest is maintained up into old age, there are strategies applied to achieve social contact but at the same time avoid potentially unpleasant encounters.

\subsection{A question of relevance - application of the positivity effect and the Strength and Vulnerability Integration model to primates}

An aspect that needs to be considered when investigating how age-related shifts in behaviour or attention occur is relevance. For instance, this applies to the consequences of paying or not paying attention to aggressive signals in species with a different level of competition and the question whether primates experience a positivity effect with age. Older rhesus macaques have been shown to display even a negativity effect and be more attentive to the negative compared to neutral pictures (Rosati et al., 2018). As discussed previously, the open mouth threat face, the stimulus that has been used in both the rhesus macaque study and this study, might function as a signal to create spatial distance without physical conflict. Yet, in the despotic rhesus macaque escalating conflicts are more common than in the more egalitarian Barbary macaque (Preuschoft et al., 1998; Thierry, 1985, 2007), which might explain the differences in attention. In rhesus monkeys, an aggressive signal may elicit more attention due to the higher relevance of likely becoming involved in a conflict. Changes in attention towards negative stimuli also depend on the context they are witnessed in. Rhesus macaques looked away from a picture of an aggressive face much faster after a health check-up which is accompanied with elevated stress levels compared to a situation of enrichment where they were presented with baited devices. Gaze aversion shortly after experiencing a stressful situation could function as a strategy to avoid presumably aggressive confrontations (Bethell, Holmes, MacLarnon, \& Semple, 2012). These results illustrate the importance of the context of an experimental set-up, but also how species-specific characteristics, such as the strictness of the dominance hierarchy, influence attention towards the social environment. 
In humans, there are also differences in the urge to strive for positivity and in the extent to which attempts are made to avoid negative events. It also depends on the relevance or urgency of a situation. Older adults do not generally avoid everything negative. When it comes to health-related decisions, the positivity effect is less pronounced (English \& Carstensen, 2015) which might be a result of situation-specific decisions based on the relevance of the negative event. In addition, when asked to recall information on potential vacation locations, older adults remembered more negative information about the locations than positive ones. Yet, this was only the case when they had to decide where to go. When participants were only asked about the general information without making a choice, then older adults were better at recalling positive information. This effect was even enhanced when the location that had to be chosen was a hospital for a potential surgery (Depping \& Freund, 2013). Together with the findings in primates, it indicates that shifts in attention have to be interpreted in a contextual framework and might change according to different circumstances.

The findings from this thesis as well as the previous literature demonstrate the importance of investigating changes in social behaviour from different perspectives: from the frequency of a behaviour, the signal and response contingencies to the attention towards social stimuli. It will remain important to investigate different species in terms of their age-related changes in behaviour and attention under consideration of their speciesspecific characteristics. This also applies to questions related to how environmental stressors such as predation pressure or harsh environmental conditions influence and change behaviour across the lifespan.

\section{Future research: the effects of stress on social behaviour across age}

As Chapters 2, 3 and 4 have shown, there is less social activity but also less physical activity and less explorative behaviour with increasing age. While motivational changes may serve as an explanation for these changes, understanding the physiological processes involved is another aspect that would further complete the understanding of age-related behavioural shifts. This could be achieved by analysing the cortisol level, for instance. Cortisol is a commonly used proxy for the stress level an individual is experiencing in primates (Novak, Hamel, Kelly, Dettmer, \& Meyer, 2013) but also in aging research in humans (Almeida, McGonagle, \& King, 2009).

Although results are mixed, there are indications that older adults show increased levels of cortisol after experiencing negative situations. Younger adults did not experience a similar increase in cortisol which supports the assumptions of the Strength and Vulnerability 
Integration model that describes a lower physical ability to cope with stressors with increasing age (Otte et al., 2005; Piazza, Charles, Stawski, \& Almeida, 2013). A recent longitudinal study in chimpanzees revealed that age was related to an increase in cortisol levels. Yet, natural stressors such as changes in rank status did not account for the increase (Thompson et al., 2020). If similar physiological pathways could be identified in more primate species with increasing age and related to changes in social behaviour it would provide a promising avenue for future studies on how individuals cope with their environment when getting older.

Another question for which measuring cortisol levels could prove useful is whether primates that have fewer partners and spend more time alone are less stressed with increasing age. Following the assumptions of the Strength and Vulnerability Integration model and reduced socially stressful encounters, physiological markers such as cortisol could show whether older monkeys with fewer social encounters are less stressed than younger individuals with a similar number of partners. That the number of partners can have physiological effects has already been shown in female Chacma Baboons (Papio ursinus). Females were less stressed when a smaller number of grooming partners were present. Focusing on a small number of individuals therefore seems to reduce the need to keep track of many social relationships (Crockford, Wittig, Whitten, Seyfarth, \& Cheney, 2008).

\subsection{Motivational changes and problem-solving behaviour}

Age-related motivational changes do not only affect social life, but also influence the behaviour within the physical environment, for instance how individuals approach a novel object or a problem-solving task. Both Chapter $\mathbf{3}$ and Chapter 4 addressed this topic. Although age did not affect the attention directed to the neutral or aggressive picture, there was an effect of young age when characterizing the framed picture as a novel object (Chapter 3). Only juvenile and sub-adult monkeys showed a behavioural reaction towards the picture. Mostly, they threatened the picture or tried to take it away. Most likely this is related to play behaviour and curiosity. Aggressive behaviour belongs to play behaviour in infants and sub-adults as it trains the development of motor skills (Mayhew et al., 2020). In Chapter 4, I was able to demonstrate that the motivation to engage with the experimental tasks, which were unknown objects for the Barbary macaques, declined with age. Regardless of the task, monkeys were less likely to explore the tasks with increasing age. The unsolvable task specifically designed to test the monkeys' persistence clearly showed that with increasing age they were less motivated or less physically capable to persevere in exploring. These results corroborate previous work on Barbary macaques that showed a decline in motivation to explore novel non-baited objects already in early adulthood. Baited 
objects, similar to the experimental design in Chapter 4, elicited more attention, yet the motivation to approach and explore dropped for the oldest monkeys (> 19 years) (Almeling et al., 2016). Similar results on age-related changes in exploratory behaviour have been revealed in white-faced capuchin monkeys (Cebus capucinus). Based on personality ratings, younger monkeys were rated as less neophobic (more explorative in their environment) (Perry, 2020). Personality ratings in chimpanzees confirm these results as older individuals also tended to be less explorative (Massen et al., 2013). It is clear that personality ratings and observational data are not fully comparable. Overall, both findings still suggest that age has a clear influence on the motivation to explore in primates. Early studies on explorative behaviour and aging found mixed results on object manipulation (Line, Morgan, \& Markowitz, 1991; Novak et al., 1993). Yet, both studies were conducted in single-caged and paired/trio caged individuals which is likely to limit the informational value to the housing conditions.

Studies on explorative motivation in humans, for instance the time someone searches in a particular food patch for fish (which are rewarded with money) before switching to another patch, showed that older adults rather stay at one location whereas younger adults faster switch to new patches (Mata, Wilke, \& Czienskowski, 2009). With age, individuals might be less drawn to explore new objects even when including a food reward, because the value they gain is perceived as low in comparison to the costs it takes (Sherratt \& Morand-Ferron, 2018). The selection, optimization and compensation model supports the assumption that changes in behaviour are due to differences in resource management (Baltes, 1997). The propensity to take a risk varies with age. Older humans tend to be more risk averse and prefer goals that are achievable without exposure to losses (Freund \& Baltes, 2000). The thrive for novel ideas or actions further decreases with age (Blakemore \& Robbins, 2012; Lucas \& Donnellan, 2011). Whether a risk is taken or not seems to depend to a large extent on what is at stake. When older adults have to choose between certain options, they appear to be driven by avoiding losses or costs in case of monetary rewards. In a gambling task, older adults chose a risky option if this minimized a potential loss. For instance, potential loss meant that the outcome of the gamble was either a definite loss or a potential loss with chances of no loss. In contrast, younger adults opted for a risk in order to maximise a gain irrespective of potential losses (Best \& Freund, 2018; Rutledge et al., 2016). Further, information that could lead to costs or negative situations are remembered better by older than by younger adults (Depping \& Freund, 2013). On a physiological level, dopamine, a neurotransmitter which belongs to the reward system of the brain (AriasCarrión, Stamelou, Murillo-Rodríguez, Menéndez-González, \& Pöppel, 2010), has been associated with motivational changes in humans (Rutledge et al., 2016). With age, the dopamine levels decline as the brain undergoes structural changes (Bäckman, Nyberg, Lindenberger, Li, \& Farde, 2006). Thus, dopamine supposedly influences older adults' risk- 
taking behaviour as their internal reward system is less primed to seek for a reward and more focused on minimizing a loss (Rutledge et al., 2016). Likewise, a decline of the dopamine system has been reported in primates (P. R. Hof et al., 2002). How this relates to their motivation to seek for a reward remains for future investigations.

Future research: energy resources as a trade-off responsible for differences in $\underline{\text { motivation }}$

An indication that changes in motivation are also based on differences in energy resources is demonstrated by the changes in activity patterns (Chapter 2). Older Barbary macaques showed less energy demanding activities like jumping and climbing, which finds further support in the literature (Corr, 2003; McDonald Pavelka, 1994; Nakamichi, 1984; Shively et al., 2012). Further, some problem-solving tasks have high physical demands such as the unsolvable task in Chapter 4 due to the movability of the transparent tube, no reward to gain and therefore no successful end to the energy expenditure. It is likely that older individuals reached the point where the energy expenditure outweighed the potential gains faster than younger individuals. Likewise, older Barbary macaques performed less well in another study involving a task with high physical manipulation demands, i.e. opening a blocked side of a transparent tube that had to be picked up from the ground (Almeling et al., 2016). Future studies need to explore in which way lack of energy contribute to a loss in motivation. This could be achieved by investigating physiological markers such as $\mathrm{C}$ peptides, that have been implemented as a measure of energetic status in macaques and gorillas (Girard-Buttoz et al., 2011; Grueter, Deschner, Behringer, Fawcett, \& Robbins, 2014). There are further indications that age affects the glucose metabolism in long-tailed macaques under laboratory test conditions using an intravenous glucose tolerance test (Wu, Yue, Zou, Chan, \& Zhang, 2012). In particular, studies in semi-free ranging populations will help to understand how the energy status is influenced by increasing age in a more natural environment. Then, these measures can potentially be related to changes in sociality but also in problem-solving performance.

\section{Future research: motivation versus physiological competence}

Drawing on the results on the differences in persistence during the unsolvable task (Chapter 4), it would be interesting to also investigate additional measures of physiological decline, for instance the grip strength and problem-solving performance (exploration time, participation yes/no). Physical abilities are often measured as the grip strength in humans (Cooper, Kuh, \& Hardy, 2010) by using a hand dynamometer and in mouse lemurs using a force gauge where individuals have to pull (Hämäläinen, Dammhahn, Aujard, \& Kraus, 
2015). With increasing age, grip strength decreases in both humans (Kallman, Plato, \& Tobin, 1990) and mouse lemurs (Hämäläinen et al., 2015; Le Brazidec et al., 2017). Of course, motivational changes cannot be completely separated from cognitive or physical decline processes. However, including a measure of muscular or motoric functioning would still give an insight into a potential relation between physiological decline and motivational changes.

\subsection{Cognitive performance across age}

The results of Chapter $\mathbf{4}$ show that an age effect was less clear in executive functions than the decline in motivation. The performance in the inhibitory control task did not differ with age, not regarding success nor exploration time. In the cognitive flexibility task, monkeys did not perform well across age. Literature on cognitive abilities in primates shows mixed results, from no difference to mild or great differences with age (Bliss-Moreau \& Baxter, 2019; Manrique \& Call, 2015; Vlamings et al., 2010; Zeamer et al., 2011). While memory and learning abilities are reported to decrease with age (Nagahara, Bernot, \& Tuszynski, 2010), other executive functions like cognitive flexibility are less clearly related to age and potentially highly task specific (Zeamer et al., 2011). Studies on four ape species found a general inflexibility for older but also younger individuals, indicated by the number of errors made during a problem-solving task (Manrique \& Call, 2015). Another study, that measured flexibility by counting the times a monkey switched to another behaviour, reported an age-related decreased in techniques used to open a fruit (Perry, 2020). The inconsistent use of the term cognitive flexibility but also inhibitory control, hampers obtaining a consistent insight into how certain characteristics such as age are related to changes in these traits (Audet \& Lefebvre, 2017; Beran, 2015; van Horik \& Madden, 2016). Often, cognitive flexibility is also intermingled with inhibitory processes which are fundamentally important to behave flexible (Audet \& Lefebvre, 2017; MacLean et al., 2014) but can be also tested in manifold ways including different tasks and procedures (Audet \& Lefebvre, 2017; Griffin \& Guez, 2014). The same applies to differences in thresholds for entering the testing procedure. For example, most studies that investigate inhibitory control and cognitive flexibility include a learning phase. Test subjects first learn one strategy until they succeed to a certain percentage. The next stage of testing incorporates a change, i.e. the prior strategy becomes incorrect, and subjects have to adapt to the new circumstances (Lacreuse et al., 2018; Lacreuse, Russell, Hopkins, \& Herndon, 2014; Manrique \& Call, 2015). Memory and learning abilities play a distinct role here and have both been linked to age-related deficits (Nagahara et al., 2010; Zeamer et al., 2011). Consequently, this may lead to different conclusions regarding an age effect when certain individuals do not pass 
the testing threshold (Moore, Killiany, Herndon, Rosene, \& Moss, 2006; Zeamer et al., 2011).

Likewise, the human cognitive aging process is highly individual (Deary et al., 2009; Lindenberger, 2014). This seems to be particularly the case for the trajectory of executive functions such as cognitive flexibility and inhibitory control. While there are many studies that show a decline in these traits, other studies did not report a difference compared to younger adults (Andrés, Guerrini, Phillips, \& Perfect, 2008; Bedard et al., 2002; Rey-Mermet $\&$ Gade, 2018). Due to the high degree of individuality, the distinction between normal and pathological cognitive aging is difficult and subject to much debate. Some adults show no signs of dementia or any other cognitive disease but do exhibit structural changes in the brain (Solbakk et al., 2008). Similar to primate studies, methodological issues such as inconsistent use and measurement of cognitive abilities might result in different outcomes (Jurado \& Rosselli, 2007; Kray, 2006; Rey-Mermet \& Gade, 2018).

\section{Future research: long-term studies}

A promising way for future studies on primate cognitive aging, in particular with focus on cognitive flexibility and inhibitory control, would probably be long-term studies that investigate individuals' performance over a longer period. Two and three-year studies on common marmosets and chimpanzees did not find a poorer performance in the following years (Lacreuse et al., 2014; Workman, Healey, Carlotto, \& Lacreuse, 2018). This emphasizes that in order to track cognitive changes on a group but also on an individual level long-term studies are needed that will provide more basis for age-related changes in executive functions. Further, collaborations on a larger scale that investigate different species with the same methodological approaches and in particular the same definitions of observed behaviours are needed to gain comparative results of age-related changes in cognitive processes.

\subsection{Conclusion}

In this thesis I have demonstrated that age is an important determinant of social and motivational changes in Barbary macaques. The strength of this project lies in bridging different research areas from social behaviour to cognitive performance, both linked by the impact motivation has on choices that individuals make. Further, the combination of crosssectional behavioural observation and field experiments provided the basis to study agerelated differences on a broader scale. With the findings of this thesis, I have expanded the current literature by a) examining how age influences not only females but also males in 
their social behaviour, b) highlighting that there is a need to study how group members treat and respond to older individuals and c) emphasising that motivation is an often underestimated determinant to cognitive performance and problem-solving behaviour. I showed that primates - in this case Barbary macaques - are a valuable model organism to study aging and its consequences on various areas of life. Further, I pointed out that aging is a complex phenomenon which requires that various factors are considered in order to understand and interpret observed changes, such as housing conditions, the training regime in case of experimental testing, and the social structure.

Throughout my work, I addressed psychological theories from human lifespan theory and their application to primates. While some seem to share a common basis among humans and primates (socioemotional selectivity theory; selection and optimization model), others may work on a different level in primates than they do in humans (positivity effect, Strength and Vulnerability Integration model).

To return to the introduction of this thesis: with the growing proportion of older adults in many societies around the world, it remains important to study how other species age on a social level and how older individuals sometimes occupy special roles. It appears that many aspects of the aging process are biologically determined and do not necessarily need the cognitive capacity or awareness of a limited lifetime. Therefore, comparative research combining social, motivational and cognitive aspects remains essential. It not only helps to better understand the behaviour of our closest relatives but can also contribute to the study of the human aging process by focusing on behavioural foundations shared in humans and many other primates. For future research, I consider it as enormously important to work multidisciplinary and thus benefit from other disciplines by sharing knowledge beyond the boundaries of one's own research field. With this work, I have closed gaps in the existing literature, but also pointed out ways for future research that can tie in with previous results. 


\section{Supplementary Material}

\section{Chapter 2}

Table 1. Influence of age, sex and rank on the indegree.

\begin{tabular}{cccccc}
\hline Term & Estimate \pm Std. Error & z value & $\begin{array}{c}\text { Confidence } \\
\text { interval (lower) }\end{array}$ & $\begin{array}{c}\text { Confidence } \\
\text { interval (higher) }\end{array}$ & $P$ \\
\hline (Intercept) & $-0.80 \pm 0.05$ & -16.07 & -0.90 & -0.70 & \\
Z.age & $-0.07 \pm 0.03$ & -2.07 & -0.13 & 0.00 & 0.04 \\
I(z.age 2 2) & $-0.12 \pm 0.03$ & -3.37 & -0.19 & -0.05 & $<0.001$ \\
sexmale & $-0.22 \pm 0.08$ & -2.64 & -0.39 & -0.06 & 0.01 \\
Z.rank & $0.16 \pm 0.05$ & 3.34 & 0.07 & 0.26 & $<0.001$ \\
\hline
\end{tabular}

Based on 84 individuals

Table 2. Influence of age, sex and rank on the instrength.

\begin{tabular}{cccccc}
\hline Term & Estimate \pm Std. Error & $z$ value & $\begin{array}{c}\text { Confidence } \\
\text { interval (lower) }\end{array}$ & $\begin{array}{c}\text { Confidence } \\
\text { interval (higher) }\end{array}$ & $P$ \\
\hline (Intercept) & $0.63 \pm 0.08$ & 7.44 & 0.46 & 0.81 & \\
z.age & $-0.41 \pm 0.06$ & -6.79 & -0.52 & -0.29 & $<0.001$ \\
sexmale & $-0.88 \pm 0.17$ & -5.28 & -1.23 & -0.54 & $<0.001$ \\
z.rank & $0.22 \pm 0.09$ & 2.55 & 0.05 & 0.39 & 0.01 \\
\hline Based on 84 individuals & & & &
\end{tabular}

Table 3. Influence of age, sex and rank on the outdegree.

\begin{tabular}{cccccc}
\hline Term & Estimate \pm Std. Error & z value & $\begin{array}{c}\text { Confidence } \\
\text { interval (lower) }\end{array}$ & $\begin{array}{c}\text { Confidence } \\
\text { interval (higher) }\end{array}$ & $\mathrm{P}$ \\
\hline (Intercept) & $-0.94 \pm 0.05$ & -19.98 & -1.03 & -0.84 & \\
Z.age & $-0.12 \pm 0.03$ & -4.05 & -0.18 & -0.06 & $<0.001$ \\
I(z.age 2 ) & $-0.08 \pm 0.03$ & -2.40 & -0.14 & -0.01 & 0.02 \\
sexmale & $-0.02 \pm 0.08$ & -0.24 & -0.17 & 0.13 & 0.81 \\
z.rank & $0.10 \pm 0.04$ & 2.20 & 0.01 & 0.19 & 0.03 \\
\hline
\end{tabular}

Based on 84 individuals

Table 4. Influence of age, sex and rank on the outstrength.

\begin{tabular}{cccccc}
\hline Term & Estimate \pm Std. Error & z value & $\begin{array}{c}\text { Confidence } \\
\text { interval (lower) }\end{array}$ & $\begin{array}{c}\text { Confidence } \\
\text { interval (higher) }\end{array}$ & $P$ \\
\hline (Intercept) & $0.62 \pm 0.07$ & 8.62 & 0.48 & 0.77 & \\
z.age & $-0.43 \pm 0.05$ & -8.35 & -0.53 & -0.32 & $<0.001$ \\
z.rank & $0.27 \pm 0.07$ & 3.64 & 0.13 & 0.41 & $<0.001$ \\
sexmale & $-0.90 \pm 0.14$ & -6.40 & -1.19 & -0.62 & $<0.001$ \\
\hline
\end{tabular}

Based on 84 individuals

Table 5. Influence of age, sex and rank on the eigenvector centrality.

\begin{tabular}{cccccc}
\hline Term & Estimate \pm Std. Error & $\mathrm{t}$ value & $\begin{array}{c}\text { Confidence } \\
\text { interval (lower) }\end{array}$ & $\begin{array}{c}\text { Confidence } \\
\text { interval (higher) }\end{array}$ & $\mathrm{P}$ \\
\hline (Intercept) & $-2.40 \pm 0.23$ & -10.48 & -2.86 & -1.95 & \\
z.age & $-0.76 \pm 0.16$ & -4.74 & -1.08 & -0.44 & $<0.001$ \\
z.rank & $0.33 \pm 0.23$ & 1.43 & -0.13 & 0.80 & 0.16 \\
sexmale & $-1.64 \pm 0.45$ & -3.66 & -2.52 & -0.75 & $<0.001$ \\
\hline
\end{tabular}

Based on 84 individuals

Table 6. Influence of age, sex and rank on the clustering coefficient.

\begin{tabular}{ccclll}
\hline Term & $\begin{array}{c}\text { Estimate } \pm \text { Std. } \\
\text { Error }\end{array}$ & t value & $\begin{array}{l}\text { Confidence } \\
\text { interval (lower) }\end{array}$ & $\begin{array}{l}\text { Confidence } \\
\text { interval (higher) }\end{array}$ & $P$ \\
\hline (Intercept) & $0.52 \pm 0.01$ & 36.84 & 0.50 & 0.55 &
\end{tabular}




\begin{tabular}{cccccc} 
z.age & $0.01 \pm 0.01$ & 0.80 & -0.01 & 0.03 & 0.43 \\
sexmale & $0.00 \pm 0.03$ & -0.04 & -0.06 & 0.05 & 0.97 \\
z.rank & $-0.03 \pm 0.01$ & -2.14 & -0.06 & 0.00 & 0.04 \\
\hline
\end{tabular}

Based on 84 individuals

Table 7. Influence of age and sex on proximity.

\begin{tabular}{cccccc}
\hline Term & Estimate \pm Std. Error & z value & $\begin{array}{c}\text { Confidence } \\
\text { interval (lower) }\end{array}$ & $\begin{array}{c}\text { Confidence } \\
\text { interval (higher) }\end{array}$ & $P$ \\
\hline (Intercept) & $0.45 \pm 0.03$ & 13.72 & 0.39 & 0.52 & \\
z.age & $-0.10 \pm 0.03$ & -3.96 & -0.15 & -0.05 & $<0.001$ \\
sexmale & $0.06 \pm 0.05$ & 1.08 & -0.05 & 0.16 & 0.27 \\
\hline
\end{tabular}

Based on 84 individuals

Table 8. Influence of age, sex and rank on energy-demanding activities.

\begin{tabular}{cccccc}
\hline Term & Estimate \pm Std. Error & z value & $\begin{array}{c}\text { Confidence } \\
\text { interval (lower) }\end{array}$ & $\begin{array}{c}\text { Confidence } \\
\text { interval (higher) }\end{array}$ & $\mathrm{P}$ \\
\hline (Intercept) & $0.10 \pm 0.09$ & 1.09 & -0.08 & 0.28 & \\
z.age & $-0.62 \pm 0.06$ & -10.03 & -0.74 & -0.50 & $<0.001$ \\
z.rank & $0.16 \pm 0.09$ & 1.75 & -0.03 & 0.35 & 0.10 \\
sexmale & $0.30 \pm 0.17$ & 1.75 & -0.05 & 0.64 & 0.09 \\
\hline
\end{tabular}

Based on 84 individuals

Table 9. Influence of age, sex and rank on commenting behaviour.

\begin{tabular}{cccccc}
\hline Term & Estimate \pm Std. Error & z value & $\begin{array}{c}\text { Confidence } \\
\text { interval (lower) }\end{array}$ & $\begin{array}{c}\text { Confidence } \\
\text { interval (higher) }\end{array}$ & $\mathrm{P}$ \\
\hline (Intercept) & $0.01 \pm 0.12$ & 0.08 & -0.23 & 0.26 & \\
Z.age & $-0.08 \pm 0.09$ & -0.96 & -0.25 & 0.08 & 0.32 \\
Z.rank & $0.57 \pm 0.13$ & 4.43 & 0.31 & 0.82 & $<0.001$ \\
sexmale & $-0.95 \pm 0.24$ & -3.91 & -1.44 & -0.47 & $<0.001$ \\
\hline
\end{tabular}

Based on 84 individuals

\section{Chapter 3}

Table 1. Study population by age and sex

\begin{tabular}{|c|c|c|c|c|c|c|c|}
\hline \multirow{2}{*}{$\begin{array}{l}\text { Group PB } \\
\text { Female } \\
\text { ID }\end{array}$} & \multicolumn{7}{|c|}{ Group GB } \\
\hline & $\begin{array}{l}\text { Age } \\
\text { [years] }\end{array}$ & $\begin{array}{l}\text { Male } \\
\text { ID } \\
\end{array}$ & Age [years] & $\begin{array}{l}\text { Female } \\
\text { ID }\end{array}$ & $\begin{array}{l}\text { Age } \\
\text { [years] }\end{array}$ & $\begin{array}{l}\text { Male } \\
\text { ID }\end{array}$ & Age [years] \\
\hline C121 & $<1$ & C122 & $<1$ & X93 & 4 & $\mathrm{C} 2$ & $<1$ \\
\hline C120 & $<1$ & A115 & 1 & V71 & 5 & C3 & $<1$ \\
\hline Z104 & 2 & A118 & 1 & T63 & 6 & B123 & 1 \\
\hline T60 & 5 & Z102 & 2 & R50 & 7 & A111 & 2 \\
\hline T61 & 5 & X95 & 3 & R51 & 7 & A113 & 2 \\
\hline R52 & 6 & X87 & 3 & R53 & 7 & X82 & 4 \\
\hline O31 & 8 & V72 & 4 & O32 & 8 & X92 & 4 \\
\hline M21 & 9 & V73 & 4 & M20 & 10 & V70 & 5 \\
\hline $\mathrm{O} 32$ & 9 & V74 & 4 & M23 & 10 & T61 & 6 \\
\hline L11 & 10 & T60 & 5 & M24 & 10 & T62 & 6 \\
\hline K431 & 11 & R52 & 6 & K430 & 12 & T63 & 6 \\
\hline $\mathrm{H} 412$ & 13 & R55 & 6 & K432 & 12 & R53 & 7 \\
\hline G400 & 14 & R56 & 6 & 1420 & 13 & R57 & 7 \\
\hline D370 & 17 & P40 & 7 & 1421 & 13 & P41 & 8 \\
\hline C360 & 18 & M21 & 9 & 1422 & 13 & O31 & 9 \\
\hline B350 & 19 & L10 & 10 & $\mathrm{H} 410$ & 14 & M23 & 10 \\
\hline B353 & 19 & L12 & 10 & F390 & 16 & L14 & 11 \\
\hline B355 & 19 & 1421 & 12 & E380 & 17 & K430 & 12 \\
\hline A330 & 20 & 142 & 12 & B354 & 20 & K431 & 12 \\
\hline A331 & 20 & $\mathrm{H} 410$ & 13 & Y310 & 23 & G401 & 15 \\
\hline
\end{tabular}




\begin{tabular}{|c|c|c|c|c|c|c|}
\hline Z320 & 21 & H412 & 13 & Y311 & 23 & G402 \\
\hline T268 & 26 & H416 & 13 & W291 & 25 & D372 \\
\hline T274 & 26 & G403 & 14 & $\mathrm{R} 253$ & 27 & B352 \\
\hline T277 & 26 & F391 & 15 & T261 & 27 & T262 \\
\hline P227 & 28 & E380 & 16 & T264 & 27 & \\
\hline M189 & 30 & D370 & 17 & T275 & 27 & \\
\hline & & C361 & 18 & R248 & 28 & \\
\hline & & A337 & 20 & O200 & 30 & \\
\hline & & A340 & 20 & & & \\
\hline & & Z321 & 21 & & & \\
\hline & & W283 & 24 & & & \\
\hline & & U282 & 25 & & & \\
\hline & & R247 & 27 & & & \\
\hline & & O202 & 29 & & & \\
\hline & & M189 & 30 & & & \\
\hline
\end{tabular}

Table 2. Influence of age, sex and rank with regard to the number of affiliative signals.

\begin{tabular}{cccccr}
\hline Term & $\begin{array}{c}\text { Estimate } \pm \text { Std. } \\
\text { Error }\end{array}$ & z value & $\begin{array}{c}\text { Confidence } \\
\text { interval (lower) }\end{array}$ & $\begin{array}{c}\text { Confidence } \\
\text { interval } \\
\text { (higher) }\end{array}$ & $P$ \\
\hline (Intercept) & $-0.42 \pm 0.11$ & -3.92 & -0.62 & -0.20 & $<0.001$ \\
z.age & $-0.31 \pm 0.07$ & -4.19 & -0.45 & -0.17 & $<0.001$ \\
z.rank & $0.44 \pm 0.11$ & 4.08 & 0.24 & -0.64 & 0.02 \\
sexmale & $-0.49 \pm 0.21$ & -2.37 & -0.89 & &
\end{tabular}

Table 3. Influence of age and sex in relation to the number of aggressive signals.

\begin{tabular}{cccccr}
\hline Term & $\begin{array}{c}\text { Estimate } \pm \text { Std. } \\
\text { Error }\end{array}$ & z value & $\begin{array}{c}\text { Confidence } \\
\text { interval (lower) }\end{array}$ & $\begin{array}{c}\text { Confidence } \\
\text { interval } \\
\text { (higher) }\end{array}$ & $P$ \\
\hline (Intercept) & $-0.07 \pm 0.09$ & -0.77 & -0.24 & 0.11 & $<0.001$ \\
z.age & $-0.30 \pm 0.07$ & -4.38 & -0.46 & -0.15 & $<0.001$ \\
sexmale & $0.54 \pm 0.14$ & 3.84 & 0.26 & 0.81 & $<01$ \\
\hline
\end{tabular}

The GLM was based on 84 subjects.

Table 4. Influence of the signaller age, receiver age and signaller sex on the likelihood to obtain a response respective of the signal category (affiliative/aggressive).

\begin{tabular}{llllll}
\hline Term & $\begin{array}{l}\text { Estimate } \pm \text { Std. } \\
\text { Error }\end{array}$ & $z$ value & $\begin{array}{l}\text { Confidence } \\
\text { interval (lower) }\end{array}$ & $\begin{array}{l}\text { Confidence } \\
\text { interval } \\
\text { (higher) }\end{array}$ & $\mathrm{P}$ \\
\hline (Intercept) & $1.18 \pm 0.18$ & 6.48 & 0.83 & 1.47 & \\
SignalCategoryAGG & $0.05 \pm 0.21$ & 0.24 & -0.33 & 0.43 & 0.82 \\
z.signaller.age & $-0.30 \pm 0.08$ & -3.85 & -0.45 & -0.15 & $<0.01$ \\
signaller_sexmale & $-0.29 \pm 0.20$ & -1.42 & -0.63 & -0.08 & 0.16 \\
z.receiver.age & $0.10 \pm 0.08$ & 1.28 & -0.06 & 0.24 & 0.21 \\
\hline
\end{tabular}

The GLMM was based on 3126 interactions.

Table 5. Likelihood ratio results from analysis of the disengagement time (duration of first look)

\begin{tabular}{ccccccccc}
\hline Term & Df & AIC & BIC & $\begin{array}{c}\text { logLik } \\
\text { deviance }\end{array}$ & Chisq & Chi & Df & P \\
\hline $\begin{array}{c}\text { Null model } \\
\text { (without age) }\end{array}$ & 13 & 465.69 & 506.30 & -219.85 & 439.69 & & & \\
$\begin{array}{c}\text { Full model } \\
\text { (including age) }\end{array}$ & 15 & 467.96 & 514.82 & -218.98 & 437.96 & 1.73 & 2 & 0.42 \\
\hline The GLMM was based on 168 observations. & & & & & &
\end{tabular}

The GLMM was based on 168 observations. 
(a)

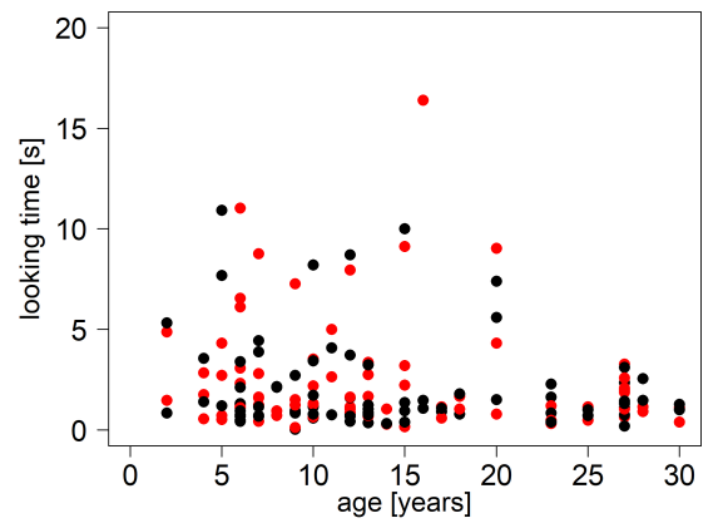

(b)

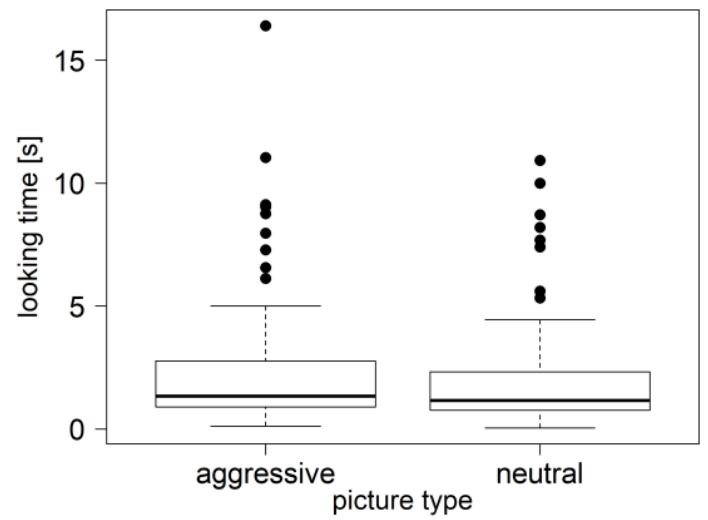

Figure 1. Disengagement towards the aggressive and neural pictures during one-minute exposure. (a) depicts the first look (latency until looked away for the first time) in relation to age. (b) depicts disengagement looking time by picture type (aggressive, neutral). Every point represents one data point. Colours in (a) indicate picture type (red=aggressive; black=neutral).

Table 6. Likelihood ratio results from analysis of the total looking time

\begin{tabular}{ccccccccc}
\hline Term & Df & AIC & BIC & $\begin{array}{c}\text { logLik } \\
\text { deviance }\end{array}$ & Chisq & Chi & Df & P \\
\hline $\begin{array}{c}\text { Null model } \\
\text { (without age) } \\
\begin{array}{c}\text { Full model } \\
\text { (including age) }\end{array}\end{array}$ & 13 & 543.42 & 583.88 & -258.71 & 517.42 & & & \\
\hline
\end{tabular}

The GLMM was based on 166 interactions

Table 7. Behavioural response (touching, threatening, taking it away) towards the picture in relation to age.

\begin{tabular}{ccc}
\hline Age [years] & \multicolumn{2}{c}{ Behavioural reaction } \\
\cline { 2 - 3 } & no & yes \\
\hline 1 & 1 & 1 \\
2 & 0 & 5 \\
4 & 2 & 5 \\
5 & 2 & 5 \\
6 & 11 & 5 \\
7 & 9 & 6 \\
8 & 4 & 0 \\
9 & 7 & 1 \\
10 & 11 & 1 \\
11 & 4 & 0 \\
12 & 16 & 0 \\
13 & 12 & 0 \\
14 & 4 & 0 \\
15 & 8 & 0 \\
16 & 4 & 0 \\
17 & 4 & 0 \\
18 & 4 & 0 \\
20 & 7 & 0 \\
23 & 8 & 0 \\
25 & 4 & 0 \\
27 & 16 & 0 \\
28 & 4 & 0 \\
30 & 4 & 0 \\
\hline Total & 146 & 29
\end{tabular}




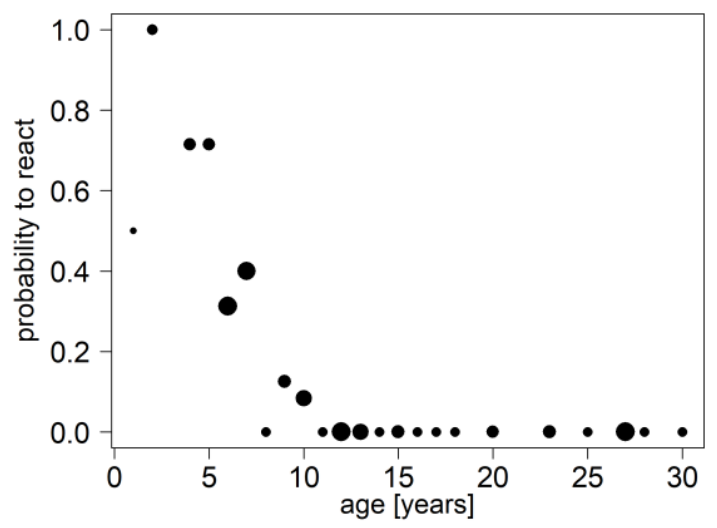

Figure 2. Probability to react behaviourally towards the picture in relation to age. Area of the points indicate number of individuals of a certain age. 


\section{References}

Allen, C. R. B., Brent, L. J. N., Motsentwa, T., Weiss, M. N., \& Croft, D. P. (2020). Importance of old bulls: leaders and followers in collective movements of all-male groups in African savannah elephants (Loxodonta africana). Scientific Reports, 10(1), 13996. https://doi.org/10.1038/s41598-020-70682-y

Almeida, D. M., McGonagle, K., \& King, H. (2009). Assessing daily stress processes in social surveys by combining stressor exposure and salivary cortisol. Biodemography and Social Biology, 55(2), 219-237. https://doi.org/10.1080/19485560903382338

Almeling, L., Hammerschmidt, K., Sennhenn-Reulen, H., Freund, A. M., \& Fischer, J. (2016). Motivational shifts in aging monkeys and the origins of social selectivity. Current Biology, 26(13), 1-6. https://doi.org/10.1016/j.cub.2016.04.066

Almeling, L., Sennhenn-Reulen, H., Hammerschmidt, K., Freund, A. M., \& Fischer, J. (2017). Social interactions and activity patterns of old Barbary macaques: further insights into the foundations of social selectivity. American Journal of Primatology, 79(11), e22711. https://doi.org/10.1002/ajp.22711

Altmann, J. (1974). Observational study of behavior: sampling methods. Behaviour, 3/4, 227-267. https://doi.org/10.1163/156853974X00534

Alwin, D. F., \& Hofer, S. M. (2011). Health and cognition in aging research. The Journals of Gerontology Series B: Psychological Sciences and Social Sciences, 66B(S1), i9-i16. https://doi.org/10.1093/geronb/gbr051

Amici, F., Aureli, F., \& Call, J. (2008). Fission-fusion dynamics, behavioral flexibility, and inhibitory control in primates. Current Biology, 18(18), 1415-1419. https://doi.org/10.1016/j.cub.2008.08.020

Amici, F., Kulik, L., Langos, D., \& Widdig, A. (2019). Growing into adulthood-a review on sex differences in the development of sociality across macaques. Behavioral Ecology and Sociobiology, 73, 18. https://doi.org/10.1007/s00265-018-2623-2

Amici, F., \& Widdig, A. (2019). An evolutionary perspective on the development of primate sociality. Behavioral Ecology and Sociobiology, 73, 116. https://doi.org/10.1007/s00265-019-2722-8

Andrés, P., Guerrini, C., Phillips, L. H., \& Perfect, T. J. (2008). Differential effects of aging on executive and automatic inhibition. Developmental Neuropsychology, 33(2), 101123. https://doi.org/10.1080/87565640701884212

Archie, E. A., Tung, J., Clark, M., Altmann, J., \& Alberts, S. C. (2014). Social affiliation matters: both same-sex and opposite-sex relationships predict survival in wild female baboons. Proceedings of the Royal Society B: Biological Sciences, 281(1793), 20141261. https://doi.org/10.1098/rspb.2014.1261

Arias-Carrión, O., Stamelou, M., Murillo-Rodríguez, E., Menéndez-González, M., \& Pöppel, 
E. (2010). Dopaminergic reward system: a short integrative review. International Archives of Medicine, 3, 24. https://doi.org/10.1186/1755-7682-3-24

Audet, J.-N., \& Lefebvre, L. (2017). What's flexible in behavioral flexibility? Behavioral Ecology, 28(4), 943-947. https://doi.org/10.1093/beheco/arx007

Aureli, F., Das, M., \& Veenema, H. C. (1997). Differential kinship effect on reconciliation in three species of macaques (Macaca fascicularis, M. fuscata, and M. sylvanus). Journal of Comparative Psychology, 111(1), 91-99. https://doi.org/10.1037/07357036.111.1.91

Aureli, F., \& Yates, K. (2010). Distress prevention by grooming others in crested black macaques. Biology Letters, 6(1), 27-29. https://doi.org/10.1098/rsbl.2009.0513

Austad, S. N. (1997). Comparative aging and life histories in mammals. Experimental Gerontology, 32, 23-38. https://doi.org/10.1016/S0531-5565(96)00059-9

Bäckman, L., Nyberg, L., Lindenberger, U., Li, S.-C., \& Farde, L. (2006). The correlative triad among aging, dopamine, and cognition: current status and future prospects. Neuroscience and Biobehavioral Reviews, 30(6), 791-807. https://doi.org/10.1016/j.neubiorev.2006.06.005

Baker, K. C. (2000). Advanced age influences chimpanzee behavior in small social groups. Zoo Biology, 19(2), 111-119. https://doi.org/10.1002/1098-2361(2000)19:2<111::AIDZOO2>3.0.CO;2-5

Baltes, P. B. (1997). On the incomplete architecture of human ontogeny: selection, optimization, and compensation as foundation of developmental theory. American Psychologist, 52(4), 366-380. https://doi.org/10.1037/0003-066X.52.4.366

Baltes, P. B., \& Singer, T. (2001). Plasticity and the ageing mind: an exemplar of the biocultural orchestration of brain and behaviour. European Review, 9(1), 59-76. https://doi.org/10.1017/S1062798701000060

Barense, M. D., Fox, M. T., \& Baxter, M. G. (2002). Aged rats are impaired on an attentional set-shifting task sensitive to medial frontal cortex damage in young rats. Learning \& Memory, 9, 191-201. https://doi.org/10.1101//m.48602.and

Barr, D. J., Levy, R., Scheepers, C., \& Tily, H. J. (2013). Random effects structure for confirmatory hypothesis testing: keep it maximal. Journal of Memory and Language, 68(3), 1-43. https://doi.org/10.1016/j.jml.2012.11.001

Bates, D., Mächler, M., Bolker, B., \& Walker, S. (2015). Fitting linear mixed-effects models using Ime4 version 1.1-23. Journal of Statistical Software, 67(1), 1-48. https://doi.org/10.18637/jss.v067.i01

Bedard, A.-C., Nichols, S., Barbosa, J. A., Schachar, R., Logan, G. D., \& Tannock, R. (2002). The development of selective inhibitory control across the life span. Developmental Neuropsychology, 21(1), 93-111. https://doi.org/10.1207/S15326942DN2101_5

Benson-Amram, S., \& Holekamp, K. E. (2012). Innovative problem solving by wild spotted 
hyenas. Proceedings of the Royal Society B: Biological Sciences, 279, 4087-4095. https://doi.org/10.1098/rspb.2012.1450

Beran, M. J. (2015). The comparative science of "self-control": what are we talking about? Frontiers in Psychology, 6, 51. https://doi.org/10.3389/fpsyg.2015.00051

Berghänel, A., Ostner, J., Schröder, U., \& Schülke, O. (2011). Social bonds predict future cooperation in male Barbary macaques, Macaca sylvanus. Animal Behaviour, 81(6), 1109-1116. https://doi.org/10.1016/j.anbehav.2011.02.009

Berghänel, A., Schülke, O., \& Ostner, J. (2010). Coalition formation among Barbary macaque males: the influence of scramble competition. Animal Behaviour, 80(4), 675682. https://doi.org/10.1016/j.anbehav.2010.07.002

Best, R., \& Freund, A. M. (2018). Age, loss minimization, and the role of probability for decision-making. Gerontology, 64(5), 475-484. https://doi.org/10.1159/000487636

Bethell, E. J., Holmes, A., MacLarnon, A., \& Semple, S. (2012). Evidence that emotion mediates social attention in rhesus macaques. PLOS ONE, 7(8). https://doi.org/10.1371/journal.pone.0044387

Birditt, K. S. (2014). Age differences in emotional reactions to daily negative social encounters. Journals of Gerontology Series B: Psychological Sciences and Social Sciences, 69(4), 557-566. https://doi.org/10.1093/geronb/gbt045

Birditt, K. S., \& Fingerman, K. L. (2005). Do we get better at picking our battles? Age group differences in descriptions of behavioral reactions to interpersonal tensions. Journals of Gerontology Series B: Psychological Sciences and Social Sciences, 60B(3), P121128. https://doi.org/10.1093/geronb/60.3.P121

Bissonnette, A., Bischofberger, N., \& van Schaik, C. P. (2011). Mating skew in Barbary macaque males: the role of female mating synchrony, female behavior, and male-male coalitions. Behavioral Ecology and Sociobiology, 65(2), 167-182. https://doi.org/10.1007/s00265-010-1023-z

Bissonnette, A., de Vries, H., \& van Schaik, C. P. (2009). Coalitions in male Barbary macaques, Macaca sylvanus: strength, success and rules of thumb. Animal Behaviour, 78(2), 329-335. https://doi.org/10.1016/j.anbehav.2009.05.010

Bissonnette, A., Lange, E., \& Van Schaik, C. P. (2009). A cardinal measure of competitive ability in Barbary macaque males (Macaca sylvanus). Ethology, 115(7), 671-681. https://doi.org/10.1111/j.1439-0310.2009.01652.x

Bizon, J. L., Foster, T. C., Alexander, G. E., \& Glisky, E. L. (2012). Characterizing cognitive aging of working memory and executive function in animal models. Frontiers in Aging Neuroscience, 4, 19. https://doi.org/10.3389/fnagi.2012.00019

Blakemore, S.-J., \& Robbins, T. W. (2012). Decision-making in the adolescent brain. Nature Neuroscience, 15(9), 1184-1191. https://doi.org/10.1038/nn.3177

Blanchard-Fields, F. (2007). Everyday problem solving and emotion. Current Directions in Psychological Science, 16(1), 26-31. https://doi.org/10.1111/j.1467- 
8721.2007.00469.x

Blaszczyk, M. B. (2018). Consistency in social network position over changing environments in a seasonally breeding primate. Behavioral Ecology and Sociobiology, 72(1), 11. https://doi.org/10.1007/s00265-017-2425-y

Bliss-Moreau, E., \& Baxter, M. G. (2019). Interest in non-social novel stimuli as a function of age in rhesus monkeys. Royal Society Open Science, 6(9), 182237. https://doi.org/10.1098/rsos.182237

Botvinick, M., \& Braver, T. (2015). Motivation and cognitive control: from behavior to neural mechanism. Annual Review of Psychology, 66, 83-113. https://doi.org/10.1146/annurev-psych-010814-015044

Braver, T. S., Krug, M. K., Chiew, K. S., Kool, W., Westbrook, J. A., Clement, N. J., ... Somerville, L. H. (2014). Mechanisms of motivation-cognition interaction: challenges and opportunities. Cognitive Affective and Behavioral Neuroscience, 14(2), 443-472. https://doi.org/10.3758/s13415-014-0300-0

Bremer, D., Lüdecke, D., \& von dem Knesebeck, O. (2019). Social relationships, age and the use of preventive health services: findings from the German ageing survey. International Journal of Environmental Research and Public Health, 16, 4272. https://doi.org/10.3390/ijerph16214272

Brent, L. J. N. (2015). Friends of friends: are indirect connections in social networks important to animal behaviour? Animal Behaviour, 103, 211-222. https://doi.org/10.1016/j.anbehav.2015.01.020

Brent, L. J. N., Franks, D. W., Foster, E. A., Balcomb, K. C., Cant, M. A., \& Croft, D. P. (2015). Ecological knowledge, leadership, and the evolution of menopause in killer whales. Current Biology, 25(6), 746-750. https://doi.org/10.1016/j.cub.2015.01.037

Brent, L. J. N., Ruiz-Lambides, A., \& Platt, M. L. (2017). Family network size and survival across the lifespan of female macaques. Proceedings of the Royal Society $B$ : Biological Sciences, 284(1854), 20170515. https://doi.org/10.1098/rspb.2017.0515

Brumm, H., Kipper, S., Riechelmann, C., \& Todt, D. (2005). Do Barbary macaques "comment" on what they see? A first report on vocalizations accompanying interactions of third parties. Primates, 46(2), 141-144. https://doi.org/10.1007/s10329-004-0107-7

Byrne, R. W. (1996). Machiavellian intelligence. Evolutionary Anthropology, 5(5), 172-180. https://doi.org/10.1002/(SICI)1520-6505(1996)5:5<172::AID-EVAN6>3.0.CO;2-H

Cacioppo, S., \& Cacioppo, J. T. (2012). Decoding the invisible forces of social connections. Frontiers in Integrative Neuroscience, 6, 51. https://doi.org/10.3389/fnint.2012.00051

Carey, J. R., \& Gruenfelder, C. (1997). Population biology of the elderly. In K. W. Wachter \& C. E. Finch (Eds.), Between Zeus and the salmon: the biodemography of longevity (pp. 127-160). Washington DC: National Academies Press.

Carstensen, L. L. (1993). Motivation for social contact across the life span: a theory of socioemotional selectivity. In J. E. Jacobs \& J. E. (Ed) Jacobs (Eds.), Current theory 
and research in motivation, Vol. 40. Nebraska Symposium on Motivation, 1992: Developmental perspectives on motivation (pp. 209-254). University of Nebraska Press.

Carstensen, L. L., \& DeLiema, M. (2018). The positivity effect: a negativity bias in youth fades with age. Current Opinion in Behavioral Sciences, 19, 7-12. https://doi.org/10.1016/j.cobeha.2017.07.009

Carstensen, L. L., Fung, H. H., \& Charles, S. T. (2003). Socioemotional selectivity theory and emotion regulation in the second half of life. Motivation and Emotion, 27(2), 103123. https://doi.org/0146-7239/03/0600-0103/0

Carstensen, L. L., \& Löckenhoff, C. E. (2003). Aging, emotion, and evolution: the bigger picture. Annals of the New York Academy of Sciences, 1000, 152-179. https://doi.org/10.1196/annals.1280.008

Carstensen, L. L., \& Mikels, J. A. (2005). At the intersection of emotion and cognitiom: aging and the positivity effect. Current Directions in Psychological Science, 14(3), 117-121. https://doi.org/10.1111/j.0963-7214.2005.00348.x

Carter, K. D., Brand, R., Carter, J. K., Shorrocks, B., \& Goldizen, A. W. (2013). Social networks, long-term associations and age-related sociability of wild giraffes. Animal Behaviour, 86(5), 901-910. https://doi.org/10.1016/j.anbehav.2013.08.002

Charles, S., \& Carstensen, L. L. (2010). Social and emotional aging. Annual Review of Psychology, 61, 383-409. https://doi.org/10.1146/annurev.psych.093008.100448

Charles, S. T. (2010). Strength and vulnerability integration (SAVI): a model of emotional well-being across adulthood. Psychological Bulletin, 136(6), 1068-1091. https://doi.org/10.1037/a0021232

Charles, S. T., \& Hong, J. (2015). Strength and Vulnerability Integration. In N. A. Pachana (Ed.), Encyclopedia of Geropsychology (pp. 1-6). Singapore: Springer. https://doi.org/10.1007/978-981-287-080-3_10-1

Charles, S. T., \& Carstensen, L. L. (2004). A life-span view of emotional functioning in adulthood and old age. In P. T. Costa, Jr. \& I. C. Siegler (Eds.), Recent advances in psychology and aging (Vol. 15, pp. 133-162). Amsterdam: Elsevier.

Charles, S. T., Mather, M., \& Carstensen, L. L. (2003). Aging and emotional memory: the forgettable nature of negative images for older adults. Journal of Experimental Psychology: General, 132(2), 310-324. https://doi.org/10.1037/0096-3445.132.2.310

Chen, X., Errangi, B., Li, L., Glasser, M. F., Westlye, L. T., Fjell, A. M., .. Rilling, J. K. (2013). Brain aging in humans, chimpanzees (Pan troglodytes), and rhesus macaques (Macaca mulatta): magnetic resonance imaging studies of macro- and microstructural changes. Neurobiology of Aging, 34(10), 2248-2260. https://doi.org/10.1016/j.neurobiolaging.2013.03.028

Cheney, D. L., Silk, J. B., \& Seyfarth, R. M. (2016). Network connections, dyadic bonds and fitness in wild female baboons. Royal Society Open Science, 3(7), 160255. 
https://doi.org/10.1098/rsos.160255

Chiew, K. S., \& Braver, T. S. (2011). Positive affect versus reward: emotional and motivational influences on cognitive control. Frontiers in Psychology, 2, 279. https://doi.org/10.3389/fpsyg.2011.00279

Chow, P. K. Y., Lea, S. E. G., \& Leaver, L. A. (2016). How practice makes perfect: the role of persistence, flexibility and learning in problem-solving efficiency. Animal Behaviour, 112, 273-283. https://doi.org/10.1016/j.anbehav.2015.11.014

Christensen, K., Doblhammer, G., Rau, R., \& Vaupel, J. W. (2009). Ageing populations : the challenges ahead. Lancet, 374(9696), 1196-1208. https://doi.org/1016/S01406736(09)61460-4

Cohen, A. A., Coste, C. F. D., Li, X.-Y., Bourg, S., \& Pavard, S. (2020). Are trade-offs really the key drivers of ageing and life span? Functional Ecology, 34, 153-166. https://doi.org/10.1111/1365-2435.13444

Colman, R. J. (2018). Non-human primates as a model for aging. Biochimica et Biophysica Acta (BBA) - Molecular Basis of Disease, 1864, 2733-2741. https://doi.org/10.1016/j.bbadis.2017.07.008

Colman, R. J., \& Anderson, R. M. (2011). Nonhuman primate calorie restriction. Antioxidants and Redox Signaling, 14(2), 229-239. https://doi.org/10.1089/ars.2010.3224

Colman, R. J., \& Binkley, N. (2002). Skeletal aging in macaque monkeys. In J. M. Erwin \& P. R. Hof (Eds.), Aging in Nonhuman Primates (Vol. 31, pp. 32-47). Basel: Karger.

Cooper, M. A., \& Bernstein, I. S. (2008). Evaluating dominance styles in Assamese and rhesus macaques. International Journal of Primatology, 29(1), 225-243. https://doi.org/10.1007/s10764-008-9236-y

Cooper, R., Kuh, D., \& Hardy, R. (2010). Objectively measured physical capability levels and mortality: systematic review and meta-analysis. BMJ, 341, c4467. https://doi.org/10.1136/bmj.c4467

Cordier, R., \& Wilson, N. J. (2014). Community-based men's sheds: promoting male health, wellbeing and social inclusion in an international context. Health Promotion International, 29(3), 483-493. https://doi.org/10.1093/heapro/dat033

Cornwell, B. (2011). Independence through social networks: bridging potential among older women and men. Journals of Gerontology Series B: Psychological Sciences and Social Sciences, 66(6), 782-794. https://doi.org/10.1093/geronb/gbr111

Cornwell, E. Y., \& Waite, L. J. (2009). Social disconnectedness, perceived isolation, and health among older adults. Journal of Health and Social Behavior, 50(1), 31-48. https://doi.org/10.1177/002214650905000103

Corr, J. (2003). Social behavior in aged rhesus macaques. Collegium Antropologicum, 27(1), 87-94.

Cramer, P. E., Gentzel, R. C., Tanis, K. Q., Vardigan, J., Wang, Y., Connolly, B., ... Uslaner, 
J. M. (2018). Aging African green monkeys manifest transcriptional, pathological, and cognitive hallmarks of human Alzheimer's disease. Neurobiology of Aging, 64, 92-106. https://doi.org/10.1016/j.neurobiolaging.2017.12.011

Crockford, C., Wittig, R. M., Whitten, P. L., Seyfarth, R. M., \& Cheney, D. L. (2008). Social stressors and coping mechanisms in wild female baboons (Papio hamadryas ursinus). Hormones and Behavior, 53(1), 254-265. https://doi.org/10.1016/j.yhbeh.2007.10.007

Csárdi, G., \& Nepusz, T. (2006). The igraph software package for complex network research. International Journal of Complex Systems, 1695, 1-6. https://doi.org/10.3724/sp.j.1087.2009.02191

Cumming, E., \& Henry, W. E. (1961). Growing old: the process of disengagement. New York: Basic Books.

Dahl, C. D., Wallraven, C., Bülthoff, H. H., \& Logothetis, N. K. (2009). Humans and macaques employ similar face-processing strategies. Current Biology, 19(6), 509-513. https://doi.org/10.1016/j.cub.2009.01.061

Darowski, E. S., Helder, E., Zacks, R. T., Hasher, L., \& Hambrick, D. Z. (2008). Age-related differences in cognition: the role of distraction control. Neuropsychology, 22(5), 638644. https://doi.org/10.1037/0894-4105.22.5.638

de Turckheim, G., \& Merz, E. (1984). Breeding Barbary macaques in outdoor open enclosures. In J. E. Fa (Ed.), The Barbary macaque: a case study in conservation (pp. 241-261). New York: Plenum Publishing Corporation. https://doi.org/10.1007/978-14613-2785-1_10

Deary, I. J., Corley, J., Gow, A. J., Harris, S. E., Houlihan, L. M., Marioni, R. E., .. Starr, J. M. (2009). Age-associated cognitive decline. British Medical Bulletin, 92(1), 135-152. https://doi.org/10.1093/bmb/ldp033

Depping, M. K., \& Freund, A. M. (2013). When choice matters: task-dependent memory effects in older adulthood. Psychology and Aging, 28(4), 923-936. https://doi.org/10.1037/a0034520

Diamond, A. (2013). Executive functions. Annual Review of Psychology, 64, 135-168. https://doi.org/10.1146/annurev-psych-113011-143750

Dobson, A. J. (2002). An introduction to generalized linear models. Boca Raton: Chapman $\mathrm{Hall} / \mathrm{CRC}$.

Eaton, G. G., Modahl, K. B., \& Johnson, D. F. (1981). Aggressive behavior in a confined troop of Japanese macaques: effects of density, season, and gender. Aggressive Behavior, 7(2), 145-164. https://doi.org/10.1002/1098-2337(1981)7:2<145::AIDAB2480070207>3.0.CO;2-M

Ebel, S. J., \& Call, J. (2018). The interplay of prior experience and motivation in great ape problem-solving (Gorilla gorilla, Pan paniscus, Pan troglodytes, and Pongo abelii). Journal of Comparative Psychology, 132(3), 294-305. https://doi.org/10.1037/com0000117 
Emery, N. J., \& Clayton, N. S. (2001). Effects of experience and social context on prospective caching strategies by scrub jays. Nature, 414, 443-446. https://doi.org/10.1038/35106560

English, T., \& Carstensen, L. L. (2015). Does positivity operate when the stakes are high?: health status and decision-making among older adults. Psychology and Aging, 30(2), 348-355. https://doi.org/10.1037/a0039121

Ennis, G. E., Hess, T. M., \& Smith, B. T. (2013). The impact of age and motivation on cognitive effort: implications for cognitive engagement in older adulthood. Psychology and Aging, 28(2), 495-504. https://doi.org/10.1037/a0031255

Fantz, R. L. (1964). Visual experience in infants: decreased attention to familiar patterns relative to novel ones. Science. https://doi.org/10.1126/science.146.3644.668

Faragher, R. G. A. (2015). Should we treat aging as a disease? The consequences and dangers of miscategorisation. Frontiers in Genetics, 6, 171. https://doi.org/10.3389/fgene.2015.00171

Fischer, J. (2017). On the social life and motivational changes of aging monkeys. Gerontology, 63(6), 572-579. https://doi.org/10.1159/000477401

Fischer, J., Farnworth, M. S., Sennhenn-Reulen, H., \& Hammerschmidt, K. (2017). Quantifying social complexity. Animal Behaviour, 130, 57-66. https://doi.org/10.1016/j.anbehav.2017.06.003

Fooden, J. (2007). Systematic review of the Barbary macaque, Macaca sylvanus (Linnaeus, 1758). Fieldiana Zoology, 113, 1-60. https://doi.org/10.5962/bhl.title.14256

Forstmeier, W., \& Schielzeth, H. (2011). Cryptic multiple hypotheses testing in linear models: overestimated effect sizes and the winner's curse. Behavioral Ecology and Sociobiology, 65(1), 47-55. https://doi.org/10.1007/s00265-010-1038-5

Foster, E. A., Franks, D. W., Mazzi, S., Darden, S. K., Balcomb, K. C., Ford, J. K. B., \& Croft, D. P. (2012). Adaptive prolonged postreproductive life span in killer whales. Science, 337, 1313-1313. https://doi.org/10.1126/science.1224198

Fox, E., Lester, V., Russo, R., Bowles, R. J., Pichler, A., \& Dutton, K. (2000). Facial expressions of emotion: are angry faces detected more efficiently? Cognition and Emotion, 14(1), 61-92. https://doi.org/10.1080/026999300378996

Fox, J., \& Weisberg, S. (2011). An R companion to applied regression. Los Angeles: SAGE Publications.

Franks, V. R., \& Thorogood, R. (2018). Older and wiser? Age differences in foraging and learning by an endangered passerine. Behavioural Processes, 148, 1-9. https://doi.org/10.1016/j.beproc.2017.12.009

Fraser, H. B., Khaitovich, P., Plotkin, J. B., Pääbo, S., \& Eisen, M. B. (2005). Aging and gene expression in the primate brain. PLoS Biology, 3(9), e274. https://doi.org/10.1371/journal.pbio.0030274

Freund, A. M. (2006). Age-differential motivational consequences of optimization versus 
compensation focus in younger and older adults. Psychology and Aging, 21(2), 240252. https://doi.org/10.1037/0882-7974.21.2.240

Freund, A. M., \& Baltes, P. B. (2000). The orchestration of selection, optimization and compensation: an action-theoretical conceptualization of a theory of developmental regulation. In W. Perrig \& A. Grob (Eds.), Control of human behavior, mental processes, and consciousness: essays in honor of the 60th birthday of August Flammer (pp. 35-58). Mahwah, NJ: Erlbaum.

Fröhlich, M., \& Hobaiter, C. (2018). The development of gestural communication in great apes. Behavioral Ecology and Sociobiology, 72, 194. https://doi.org/10.1007/s00265018-2619-y

Fruchterman, T. M. J., \& Reingold, E. M. (1991). Graph drawing by force-directed placement. Software-: Practice and Experience, 21(11), 1129-1164. https://doi.org/10.1002/spe.4380211102

Gaillard, J.-M., \& Lemaître, J.-F. (2020). An integrative view of senescence in nature. Functional Ecology, 34, 4-16. https://doi.org/10.1111/1365-2435.13506

Gana, K., Bailly, N., Saada, Y., Joulain, M., \& Alaphilippe, D. (2013). Does life satisfaction change in old age: results from an 8-year longitudinal study. Journals of Gerontology Series B: Psychological Sciences and Social Sciences, 68(4), 540-552. https://doi.org/10.1093/geronb/gbs093

Girard-Buttoz, C., Higham, J. P., Heistermann, M., Wedegärtner, S., Maestripieri, D., \& Engelhardt, A. (2011). Urinary C-peptide measurement as a marker of nutritional status in macaques. PLoS ONE, 6(3), e18042. https://doi.org/10.1371/journal.pone.0018042

Gratton, G., Cooper, P., Fabiani, M., Carter, C. S., \& Karayanidis, F. (2018). Dynamics of cognitive control: theoretical bases, paradigms, and a view for the future. Psychophysiology, 55, e13016. https://doi.org/10.1111/psyp.13016

Griffin, A. S., \& Guez, D. (2014). Innovation and problem solving: a review of common mechanisms. Behavioural Processes, 109, 121-134. https://doi.org/10.1016/j.beproc.2014.08.027

Grueter, C. C., Deschner, T., Behringer, V., Fawcett, K., \& Robbins, M. M. (2014). Socioecological correlates of energy balance using urinary $\mathrm{C}$-peptide measurements in wild female mountain gorillas. Physiology and Behavior, 127, 13-19. https://doi.org/10.1016/j.physbeh.2014.01.009

Gurven, M., \& Kaplan, H. (2007). Longevity among hunter-gatherers: a cross-cultural examination. Population and Development Review, 33(2), 321-365. https://doi.org/10.1111/j.1728-4457.2007.00171.x

Gust, D. A., Gordon, T. P., Hambright, M. K., \& Wilson, M. E. (1993). Relationship between social factors and pituitary - adrenocortical activity in female rhesus monkeys (Macaca mulatta). Hormones and Behavior, 27(3), 318-331. https://doi.org/10.1006/hbeh.1993.1024 
Hallgren, K. A. (2012). Computing inter-rater reliability for observational data: an overview and tutorial. Tutorials in Quantitative Methods for Psychology, 8(1), 23-34. https://doi.org/10.20982/tqmp.08.1.p023

Hamada, Y., \& Yamamoto, A. (2010). Morphological characteristics, growth, and aging in Japanese macaques. In N. Nakagawa, M. Nakamichi, \& H. Sugiura (Eds.), The Japanese macaques. Primatology monographs. Tokyo: Springer. https://doi.org/10.1007/978-4-431-53886-8_2

Hämäläinen, A., Dammhahn, M., Aujard, F., \& Kraus, C. (2015). Losing grip: senescent decline in physical strength in a small-bodied primate in captivity and in the wild. Experimental Gerontology, 61, 54-61. https://doi.org/10.1016/j.exger.2014.11.017

Harada, C. N., Natelson Love, M. C., \& Triebel, K. (2013). Normal cognitive aging. Clinics in Geriatric Medicine, 29(4), 737-752. https://doi.org/10.1016/j.cger.2013.07.002

Hasher, L., Zacks, R. T., \& May, C. P. (1999). Inhibitory control, circadian arousal, and age. In D. Gopher \& A. Koriat (Eds.), Attention and Performance XVII: Cognitive regulation of performance: Interaction of theory and application (pp. 653-675). Cambridge, MA: MIT PRess.

Havighurst, R. J. (1961). Successful aging. The Gerontologist, 1(1), 8-13. https://doi.org/10.1093/geront/1.1.8

Hawkes, K., O'Connel, J. F., \& Blurton Jones, N. G. (1997). Hadza women's time allocation, offspring provisioning, and the evolution of long postmenopausal life spans. Current Anthropology, 38(4), 551-577. https://doi.org/10.1086/204646

Heckhausen, J., Wrosch, C., \& Schulz, R. (2010). A motivational theory of life-span development. Psychological Review, 117(1), 32. https://doi.org/10.1037/a0017668

Heckhausen, J., Wrosch, C., \& Schulz, R. (2019). Agency and motivation in adulthood and old age. Annual Review of Psychology, 70(1), 191-217. https://doi.org/10.1146/annurev-psych-010418-103043

Hedden, T., \& Gabrieli, J. D. E. (2004). Insights into the ageing mind: a view from cognitive neuroscience. Nature Reviews Neuroscience, 5(2), 87-96. https://doi.org/10.1038/nrn1323

Henkel, S., Heistermann, M., \& Fischer, J. (2010). Infants as costly social tools in male Barbary macaque networks. Animal Behaviour, 79(6), 1199-1204. https://doi.org/10.1016/j.anbehav.2010.02.005

Herndon, J. G., Moss, M. B., Rosene, D. L., \& Killiany, R. J. (1997). Patterns of cognitive decline in aged rhesus monkeys. Behavioural Brain Research, 87(1), 25-34. https://doi.org/10.1016/S0166-4328(96)02256-5

Hesler, N., \& Fischer, J. (2007). Gestural communication in Barbary macaques (Macaca sylvanus). In J. Call \& M. Tomasello (Eds.), The gestural communication of apes and monkeys (pp. 159-195). New York: Lawrence Erlbaum.

Hess, T. M. (2014). Selective engagement of cognitive resources: motivational influences 
on older adults' cognitive functioning. Perspectives on Psychological Science, 9(4), 388-407. https://doi.org/10.1177/1745691614527465

Hof, P. R., Gilissen, E. P., Sherwood, C. C., Duan, H., Lee, P. W. H., Delman, B. N., ... Erwin, J. M. (2002). Comparative neuropathology of brain aging in primates. In E. J. M. Hof \& P. R. Hof (Eds.), Aging in nonhuman primates (Vol. 31, pp. 130-154). Basel: Karger.

Horvath, S., \& Raj, K. (2018). DNA methylation-based biomarkers and the epigenetic clock theory of ageing. Nature Reviews Genetics, 19(6), 371-384. https://doi.org/10.1038/s41576-018-0004-3

Huebner, F., \& Fichtel, C. (2015). Innovation and behavioral flexibility in wild redfronted lemurs (Eulemur rufifrons). Animal Cognition, 18(3), 777-787. https://doi.org/10.1007/s10071-015-0844-6

Isaacowitz, D. M., Wadlinger, H. A., Goren, D., \& Wilson, H. R. (2006). Selective preference in visual fixation away from negative images in old age? An eye-tracking study. Psychology and Aging, 21(1), 40-48. https://doi.org/10.1037/0882-7974.21.1.40

Jimura, K., Locke, H. S., \& Braver, T. S. (2010). Prefrontal cortex mediation of cognitive enhancement in rewarding motivational contexts. Proceedings of the National Academy of Sciences, 107(19), 8871-8876. https://doi.org/10.1073/pnas.1002007107 Joly, M., Ammersdörfer, S., Schmidtke, D., \& Zimmermann, E. (2014). Touchscreen-based cognitive tasks reveal age-related impairment in a primate aging model, the grey mouse lemur (Microcebus murinus). PLOS ONE, 9(10), e109393. https://doi.org/10.1371/journal.pone.0109393

Joly, M., Micheletta, J., De Marco, A., Langermans, J. A., Sterck, E. H. M., \& Waller, B. M. (2017). Comparing physical and social cognitive skills in macaque species with different degrees of social tolerance. Proceedings of the Royal Society B: Biological Sciences, 284(1862), 20162738. https://doi.org/10.1098/rspb.2016.2738

Jurado, M. B., \& Rosselli, M. (2007). The elusive nature of executive functions: a review of our current understanding. Neuropsychology Review, 17(3), 213-233. https://doi.org/10.1007/s11065-007-9040-z

Kabadayi, C., Taylor, L. A., Bayern, A. M. P. von, \& Osvath, M. (2016). Ravens, New Caledonian crows and jackdaws parallel great apes in motor self-regulation despite smaller brains. Royal Society Open Science, 3(4), 160104. https://doi.org/http://dx.doi.org/10.1098/rsos.160104

Kallman, D. A., Plato, C. C., \& Tobin, J. D. (1990). The role of muscle loss in the age-related decline of grip strength: cross-sectional and longitudinal perspectives. Journals of Gerontology, 45(3), M82-88. https://doi.org/10.1093/geronj/45.3.m82

Kemperman, A., van den Berg, P., Weijs-Perrée, M., \& Uijtdewillegen, K. (2019). Loneliness of older adults: social network and the living environment. International Journal of Environmental Research and Public Health, 16(3), 406. 
https://doi.org/10.3390/ijerph16030406

Kendal, R. L., Coe, R. L., \& Laland, K. N. (2005). Age differences in neophilia, exploration, and innovation in family groups of callitrichid monkeys. American Journal of Primatology, 66(2), 167-188. https://doi.org/10.1002/ajp.20136

Kim, S.-H., Kaminker, P., \& Campisi, J. (2002). Telomeres, aging and cancer: in search of a happy ending. Oncogene, 21, 503-511. https://doi.org/10.1038/sj/onc/1205077

Kirkwood, T. B. L. (2005). Understanding the odd science of aging. Cell, 120(4), 437-447. https://doi.org/10.1016/j.cell.2005.01.027

Kirkwood, T. B. L., \& Austad, S. N. (2000). Why do we age? Nature, 408(6809), 233-238. https://doi.org/10.1038/35041682

Kray, J. (2006). Task-set switching under cue-based versus memory-based switching conditions in younger and older adults. Brain Research, 1105(1), 83-92. https://doi.org/10.1016/j.brainres.2005.11.016

Kuester, J., \& Paul, A. (1984). Female reproductive characteristics in semifree-ranging Barbary macaques (Macaca sylvanus L. 1758). Folia Primatologica, 43(2-3), 69-83. https://doi.org/10.1159/000156173

Kuester, J., \& Paul, A. (1992). Influence of male competition and female mate choice on male mating success in Barbary macaques (Macaca sylvanus). Behaviour, 120(3-4), 192-216. https://doi.org/10.2307/4535008

Kummer, H. (1995). In quest of the sacred baboon: a scientist's journey. Princeton, NJ: Princeton University Press. https://doi.org/10.2307/j.ctt1m322x5

Lacreuse, A., Parr, L., Chennareddi, L., \& Herndon, J. G. (2018). Age-related decline in cognitive flexibility in female chimpanzees. Neurobiology of Aging, 72, 83-88. https://doi.org/10.1016/j.neurobiolaging.2018.08.018

Lacreuse, A., Russell, J. L., Hopkins, W. D., \& Herndon, J. G. (2014). Cognitive and motor aging in female chimpanzees. Neurobiology of Aging, 35(3), 623-632. https://doi.org/10.1016/j.neurobiolaging.2013.08.036

Lacreuse, A., Schatz, K., Strazzullo, S., King, H. M., \& Ready, R. (2013). Attentional biases and memory for emotional stimuli in men and male rhesus monkeys. Animal Cognition, 16(6), 861-871. https://doi.org/10.1007/s10071-013-0618-y

Lang, F. R., \& Carstensen, L. L. (2002). Time counts: future time perspective, goals, and social relationships. Psychology and Aging, 17(1), 125-139. https://doi.org/10.1037/0882-7974.17.1.125

Le Brazidec, M., Herrel, A., Thomas, P., Grégoire, B. A., Aujard, F., \& Pouydebat, E. (2017). How aging affects grasping behavior and pull strength in captive gray mouse lemurs (Microcebus murinus). International Journal of Primatology, 38(6), 1120-1129. https://doi.org/10.1007/s10764-017-0001-y

Lee, H. C., \& Teichroeb, J. A. (2016). Partially shared consensus decision making and distributed leadership in vervet monkeys: older females lead the group to forage. 
American Journal of Physical Anthropology, 161(4), 580-590. https://doi.org/10.1002/ajpa.23058

Lehmann, J., \& Ross, C. (2011). Baboon (Papio anubis) social complexity-a network approach. American Journal of Primatology, 73(8), 1-15. https://doi.org/10.1002/ajp.20967

Leigh, S. R. (2001). Evolution of human growth. Evolutionary Anthropology, 10, 223-236. https://doi.org/10.1002/evan.20002

Lepore, M. (2020). Building a new future in politics and aging. Public Policy \& Aging Report, 30(2), 37-38. https://doi.org/10.1093/ppar/praa008

Liao, Z., Sosa, S., Wu, C., \& Zhang, P. (2017). The influence of age on wild rhesus macaques' affiliative social interactions. American Journal of Primatology, e22733. https://doi.org/10.1002/ajp.22733

Libertini, G. (2013). Evidence for aging theories from the study of a hunter - gatherer people (Ache of Paraguay). Biochemistry (Moscow), 78(9), 1023-1032. https://doi.org/10.1134/s0006297913090083

Liebal, K., \& Call, J. (2012). The origins of non-human primates' manual gestures. Philosophical Transactions of the Royal Society B: Biological Sciences, 367(1585), 118-128. https://doi.org/10.1098/rstb.2011.0044

Liebal, K., Pika, S., \& Tomasello, M. (2004). Social communication in siamangs (Symphalangus syndactylus): use of gestures and facial expressions. Primates, 45(1), 41-57. https://doi.org/10.1007/s10329-003-0063-7

Lindenberger, U. (2014). Human cognitive aging: corriger la fortune? Science, 346(6209), 572-578. https://doi.org/10.1126/science.1254403

Lindstrom, K., Guyer, A. E., Mogg, K., Bradley, B. P., Fox, N. A., Ernst, M., .. Bar-Haim, Y. (2009). Normative data on development of neural and behavioral mechanisms underlying attention orienting toward social-emotional stimuli: an exploratory study. Brain Research, Oct 6(1292), 61-70. https://doi.org/10.1016/j.brainres.2009.07.045

Line, S. W., Morgan, K. N., \& Markowitz, H. (1991). Simple toys do not alter the behavior of aged rhesus monkeys. Zoo Biology, 10(6), 473-484. https://doi.org/10.1002/zoo.1430100606

Löckenhoff, C. E., \& Carstensen, L. L. (2007). Aging, emotion, and health-related decision strategies: motivational manipulations can reduce age differences. Psychology and Aging, 22(1), 134-146. https://doi.org/10.1037/0882-7974.22.1.134

Löckenhoff, C. E., De Fruyt, F., Terracciano, A., McCrae, R. R., De Bolle, M., Costa Jr., P. T., ... Barbaranelli, C. (2009). Perceptions of aging across 26 cultures and their culturelevel associates associates. Psychology and Aging, 24(4), 941-954. https://doi.org/10.1037/a0016901

Lucas, R. E., \& Donnellan, M. B. (2011). Personality development across the life span: longitudinal analyses with a national sample from Germany. Journal of Personality and 
Social Psychology, 101(4), 847-861. https://doi.org/10.1037/a0024298

Luong, G., Charles, S. T., \& Fingerman, K. L. (2011). Better with age: social relationships across adulthood. Journal of Social and Personal Relationships, 28(1), 9-23. https://doi.org/10.1177/0265407510391362

MacLean, E. L., Hare, B., Nunn, C. L., Addessi, E., Amici, F., Anderson, R. C., ... Zhao, Y. (2014). The evolution of self-control. Proceedings of the National Academy of Sciences, 111(20), E2140-E2148. https://doi.org/10.1073/pnas.1323533111

Maklakov, A. A., \& Chapman, T. (2019). Evolution of ageing as a tangle of trade-offs: energy versus function. Proceedings of the Royal Society B: Biological Sciences, 286, 20191604. https://doi.org/10.1098/rspb.2019.1604

Manrique, H. M., \& Call, J. (2015). Age-dependent cognitive inflexibility in great apes. Animal Behaviour, 102, 1-6. https://doi.org/10.1016/j.anbehav.2015.01.002

Martin, P., \& Bateson, P. P. G. (1986). Measuring behaviour: an introductory guide. Cambridge University Press.

Mason, A., \& Lee, R. (2011). Population aging and the generational economy: key findings. In R. Lee \& A. Mason (Eds.), Population aging and the generational economy: a global perspective (pp. 3-31). Cheltenham, UK: Edward Elgar Publishing.

Massen, J. J. M., Antonides, A., Arnold, A.-M. K., Bionda, T., \& Koski, S. E. (2013). A behavioral view on chimpanzee personality: exploration tendency, persistence, boldness, and tool-orientation measured with group experiments. American Journal of Primatology, 75(9), 947-958. https://doi.org/10.1002/ajp.22159

Mata, R., Wilke, A., \& Czienskowski, U. (2009). Cognitive aging and adaptive foraging behavior. Journals of Gerontology Series B: Psychological Sciences and Social Sciences, 64(4), 474-481. https://doi.org/10.1093/geronb/gbp035

Mather, M., \& Carstensen, L. L. (2003). Aging and attentional biases for emotional faces. Psychological Science, 14(5), 409-415. https://doi.org/10.1111/1467-9280.01455

Mather, M., \& Carstensen, L. L. (2005). Aging and motivated cognition: the positivity effect in attention and memory. Trends in Cognitive Sciences, 9(10), 496-502. https://doi.org/10.1016/j.tics.2005.08.005

Matuschek, H., Kliegl, R., Vasishth, S., Baayen, H., \& Bates, D. (2017). Balancing Type I error and power in linear mixed models. Journal of Memory and Language, 94, 305315. https://doi.org/10.1016/j.jml.2017.01.001

Mayhew, J. A., Funkhouser, J. A., \& Wright, K. R. (2020). Considering social play in primates: a case study in juvenile Tibetan macaques (Macaca thibetana). In J.-H. Li, L. Sun, \& P. M. Kappeler (Eds.), The behavioral ecology of the Tibetan macaque (pp. 93-117). Cham: Springer. https://doi.org/10.1007/978-3-030-27920-2_6

McComb, K., Moss, C., Durant, S. M., Baker, L., \& Sayialel, S. (2001). Matriarchs act as repositories of social knowledge in African elephants. Science, 292(5516), 491-494. https://doi.org/10.1126/science.1057895 
McComb, K., Shannon, G., Durant, S. M., Sayialel, K., Slotow, R., Poole, J., \& Moss, C. (2011). Leadership in elephants: the adaptive value of age. Proceedings of the Royal Society B: Biological Sciences, 278(1722), 3270-3276. https://doi.org/10.1098/rspb.2011.0168

McCullagh, P., \& Nelder, J. A. (1989). Generalized linear models. London: Chapman and Hall.

McDonald Pavelka, M. S. (1990). Do old female monkeys have a specific social role? Primates, 31(3), 363-373. https://doi.org/10.1007/BF02381107

McDonald Pavelka, M. S. (1991). Sociability in old female Japanese monkeys: human versus nonhuman primate aging. American Anthropologist, 93(3), 588-598. https://doi.org/10.1525/aa.1991.93.3.02a00030

McDonald Pavelka, M. S. (1994). The nonhuman primate perspective: old age, kinship and social partners in a monkey society. Journal of Cross-Cultural Gerontology, 9, 219229.

McLaughlin, D., Vagenas, D., Pachana, N. A., Begum, N., \& Dobson, A. (2010). Gender differences in social network size and satisfaction in adults in their 70s. Journal of Health Psychology, 15(5), 671-679. https://doi.org/10.1177/1359105310368177

Medawar, P. B. (1952). An unsolved problem of biology. London: Lewis.

Mehlman, P. (1986). Male intergroup mobility in a wild population of the Barbary macaque (Macaca sylvanus), Ghomaran rif mountains, Morocco. American Journal of Primatology, 10(1), 67-81. https://doi.org/10.1002/ajp.1350100107

Ménard, N., \& Vallet, D. (1997). Behavioral responses of Barbary macaques (Macaca sylvanus) to variations in environmental conditions in Algeria. American Journal of Primatology, 43(4), 285-304. https://doi.org/10.1002/(SICl)10982345(1997)43:4<285::AID-AJP1>3.0.CO;2-T

Meyer, C., Kerns, A., Haberthur, K., \& Messaoudi, I. (2012). Improving immunity in the elderly: current and future lessons from nonhuman primate models. Age, 34, 11571168. https://doi.org/10.1007/s11357-011-9353-y

Micheletta, J., Whitehouse, J., Parr, L. A., \& Waller, B. M. (2015). Facial expression recognition in crested macaques (Macaca nigra). Animal Cognition, 18(4), 985-990. https://doi.org/10.1007/s10071-015-0867-z

Mitchell, S. J., Scheibye-Knudsen, M., Longo, D. L., \& de Cabo, R. (2015). Animal models of aging research: implications for human aging and age-related diseases. Annual Review of Animal Biosciences, 3(1), 283-303. https://doi.org/10.1146/annurev-animal022114-110829

Miyake, A., \& Friedman, N. P. (2012). The nature and organization of individual differences in executive functions: four general conclusions. Current Directions in Psychological Science, 21(1), 8-14. https://doi.org/10.1177/0963721411429458

Miyake, A., Friedman, N. P., Emerson, M. J., Witzki, A. H., Howerter, A., \& Wager, T. D. 
(2000). The unity and diversity of executive functions and their contributions to complex "frontal lobe" tasks: a latent variable analysis. Cognitive Psychology, 41(1), 49-100. https://doi.org/10.1006/cogp.1999.0734

Moore, T. L., Killiany, R. J., Herndon, J. G., Rosene, D. L., \& Moss, M. B. (2006). Executive system dysfunction occurs as early as middle-age in the rhesus monkey. Neurobiology of Aging, 27(10), 1484-1493. https://doi.org/10.1016/j.neurobiolaging.2005.08.004

Moos, R. H., Brennan, P. L., Schutte, K. K., \& Moos, B. S. (2006). Older adults' coping with negative life events: common processes of managing health, interpersonal, and financial/work stressors. International Journal of Aging and Human Development, 62(1), 39-59. https://doi.org/10.2190/ENLH-WAA2-AX8J-WRT1

Morbeck, M. E., Galloway, A., \& Sumner, D. R. (2002). Getting old at Gombe: skeletal aging in wild-ranging chimpanzees. In J. M. Erwin \& P. R. Hof (Eds.), Aging in nonhuman primates (Vol. 31, pp. 48-62). Basel: Karger.

Mumby, H., \& Vinicius, L. (2008). Primate growth in the slow lane: a study of inter-species variation in the growth constant A. Evolutionary Biology, 35(4), 287-295. https://doi.org/10.1007/s11692-008-9040-9

Nagahara, A. H., Bernot, T., \& Tuszynski, M. H. (2010). Age-related cognitive deficits in rhesus monkeys mirror human deficits on an automated test battery. Neurobiology of Aging, 31(6), 1020-1031. https://doi.org/10.1016/j.neurobiolaging.2008.07.007

Nakamichi, M. (1984). Behavioral characteristics of old female Japanese monkeys in a freeranging group. Primates, 25(2), 192-203. https://doi.org/10.1007/BF02382391

Nakamichi, M. (2003). Age-related differences in social grooming among adult female Japanese monkeys (Macaca fuscata). Primates, 44(3), 239-246. https://doi.org/10.1007/s10329-003-0036-x

Nattrass, S., Croft, D. P., Ellis, S., Cant, M. A., Weiss, M. N., Wright, B. M., ... Franks, D. W. (2019). Postreproductive killer whale grandmothers improve the survival of their grandoffspring. Proceedings of the National Academy of Sciences, 116(52), 2666926673. https://doi.org/10.1073/pnas.1903844116

Neumann, C., \& Kulik, L. (2014). EloRating: Animal Dominance Hierarchies by Elo Rating. $R$ package version 0.43 .

Newman, M. E. J. (2003). The structure and function of complex networks. SIAM Review, 45(2), 167-256. https://doi.org/10.1137/S003614450342480

Nikitin, J., Burgermeister, L. C., \& Freund, A. M. (2012). The role of age and social motivation in developmental transitions in young and old adulthood. Frontiers in Psychology, 3, 1-14. https://doi.org/10.3389/fpsyg.2012.00366

Nikitin, J., Schoch, S., \& Freund, A. M. (2014). The role of age and motivation for the experience of social acceptance and rejection. Developmental Psychology, 50(7), 1943-1950. https://doi.org/10.1037/a0036979

Noë, R., \& Sluijter, A. A. (1995). Which adult male savanna baboons form coalitions? 
International Journal of Primatology, 16(1), 77-105. https://doi.org/10.1007/BF02700154

North, M. S., \& Fiske, S. T. (2015). Modern attitudes toward older adults in the aging world: a cross-cultural meta-analysis. Psychological Bulletin, 141(5), 993-1021. https://doi.org/10.1037/a0039469

Novak, M. A., Hamel, A. F., Kelly, B. J., Dettmer, A. M., \& Meyer, J. S. (2013). Stress, the HPA axis, and nonhuman primate well-being: a review. Applied Animal Behaviour Science, 143(2-4), 135-149. https://doi.org/10.1016/j.applanim.2012.10.012

Novak, M. A., Musante, A., Munroe, H., O’Neill, P. L., Price, C., \& Suomi, S. J. (1993). Old, socially housed rhesus monkeys manipulate objects. Zoo Biology, 12(3), 285-298. https://doi.org/10.1002/zoo.1430120306

Nussey, D. H., Froy, H., Lemaitre, J. F., Gaillard, J. M., \& Austad, S. N. (2013). Senescence in natural populations of animals: widespread evidence and its implications for biogerontology. Ageing Research Reviews. https://doi.org/10.1016/j.arr.2012.07.004

Ogura, S., \& Jakovljevic, M. M. (2018). Editorial: global population aging - health care, social and economic consequences. Frontiers in Public Health, 6, 335. https://doi.org/10.3389/fpubh.2018.00335

Ostner, J., \& Schülke, O. (2014). The evolution of social bonds in primate males. Behaviour, 151(7), 871-906. https://doi.org/10.1163/1568539X-00003191

Otte, C., Hart, S., Neylan, T. C., Marmar, C. R., Yaffe, K., \& Mohr, D. C. (2005). A metaanalysis of cortisol response to challenge in human aging: importance of gender. Psychoneuroendocrinology, $30(1)$,

80-91. https://doi.org/10.1016/j.psyneuen.2004.06.002

Padmala, S., \& Pessoa, L. (2011). Reward reduces conflict by enhancing attentional control and biasing visual cortical processing. Journal of Cognitive Neuroscience, 23(11), 3419-3432. https://doi.org/10.1162/jocn_a_00011

Parr, L. A., \& Heintz, M. (2009). Facial expression recognition in rhesus monkeys, Macaca mulatta. Animal Behaviour, 77(6), 1507-1513. https://doi.org/10.1016/j.anbehav.2009.02.024

Parr, L. A., Winslow, J. T., Hopkins, W. D., \& de Waal, F. B. M. (2000). Recognizing facial cues: individual discrimination by chimpanzees (Pan troglodytes) and rhesus monkeys (Macaca mulatto). Journal of Comparative Psychology, 114(1), 47-60. https://doi.org/10.1037/0735-7036.114.1.47

Paul, A., \& Kuester, J. (1985). Intergroup transfer and incest avoidance in semifree-ranging Barbary macaques (Macaca sylvanus) at Salem. American Journal of Primatology, 8(4), 317-322. https://doi.org/10.1002/ajp.1350080407

Paul, A., Kuester, J., \& Arnemann, J. (1996). The sociobiology of male - infant interactions in Barbary macaques, Macaca sylvanus. Animal Behaviour, 51(1), 155-170. https://doi.org/10.1006/anbe.1996.0013 
Paul, A., Kuester, J., \& Podzuweit, D. (1993). Reproductive senescence and terminal investisment in female Barbary macaques (Macaca sylvanus) at Salem. International Journal of Primatology, 14(1), 105-124. https://doi.org/10.1007/BF02196506

Perry, S. (2020). Behavioural variation and learning across the lifespan in wild white-faced capuchin monkeys. Philosophical Transactions of the Royal Society B: Biological Sciences, 375(1803), 20190494. https://doi.org/10.1098/rstb.2019.0494

Piazza, J. R., Charles, S. T., Stawski, R. S., \& Almeida, D. M. (2013). Age and the association between negative affective states and diurnal cortisol. Psychology and Aging, 28(1), 47-56. https://doi.org/10.1037/a0029983

Picq, J.-L. (1992). Aging and social behaviour in captivity in Microcebus murinus. Folia Primatologica, 59, 217-220.

Pika, S., Liebal, K., \& Tomasello, M. (2003). Gestural communication in young gorillas (Gorilla gorilla): gestural repertoire, learning, and use. American Journal of Primatology, 60(3), 95-111. https://doi.org/10.1002/ajp.10097

Pokorny, J. J., \& de Waal, F. B. M. (2009). Monkeys recognize the faces of group mates in photographs. Proceedings of the National Academy of Sciences, 106(51), 2153921543. https://doi.org/10.1073/pnas.0912174106

Preuschoft, S., Paul, A., \& Kuester, J. (1998). Dominance styles of female and male Barbary macaques (Macaca sylvanus). Behaviour, 135(6), 731-755. https://doi.org/10.1163/156853998792640477

R Core Team. (2019). R: a language and environment for statistical computing. Vienna, Austria: R Foundation for Statistical Comp. Retrieved from http://www.r-project.org

Rafnsson, S. B., Orrell, M., D’Orsi, E., Hogervorst, E., \& Steptoe, A. (2020). Loneliness, social integration, and incident dementia over 6 years: prospective findings from the english longitudinal study of ageing. Journals of Gerontology Series B: Psychological Sciences and Social Sciences, 75(1), 114-124. https://doi.org/10.1093/geronb/gbx087

Rakotonirina, H., Kappeler, P. M., \& Fichtel, C. (2018). The role of facial pattern variation for species recognition in red-fronted lemurs (Eulemur rufifrons). BMC Evolutionary Biology, 18(1), 19. https://doi.org/10.1186/s12862-018-1126-0

Rathke, E.-M., Berghänel, A., Bissonnette, A., Ostner, J., \& Schülke, O. (2017). Agedependent change of coalitionary strategy in male Barbary macaques. Primate Biology, 4, 1-7. https://doi.org/10.5194/pb-4-1-2017

Ratnayeke, S. (1994). The behavior of postreproductive females in a wild population of toque macaques (Macaca sinica) in Sri Lanka. International Journal of Primatology, 15(3), 445-469. https://doi.org/10.1007/BF02696103

Reed, A. E., \& Carstensen, L. L. (2012). The theory behind the age-related positivity effect. Frontiers in Psychology, 3, 339. https://doi.org/10.3389/fpsyg.2012.00339

Rehmert, A. E., \& Kisley, M. A. (2013). Can older adults resist the positivity effect in neural responding: the impact of verbal framing on event-related brain potentials elicited by 
emotional images. Emotion, 13(5), 949-959. https://doi.org/10.1037/a0032771

Rey-Mermet, A., \& Gade, M. (2018). Inhibition in aging: what is preserved? What declines?

A meta-analysis. Psychonomic Bulletin and Review, 25(5), 1695-1716. https://doi.org/10.3758/s13423-017-1384-7

Rhodes, M. G. (2004). Age-related differences in performance on the Wisconsin card sorting test: a meta-analytic review. Psychology and Aging, 19(3), 482-494. https://doi.org/10.1037/0882-7974.19.3.482

Ridderinkhof, K. R., Ullsperger, M., Crone, E. A., \& Nieuwenhuis, S. (2004). The role of the medial frontal cortex in cognitive control. Science, 306(5695), 443-447. https://doi.org/10.1126/science.1100301

Riediger, M., \& Freund, A. M. (2006). Focusing and restricting: two aspects of motivational selectivity in adulthood. Psychology and Aging, 21(1), 173-185. https://doi.org/10.1037/0882-7974.21.1.173

Rivera, A., Rais, M., Barr, T., Arnold, N., Sureshchandra, S., \& Messaoudi, I. (2018). Nonhuman primate models of immunosenescence. In T. Fulop, C. Franceschi, K. Hirokawa, \& G. Pawelec (Eds.), Handbook of immunosenescence (pp. 126-151). Cham: Springer. https://doi.org/10.1016/B978-0-12-381366-4.00008-0

Rosati, A. G., Arre, A. M., Platt, M. L., \& Santos, L. R. (2018). Developmental shifts in social cognition: socio-emotional biases across the lifespan in rhesus monkeys. Behavioral Ecology and Sociobiology, 72, 163. https://doi.org/10.1007/s00265-018-2573-8

Rosati, A. G., Hagberg, L., Enigk, D. K., Otali, E., Emery Thompson, M., Muller, M. N., ... Machanda, Z. P. (2020). Social selectivity in aging wild chimpanzees. Science, 370(6515), 473-476. https://doi/10.1126/science.aaz9129

Rosati, A. G., \& Santos, L. R. (2017). Tolerant Barbary macaques maintain juvenile levels of social attention in old age, but despotic rhesus macaques do not. Animal Behaviour, 130, 199-207. https://doi.org/10.1016/j.anbehav.2017.06.019

Rose, M. R., Rauser, C. L., Benford, G., Matos, M., \& Mueller, L. D. (2007). Hamilton's forces of natural selection after forty years. Evolution, 61(6), 1265-1276. https://doi.org/10.1111/j.1558-5646.2007.00120.x

Ross, C. N., Adams, J., Gonzalez, O., Dick, E., Giavedoni, L., Hodara, V. L., ... Tardif, S. D. (2019). Cross-sectional comparison of health-span phenotypes in young versus geriatric marmosets. American Journal of Primatology, 81, e22952. https://doi.org/10.1002/ajp.22952

Roth, G. S., Mattison, J. A., Ottinger, M. A., Chachich, M. E., Lane, M. A., \& Ingram, D. K. (2004). Aging in rhesus monkeys: relevance to human health interventions. Science, 305, 1423-1426. https://doi.org/10.1126/science.1102541

Roubová, V., Konečná, M., Šmilauer, P., \& Wallner, B. (2015). Whom to groom and for what? Patterns of grooming in female Barbary macaques (Macaca sylvanus). PLoS ONE, 10(2), e0117298. https://doi.org/10.1371/journal.pone.0117298 
Rutledge, R. B., Smittenaar, P., Zeidman, P., Brown, H. R., Adams, R. A., Lindenberger, U., ... Dolan, R. J. (2016). Risk taking for potential reward decreases across the lifespan. Current Biology, 26, 1634-1639. https://doi.org/10.1016/j.cub.2016.05.017

Sanderson, W. C., \& Scherbov, S. (2013). The characteristics approach to the measurement of population aging. Population and Development Review, 39(4), 673685. https://doi.org/10.1111/j.1728-4457.2013.00633.x

Schell, A., Rieck, K., Schell, K., Hammerschmidt, K., \& Fischer, J. (2011). Adult but not juvenile Barbary macaques spontaneously recognize group members from pictures. Animal Cognition, 14(4), 503-509. https://doi.org/10.1007/s10071-011-0383-8

Schielzeth, H. (2010). Simple means to improve the interpretability of regression coefficients. Methods in Ecology and Evolution, 1(2), 103-113. https://doi.org/10.1111/j.2041-210x.2010.00012.x

Schino, G. (2007). Grooming and agonistic support: a meta-analysis of primate reciprocal altruism. Behavioral Ecology, 18(1), 115-120. https://doi.org/10.1093/beheco/arl045

Schino, G., \& Pinzaglia, M. (2018). Age-related changes in the social behavior of tufted capuchin monkeys. American Journal of Primatology, 80(3), e22746. https://doi.org/10.1002/ajp.22746

Schülke, O., Dumdey, N., \& Ostner, J. (2020). Selective attention for affiliative and agonistic interactions of dominants and close affiliates in macaques. Scientific Reports, 10, 5962. https://doi.org/10.1038/s41598-020-62772-8

Schupp, H. T., Cuthbert, B. N., Bradley, M. M., Cacioppo, J. T., Ito, T., \& Lang, P. J. (2000). Affective picture processing: the late positive potential is modulated by motivational relevance. Psychophysiology, 37(2), 257-261. https://doi.org/10.1111/14698986.3720257

Segal, K. (2012). Meet one of the oldest chimpanzees in captivity.

Retrieved July 9, 2020, from https://edition.cnn.com/2012/04/21/us/oldestchimpanzee-in-captivity/index.html\#: :text=LittleMama\%2C74\%2CatFlorida\%27s,the oldest chimpanzee in captivity

Settersten, R. A. (2017). Some things I have learned about aging by studying the life course. Innovation in Aging, 1(2), 1-7. https://doi.org/10.1093/geroni/igx014

Shanley, D. P., \& Kirkwood, T. B. L. (2001). Evolution of the human menopause. BioEssays, 23(3), 282-287. https://doi.org/10.1002/1521-1878(200103)23:3<282::AIDBIES1038>3.0.CO;2-9

Sherratt, T. N., \& Morand-Ferron, J. (2018). The adaptive significance of age-dependent changes in the tendency of individuals to explore. Animal Behaviour, 138, 59-67. https://doi.org/10.1016/j.anbehav.2018.01.025

Shively, C. A., Willard, S. L., Register, T. C., Bennett, A. J., Pierre, P. J., Laudenslager, M. L., ... Kritchevsky, S. B. (2012). Aging and physical mobility in group-housed Old World monkeys. Age, 34(5), 1123-1131. https://doi.org/10.1007/s11357-011-9350-1 
Shultz, S., \& Dunbar, R. I. M. (2007). The evolution of the social brain: anthropoid primates contrast with other vertebrates. Proceedings of the Royal Society B: Biological Sciences, 274, 2429-2436. https://doi.org/10.1098/rspb.2007.0693

Shutt, K., MacLarnon, A., Heistermann, M., \& Semple, S. (2007). Grooming in Barbary macaques: better to give than to receive? Biology Letters, 3, 231-233. https://doi.org/10.1098/rsbl.2007.0052

Silk, J. B. (2002). Kin selection in primate groups. International Journal of Primatology, 23(4), 849-875. https://doi.org/10.1023/A:1015581016205

Silk, J. B. (2007). The adaptive value of sociality in mammalian groups. Philosophical Tansactions of the Royal Society of London Series B: Biological Sciences, 362(1480), 539-559. https://doi.org/10.1098/rstb.2006.1994

Silk, J. B., Altmann, J., \& Alberts, S. C. (2006). Social relationships among adult female baboons (papio cynocephalus) I. Variation in the strength of social bonds. Behavioral Ecology and Sociobiology, 61(2), 183-195. https://doi.org/10.1007/s00265-006-02492

Silk, J. B., Seyfarth, R. M., \& Cheney, D. L. (1999). The structure of social relationships among female savanna baboons in Moremi Reserve, Botswana. Behaviour, 136, 679703. https://doi.org/10.1163/156853999501522

Slocombe, K. E., Waller, B. M., \& Liebal, K. (2011). The language void: the need for multimodality in primate communication research. Animal Behaviour, 81(5), 919-924. https://doi.org/10.1016/j.anbehav.2011.02.002

Smith, S. G., Jackson, S. E., Kobayashi, L. C., \& Steptoe, A. (2018). Social isolation, health literacy, and mortality risk: findings from the English Longitudinal Study of Ageing. Health Psychology, 37(2), 160-169. https://doi.org/10.1037/hea0000541

Snyder-Mackler, N., Burger, J. R., Gaydosh, L., Belsky, D. W., Noppert, G. A., Campos, F. A., ... Tung, J. (2020). Social determinants of health and survival in humans and other animals. Science, 368, 843. https://doi.org/10.1126/science.aax9553

Solbakk, A.-K., Fuhrmann Alpert, G., Furst, A. J., Hale, L. A., Oga, T., Chetty, S., ... Knight, R. T. (2008). Altered prefrontal function with aging: insights into age-associated performance decline. Brain Research, 1232, 30-47. https://doi.org/10.1016/j.brainres.2008.07.060

Sosa, S. (2016). The influence of gender, age, matriline and hierarchical rank on individual social position, role and interactional patterns in macaca sylvanus at "La Forêt des Singes": a multilevel social network approach. Frontiers in Psychology, 7, 529. https://doi.org/10.3389/fpsyg.2016.00529

Spear, L. P. (2004). Adolescent brain development and animal models. Annals New York Academy of Sciences, 1021, 23-26. https://doi.org/10.1196/annals.1308.002

Spear, P. D., Moore, R. J., Kim, C. B., Xue, J. T., \& Tumosa, N. (1994). Effects of aging on the primate visual system: spatial and temporal processing by lateral geniculate 
neurons in young adult and old rhesus monkeys. Journal of Neurophysiology, 72(1), 402-420. https://doi.org/10.1152/jn.1994.72.1.402

Steptoe, A., Shankar, A., Demakakos, P., \& Wardle, J. (2013). Social isolation, loneliness, and all-cause mortality in older men and women. Proceedings of the National Academy of Sciences, 110(15), 5797-5801. https://doi.org/10.1073/pnas.1219686110

Sueur, C., Jacobs, A., Amblard, F., Petit, O., \& King, A. J. (2011). How can social network analysis improve the study of primate behavior? American Journal of Primatology, 73(8), 703-719. https://doi.org/10.1002/ajp.20915

Sumner, E., Steyvers, M., \& Sarnecka, B. W. (2019). It's not the treasure, it's the hunt: children are more explorative on an explore/exploit task than adults. Proceedings of the Cognitive Sciences Society, 41, 2891-2897.

Taconnat, L., Raz, N., Toczé, C., Bouazzaoui, B., Sauzéon, H., Fay, S., \& Isingrini, M. (2009). Ageing and organisation strategies in free recall: the role of cognitive flexibility. European Journal of Cognitive Psychology, 21(2-3), 347-365. https://doi.org/10.1080/09541440802296413

Tarou, L. R., Bloomsmith, M. A., Hoff, M. P., Erwin, J. M., \& Maple, T. L. (2002). The behavior of aged great apes. In J. M. Erwin \& P. R. Hof (Eds.), Aging in nonhuman primates (Vol. 31, pp. 209-231). Basel: Karger.

Taub, D. M. (1980). Testing the "agonistic buffering" hypothesis - I. The dynamics of participation in the triadic interaction. Behavioral Ecology and Sociobiology, 6(3), 187197. https://doi.org/10.1007/BF00569200

Thierry, B. (1985). Patterns of agonistic interactions in three species of macaque (Macaca mulatta, M. fascicularis, M. tonkeana). Aggressive Behavior, 11(3), 223-233. https://doi.org/10.1002/1098-2337(1985)11:3.0.CO;2-A

Thierry, B. (2007). Unity in diversity: lessons from macaque societies. Evolutionary Anthropology, 16(6), 224-238. https://doi.org/10.1002/evan.20147

Thompson, M. E., Fox, S. A., Berghänel, A., Sabbi, K. H., Phillips-Garcia, S., Enigk, D. K., ... Muller, M. N. (2020). Wild chimpanzees exhibit humanlike aging of glucocorticoid regulation. Proceedings of the National Academy of Sciences, 117(15), 8424-8430. https://doi.org/10.1073/pnas.1920593117

Thompson, M. E., Jones, J. H., Pusey, A. E., Brewer-Marsden, S., Goodall, J., Marsden, D., ... Wrangham, R. W. (2007). Aging and fertility patterns in wild chimpanzees provide insights into the evolution of menopause. Current Biology, 17(24), 2150-2156. https://doi.org/10.1016/j.cub.2007.11.033

Thornton, A., \& Samson, J. (2012). Innovative problem solving in wild meerkats. Animal Behaviour, 83(6), 1459-1468. https://doi.org/10.1016/j.anbehav.2012.03.018

Timme, A. (1995). Sex differences in infant integration in a semifree-ranging group of Barbary macaques (Macaca sylvanus, L. 1758) at Salem, Germany. American Journal of Primatology, 37(3), 221-231. https://doi.org/10.1002/ajp.1350370304 
Tokuyama, N., \& Furuichi, T. (2017). Leadership of old females in collective departures in wild bonobos (Pan paniscus) at Wamba. Behavioral Ecology and Sociobiology, 71(3), 55. https://doi.org/10.1007/s00265-017-2277-5

Torre, P., \& Fowler, C. G. (2000). Age-related changes in auditory function of rhesus monkeys (Macaca mulatta). Hearing Research, 142(1-2), 131-140. https://doi.org/10.1016/S0378-5955(00)00025-3

United Nations, Department of Economic and Social Affairs, Population Division (2020). World Population Ageing 2019 (ST/ESA/SER.A/444).

van Horik, J. O., \& Madden, J. R. (2016). A problem with problem solving: motivational traits, but not cognition, predict success on novel operant foraging tasks. Animal Behaviour, 114, 189-198. https://doi.org/10.1016/j.anbehav.2016.02.006

van Tilburg, T. (1998). Losing and gaining in old age: changes in personal network size and social support in a four-year longitudinal study. The Journals of Gerontology Series B: Psychological Sciences and Social Sciences, 53B(6), S313-S323. https://doi.org/10.1093/geronb/53B.6.S313

Veenema, H. C., Spruijt, B. M., Gispen, W. H., \& van Hooff, J. A. R. A. M. (1997). Aging, dominance history, and social behavior in Java-monkeys (Macaca fascicularis). Neurobiology of Aging, 18(5), 509-515. https://doi.org/10.1016/s01974580(97)00107-3

Veenema, H. C., van Hooff, J. A. R. A. M., Gispen, W. H., \& Spruijt, B. M. (2001). Increased rigidity with age in social behavior of Java-monkeys (Macaca fascicularis). Neurobiology of Aging, 22(2), 273-281. https://doi.org/10.1016/S01974580(00)00204-9

Verdier, J.-M., Acquatella, I., Lautier, C., Devau, G., Trouche, S., Lasbleiz, C., \& MestreFrancés, N. (2015). Lessons from the analysis of nonhuman primates for understanding human aging and neurodegenerative diseases. Frontiers in Neuroscience, 9, 64. https://doi.org/10.3389/fnins.2015.00064

Visalberghi, E., Addessi, E., Truppa, V., Spagnoletti, N., Ottoni, E., Izar, P., \& Fragaszy, D. (2009). Selection of effective stone tools by wild bearded capuchin monkeys. Current Biology, 19(3), 213-217. https://doi.org/10.1016/j.cub.2008.11.064

Vlamings, P. H. J. M., Hare, B., \& Call, J. (2010). Reaching around barriers: the performance of the great apes and 3-5-year-old children. Animal Cognition, 13(2), 273-285. https://doi.org/10.1007/s10071-009-0265-5

Völter, C. J., Tinklenberg, B., Call, J., \& Seed, A. M. (2018). Comparative psychometrics: establishing what differs is central to understanding what evolves. Philosophical Transactions of the Royal Society B: Biological Sciences, 373, 20170283. https://doi.org/10.1098/rstb.2017.0283

Walker, P. (2018). May appoints minister to tackle loneliness issues raised by Jo Cox. The Guardian. Retrieved from www.theguardian.com/society/2018/jan/16/may-appoints- 
minister-tackle-loneliness-issues-raised-jo-cox.

Warner, D. A., Miller, D. A. W., Bronikowski, A. M., \& Janzen, F. J. (2016). Decades of field data reveal that turtles senesce in the wild. Proceedings of the National Academy of Sciences, 113(23), 6502-6507. https://doi.org/10.1073/pnas.1600035113

Webb, S. J. N., Hau, J., Lambeth, S. P., \& Schapiro, S. J. (2018). Differences in behavior between elderly and nonelderly captive chimpanzees and the effects of the social environment. Journal of the American Association for Laboratory Animal Science, 58(6), 783-789. https://doi.org/10.30802/AALAS-JAALAS-19-000019

Williams, B. R., Ponesse, J. S., Schachar, R. J., Logan, G. D., \& Tannock, R. (1999). Development of inhibitory control across the life span. Developmental Psychology, 35(1), 205-213. https://doi.org/10.1037//0012-1649.35.1.205

Workman, K. P., Healey, B., Carlotto, A., \& Lacreuse, A. (2018). One-year change in cognitive flexibility and fine motor function in middle-aged male and female marmosets (Callithrix jacchus). American Journal of Primatology, 81, e22924. https://doi.org/10.1002/ajp.22924

Wrzus, C., Hänel, M., Wagner, J., \& Neyer, F. J. (2013). Social network changes and life events across the life span: a meta-analysis. Psychological Bulletin, 139(1), 53-80. https://doi.org/10.1037/a0028601

Wu, D., Yue, F., Zou, C., Chan, P., \& Zhang, Y. A. (2012). Analysis of glucose metabolism in cynomolgus monkeys during aging. Biogerontology, 13(2), 147-155. https://doi.org/10.1007/s10522-011-9364-1

Young, C., Majolo, B., Schülke, O., \& Ostner, J. (2014). Male social bonds and rank predict supporter selection in cooperative aggression in wild Barbary macaques. Animal Behaviour, 95, 23-32. https://doi.org/10.1016/j.anbehav.2014.06.007

Zanto, T. P., Hennigan, K., Östberg, M., Clapp, W. C., \& Gazzaley, A. (2010). Predictive knowledge of stimulus relevance does not influence top-down suppression of irrelevant information in older adults. Cortex, 46(4), 564-574. https://doi.org/10.1016/j.cortex.2009.08.003

Zeamer, A., Decamp, E., Clark, K., \& Schneider, J. S. (2011). Attention, executive functioning and memory in normal aged rhesus monkeys. Behavioural Brain Research, 219(1), 23-30. https://doi.org/10.1016/j.bbr.2010.12.021

Zuur, A. F., leno, E. N., \& Elphick, C. S. (2010). A protocol for data exploration to avoid common statistical problems. Methods in Ecology and Evolution, 1(1), 3-14. https://doi.org/10.1111/j.2041-210X.2009.00001.x 


\section{Declaration}

I hereby declare that all parts of my thesis titled "Determinants of cognitive performance and social preferences across age in Barbary macaques (Macaca sylvanus)" were written by myself. Assistance of third parties was only accepted if scientifically justifiable and acceptable in regards to the examination regulations. Assistance or contributions to the individual chapters are indicated and all sources have been quoted.

Göttingen, $21^{\text {st }}$ of September 2020 